\title{
INFLUÊNCIA DE CORRETIVOS DA ACIDEZ E DO GESSO AGRÍCOLA EM PROPRIEDADES QUÍMICAS DO SOLO, NA NUTRIÇÃO E PRODUÇÃO DA CANA-DE-AÇÚCAR
}

\author{
JOSÉ CARLOS ROLIM \\ Engenheiro Agrônomo
}

Orientador : Prof ${ }^{\circ}$ Dr. GODOFREDO CESAR VITTI

Tese apresemtada à Escola Superior de Agrioultura "Luiz de Queiroz", da Universidade de São Paulo, para obtenção do título de Doutor em Agronomia. Área de concentração: Solos e Nutrição de Plantas.

PIRACICABA

Estado de São Paulo - Brasil

Maio - 1995 
Ficha catalográfica preparada pela Seçăo de Livros da Divisăo de Eiblioteca e Documentacăo - FCLQ/USF

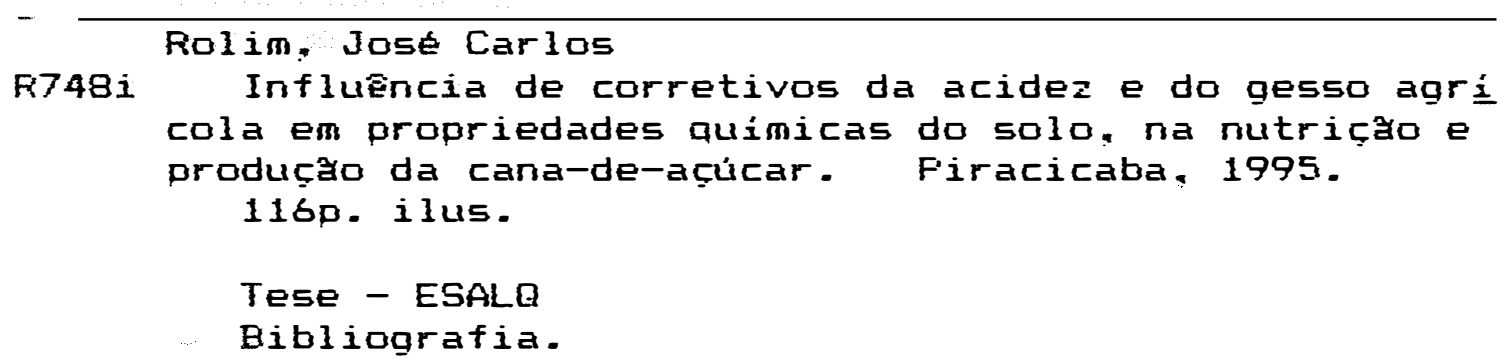
cola em propriedades quimicas do solo. na nutriçăo e produçăo da cana-de-açúcar. Firacicaba, 1995. 116p. ilus.

Tese - ESALQ

Bibliografia.

1. Cana-de-açúcar - Nutriçăo - Efeito do corretivo agricola 2. Cana-de-acúcar - Froduçăo - Efeito do cor retivo agricola 3 . Gesso agricola 4. Solo - Froprieda de quimica 5. Solo - Acidez - Efeito do corretivo agrí cola I. Escola Superior de Agricultura Luiz de Rueiroz Firacicaba 


\section{INFLUÊNCIA DE CORRETIVOS DA ACIDEZ E DO GISSO AGRÍCOLA EM PROPRIEDADES QUÍMICAS DO SOLO, NA NUTRIÇÃO E PRODUÇÃO DA CANA-DE-AÇÚCAR}

JOSÉ CARLOS ROLIM

Aprovada em : 30/05/1995.

\section{Comissão Julgadora :}

Prof. Dr. Godofredo Cesar Vitti

Prof. Dr. Gil Miguel de Sousa Câmara

Prof. Dr. Jairo Antonio Mazza

Prof. Dr. Ailto Antonio Casagrande

Prof. Dr. José Carlos Casagrande
ESALQ/USP

ESALQ/USP

ESALQ/USP

FCAVJ/UNESP

CCA/UFSCar

Prof. Dr. Godofredo Cesar Vitti

Orientador 
Aos meus pais

Antonio (in memoriam), Maria Alice e Amélia,

por terem me indicado um caminho seguro na vida

OFEREÇO

À minha querida esposa Ruth Maria

e aos meus filhos Vanessa, Flávia e Gustavo 


\section{AGRADECIMENTOS}

À DEUS, o Grande Arquiteto de nossas vidas.

Ao Prof. Dr. Godofredo Cesar Vitti, pela orientação dispensada no presente trabalho.

À Universidade Federal de São Carlos (UFSCar), à Escola Superior de Agricultura "Luiz de Queiróz" - ESALQ/USP e ao CNPq - Conselho Nacional de Desenvolvimento Científico e Tecnológico, pela oportunidade de realização do meu curso de pós-graduação.

Ao Prof. Dr. Moacyr de Oliveira Camponez Brasil Sobrinho, pelas críticas e sugestões apresentadas ao trabalho, isentando-o dos êrros cometidos.

Aos Engenheiros Agrônomos Marcos Fernando Garms e Inês Janegitz, da Destilaria Cocal, pela inestimável colaboração que emprestaram ao trabalho.

Aos colegas docentes e funcionários do Centro de Ciências Agrárias da Universidade Federal de São Carlos, pela compreensão durante o desenvolvimento do meu curso.

Aos senhores professores membros da Comissão Julgadora, pelas críticas e sugestões apresentadas.

Finalmente, a todos os que, de uma forma ou de outra, contribuiram para a consecução do objetivo final. 


\section{SUMÁRIO}

LISTA DE FIGURAS.

Página

LISTA DE FIGURAS

LISTA DE TABELAS.

vii

RESUMO.

$\mathrm{xV}$

SUMMARY

xviii

1. INTRODUÇÃO.

2. REVISÃO BIBLIOGRÁFICA.

2.1. Solos cultivados com a cultura da cana-de-açúcar

2.2. Níveis de nutrientes na cana-de-açúcar.

2.3. Corretivos da acidez do solo

2.4. Efeitos do calcário nas características químicas do solo

2.5. Efeitos do calcário na cultura da cana-de-açúcar.

2.6. Efeitos do gesso agrícola nas propriedades químicas do solo e na cultura da cana-de-açúcar

3. MATERIAL E MÉTODOS

3.1. Localização e descrição da área experimental

3.2. Delineamento experimental e tratamentos

3.3. Instalação e condução do experimento

3.4. Parâmetros analisados 
4. RESULTADOS E DISCUSSÃO ….................................................. 37

4.1. Efeitos nas características químicas do solo ................................. 37

4.1.1. $\mathrm{pH}$.................................................................. 37

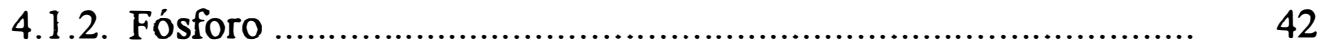

4.1.3. Potássio .................................................................... 45

4.1.4. Cálcio .................................................................... 49

4.1.5. Magnésio ............................................................. 55

4.1.6. Enxofre ..................................................................... 60

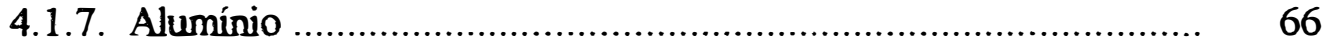

4.1.8. Capacidade de troca catiônica (CTC) ….............................. 72

4.1.9. Saturação por bases $(\mathrm{V} \%)$.......................................... 75

4.2. Efeitos nos teores de nutrientes nas folhas .................................... $\quad 80$

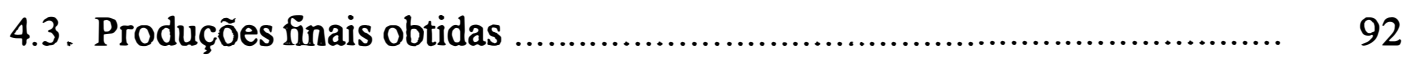

4.3.1. Número de colmos industrializáveis ................................ 92

4.3.2. Produtividades agrícolas .............................................. 93

4.3.3. Qualidade da matéria prima ........................................... 98

4.4. Correlações entre variáveis aleatórias............................................. 101

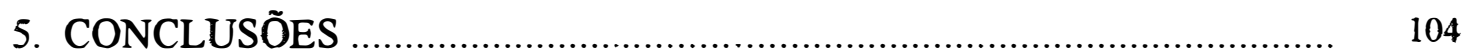

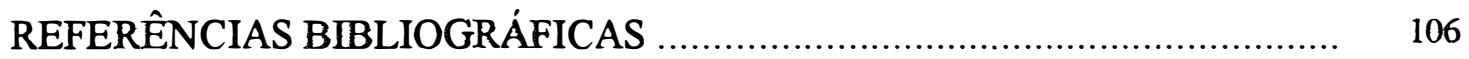




\section{LISTA DE FIGURAS}

Página

Figura 1. Teores de $\mathrm{Ca}^{2+}+\mathrm{Mg}^{2+}\left(\mathrm{meq} / 100 \mathrm{~cm}^{3}\right)$ na entrelinha da cana-deaçúcar, após a colheita da segunda soca, ao longo do perfil do solo, na testemunha e nos tratamentos com gesso e gesso em mistura com magnesita

Figura 2. Teores de $\mathrm{S}^{-\mathrm{SO}_{4}{ }^{2-}}\left(\mu \mathrm{g} / \mathrm{cm}^{3}\right)$ na entrelinha da cana-de-açúcar, ao longo do perfil do solo, após a colheita da segunda soca na testemunha e nos tratamentos que receberam gesso, gesso em mistura com magnesita e com calcário dolomítico e magnesita em mistura com calcário calcítico (a 85\%)

Figura 3. Teores de $\mathrm{S}-\mathrm{SO}_{4}{ }^{2-}\left(\mu \mathrm{g} / \mathrm{cm}^{3}\right)$ na entrelinha da cana-de-açúcar, ao longo do perfil do solo aos 6 meses após a aplicação da mistura de gesso com magnesita e após as colheitas da cana planta e das duas primeiras socas

Figura 4. Saturação de alumínio - (m \%) - na entrelinha da cana-de-açúcar, ao longo do perfil do solo, após a colheita da segunda soca na testemunha e nos tratamentos que receberam gesso, gesso em mistura com magnesita e com calcário dolomítico e magnesita em mistura com calcário calcítico (a 85\%) 
Figura 5. Saturação por bases (V \% ) na entrelinha da cana-de-açúcar, ao longo do perfil do solo, após a colheita da segunda soca na testemunha e nos tratamentos que receberam o gesso isoladamente e em mistura com calcário dolomítico e com magnesita e magnesita em mistura com calcário calcítico

Figura 6. Produtividades agrícolas ( $\mathrm{t}$ cana/ha) obtidas nos diversos tratamentos, na cana planta e nas duas primeiras socas 


\section{LISTA DE TABELAS}

Tabela 1. Precipitações pluviométricas $(\mathrm{em} \mathrm{mm}$ ) ocorridas durante $\mathrm{o}$

Tabela 2. Principais caracteristicas químicas do solo na área experimental da Destilaria Cocal (Paraguaçú Paulista/SP)

Tabela 3. Teores percentuais de Cao, MgO, PN e PRNT dos produtos corretivos e misturas utilizadas.

Tabela 4. Doses dos produtos/misturas utilizados como tratamentos (em t/ha)

Tabela 5. Resultados de análise de solo para pH em $\mathrm{CaCl}_{2}$ aos 6 meses após a aplicação dos produtos, na linha e na entrelinha, ao longo do perfil do solo.

Tabela 6. Resultados de análise de solo para $\mathrm{pH}$ em $\mathrm{CaCl}_{2}$, na colheita da cana planta, na linha e na entrelinha, ao longo do perfil do solo

Tabela 7. Resultados de análise de solo para $\mathrm{pH}$ em $\mathrm{CaCl}_{2}$, na colheita da primeira soca, na linha e na entrelinha, ao longo do perfil do solo.....

Tabela 8. Resultados de análise de solo para $\mathrm{pH}$ em $\mathrm{CaCl}_{2}$, na colheita da segunda soca, na linha e na entrelinha, ao longo do perfil do solo.....

Tabela 9. Resultados de análise de solo para $\mathrm{P}\left(\mu \mathrm{g} / \mathrm{cm}^{3}\right)$ aos 6 meses após a aplicação dos produtos, na linha e na entrelinha, ao longo do perfil do solo 
Tabela 10. Resultados de análise de solo para $\mathrm{P}\left(\mu \mathrm{g} / \mathrm{cm}^{3}\right)$ na colheita da cana planta, na linha e na entrelinha, ao longo do perfil do solo.

Tabela 11. Resultados de análise de solo para $P\left(\mu \mathrm{g} / \mathrm{cm}^{3}\right)$ na colheita da primeira soca, na linha e na entrelinha, ao longo do perfil do solo.

Tabela 12. Resultados de análise de solo para $P\left(\mu \mathrm{g} / \mathrm{cm}^{3}\right)$ na colheita da segunda soca, na linha e na entrelinha, ao longo do perfil do solo

Tabela 13. Resultados de análise de solo para $\mathrm{K}^{+}\left(\mathrm{meq} / 100 \mathrm{~cm}^{3}\right)$ aos 6 meses após a aplicação dos produtos, na linha e na entrelinha, ao longo do perfil do solo

Tabela 14. Resultados de análise de solo para $\mathrm{K}^{+}\left(\mathrm{meq} / 100 \mathrm{~cm}^{3}\right)$, na colheita da cana planta, na linha e na entrelinha, ao longo do perfil do solo

Tabela 15. Resultados de análise de solo para $\mathrm{K}^{+}\left(\mathrm{meq} / 100 \mathrm{~cm}^{3}\right)$, na colheita da primeira soca, na linha e na entrelinha, ao longo do perfil do solo.

Tabela 16. Resultados de análise de solo para $\mathrm{K}^{+}\left(\mathrm{meq} / 100 \mathrm{~cm}^{3}\right)$, na colheita da segunda soca, na linha e na entrelinha, ao longo do perfil do solo. 
Tabela 17. Resultados de análise de solo para $\mathrm{Ca}^{2+}\left(\mathrm{meq} / 100 \mathrm{~cm}^{3}\right)$ aos 6 meses após a aplicação dos produtos, na linha e na entrelinha, ao longo do perfil do solo

Tabela 18. Resultados de análise de solo para $\mathrm{Ca}^{2+}\left(\mathrm{meq} / 100 \mathrm{~cm}^{3}\right)$, na colheita da cana planta, na linha e na entrelinha, ao longo do perfil do solo.

Tabela 19. Resultados de análise de solo para $\mathrm{Ca}^{2+}\left(\mathrm{meq} / 100 \mathrm{~cm}^{3}\right)$, na colheita da primeira soca, na linha e na entrelinha, ao longo do perfil do solo.

Tabela 20. Resultados de análise de solo para $\mathrm{Ca}^{2+}\left(\mathrm{meq} / 100 \mathrm{~cm}^{3}\right)$, na colheita da segunda soca, na linha e na entrelinha, ao longo do perfil do solo.

Tabela 21. Resultados de análise de solo para $\mathrm{Mg}^{2+}\left(\mathrm{meq} / 100 \mathrm{~cm}^{3}\right)$ aos 6 meses após a aplicação dos produtos, na linha e na entrelinha, ao longo do perfil do solo.

Tabela 22. Resultados de análise de solo para $\mathrm{Mg}^{2+}\left(\mathrm{meq} / 100 \mathrm{~cm}^{3}\right)$, na colheita da cana planta, na linha e na entrelinha, ao longo do perfil do solo.

Tabela 23. Resultados de análise de solo para $\mathrm{Mg}^{2+}\left(\mathrm{meq} / 100 \mathrm{~cm}^{3}\right)$, na colheita da primeira soca, na linha e na entrelinha, ao longo do perfil do solo. 
Tabela 24. Resultados de análise de solo para $\mathrm{Mg}^{2+}\left(\mathrm{meq} / 100 \mathrm{~cm}^{3}\right)$, na colheita da segunda soca, na linha e na entrelinha, ao longo do perfil do solo.

Tabela 25. Resultados de análise de solo para $\mathrm{S}_{-} \mathrm{SO}_{4}{ }^{2-}\left(\mu \mathrm{g} / \mathrm{cm}^{3}\right)$ aos 6 meses após a aplicação dos produtos, na linha e na entrelinha, ao longo do perfil do solo.

Tabela 26. Resultados de análise de solo para) $\mathrm{S}_{-} \mathrm{SO}_{4}{ }^{2-}\left(\mu \mathrm{g} / \mathrm{cm}^{3}\right)$ na colheita da cana planta, na linha e na entrelinha, ao longo do perfil do solo

Tabela 27. Resultados de análise de solo para) $\mathrm{S}_{-} \mathrm{SO}_{4}{ }^{2-}\left(\mu \mathrm{g} / \mathrm{cm}^{3}\right)$, na colheita da primeira soca, na linha e na entrelinha, ao longo do perfil do solo.

Tabela 28. Resultados de análise de solo para) $\mathrm{S}-\mathrm{SO}_{4}{ }^{2-}\left(\mu \mathrm{g} / \mathrm{cm}^{3}\right)$, na colheita da segunda soca, na linha e na entrelinha, ao longo do perfil do solo

Tabela 29. Resultados de análise de solo para $\mathrm{Al}^{3+}\left(\mathrm{meq} / 100 \mathrm{~cm}^{3}\right)$ aos 6 meses após a aplicação dos produtos, na linha e na entrelinha, ao longo do perfil do solo

Tabela 30. Resultados de análise de solo para $\mathrm{Al}^{3+}\left(\mathrm{meq} / 100 \mathrm{~cm}^{3}\right)$, na colheita da cana planta, na linha e na entrelinha, ao longo do perfil do solo.... 
Tabela 31. Resultados de análise de solo para $\mathrm{Al}^{3+}\left(\mathrm{meq} / 100 \mathrm{~cm}^{3}\right)$, na colheita da primeira soca, na linha e na entrelinha, ao longo do perfil do solo

Tabela 32. Resultados de análise de solo para $\mathrm{Al}^{3+}\left(\mathrm{meq} / 100 \mathrm{~cm}^{3}\right)$, na colheita da segunda soca, na linha e na entrelinha, ao longo do perfil do solo.

Tabela 33. Resultados de análise de solo para CTC aos 6 meses após a aplicação dos produtos, na linha e na entrelinha, ao longo do perfil do solo.

Tabela 34. Resultados de análise de solo para CTC na colheita da cana planta, na linha e na entrelinha, ao longo do perfil do solo

Tabela 35. Resultados de análise de solo para CTC na colheita da primeira soca, na linha e na entrelinha, ao longo do perfil do solo

Tabela 36. Resultados de análise de solo para CTC na colheita da segunda soca, na linha e na entrelinha, ao longo do perfil do solo

Tabela 37. Resultados de análise de solo para $\mathrm{V} \%$ aos 6 meses após a aplicação dos produtos, na linha e na entrelinha, ao longo do perfil do solo.

Tabela 38. Resultados de análise de solo para V\% na colheita da cana planta, na linha e na entrelinha, ao longo do perfil do solo 
Tabela 39. Resultados de análise de solo para $\mathrm{V} \%$ na colheita da primeira soca, na linha e na entrelinha, ao longo do perfil do solo

Tabela 40. Resultados de análise de solo para $\mathrm{V} \%$ na colheita da segunda soca, na linha e na entrelinha, ao longo do perfil do solo

Tabela 41. Teores médios de $\mathrm{N}(\mathrm{em} \%)$ nas folhas de cana-de-açúcar, aos 6 meses após a aplicação dos produtos (cana planta) e aos 4 meses após o cultivo das soqueiras

Tabela 42. Teores médios de $\mathrm{P}$ (em \%) nas folhas de cana-de-açúcar, aos 6 meses após a aplicação dos produtos (cana planta) e aos 4 meses após o cultivo das soqueiras.

Tabela 43. Teores médios de $\mathrm{K}(\mathrm{em} \%)$ nas folhas de cana-de-açúcar, aos 6 meses após a aplicação dos produtos (cana planta) e aos 4 meses após o cultivo das soqueiras.

Tabela 44. Teores médios de $\mathrm{Ca}(\mathrm{em} \%$ ) nas folhas de cana-de-açúcar, aos 6 meses após a aplicação dos produtos (cana planta) e aos 4 meses após o cultivo das soqueiras.

Tabela 45. Teores médios de $\mathrm{Mg}$ (em \%) nas folhas de cana-de-açúcar, aos 6 meses após a aplicação dos produtos (cana planta) e aos 4 meses após o cultivo das soqueiras 
Tabela 46. Teores médios de S (em \%) nas folhas de cana-de-açúcar, aos 6 meses após a aplicação dos produtos (cana planta) e aos 4 meses após o cultivo das soqueiras

Tabela 47. Teores médios de Mn (em \%) nas folhas de cana-de-açúcar, aos 6 meses após a aplicação dos produtos (cana planta) e aos 4 meses após o cultivo das soqueiras.

Tabela 48. Teores médios de $\mathrm{Al}$ (em ppm) nas folhas de cana-de-açúcar, aos 6 meses após a aplicação dos produtos (cana planta) e aos 4 meses após o cultivo das soqueiras

Tabela 49. Número de colmos industrializáveis $\left(\mathrm{n}^{\circ}\right.$ de colmos $/ \mathrm{m}$ linear) na colheita da cana planta e das duas primeiras socas

Tabela 50. Produtividades agrícolas ( $\mathrm{t}$ cana/ha) obtidas na colheita da cana planta e das duas primeiras socas e produtividade acumulada nos 3 cortes

Tabela 51. Dados de pol \% cana obtidos na colheita da cana planta e das duas primeiras socas.

Tabela 52. Dados de fibra \% cana obtidos na colheita da cana planta e das duas primeiras socas

Tabela 53. Dados de pureza da matéria prima obtidos na colheita da cana planta e das duas primeiras socas 
. Página

Tabela 54. Correlações lineares entre os parâmetros obtidos nas análises de solo e de planta e as produtividades agrícolas $(\mathrm{TCH})$ da cana planta

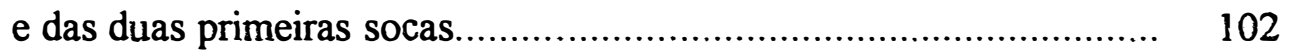




\title{
INFLUÊNCIA DE CORRETIVOS DA ACIDEZ E DO GESSO AGRÍCOLA EM PROPRIEDADES QUIMMICAS DO SOLO, NA NUTRIÇÃO E PRODUÇÃO DA CANA-DE-AÇỦCAR
}

\author{
Autor : JOSÉ CARLOS ROLIM \\ Orientador : GODOFREDO CESAR VITTI
}

RESUMO

Este trabalho teve por objetivo avaliar a eficiência de alguns produtos corretivos da acidez do solo, aplicados isoladamente e em mistura com o gesso agrícola e com magnesita, na cultura da cana-de-açúcar. Procurou-se estudar os efeitos dos produtos no solo, com referência às suas características químicas ao longo do perfil, na linha e na entrelinha da cultura, e na planta, no que diz respeito à sua produtividade agrícola e às suas características tecnológicas.

Para tanto, instalou-se um experimento na Destilaria Cocal, em Paraguaçú Paulista, situada no Estado de São Paulo, na latitude $22^{\circ} 30^{\prime} \mathrm{S}$ e longitude $50^{\circ} 22^{\prime} \mathrm{W}$, em

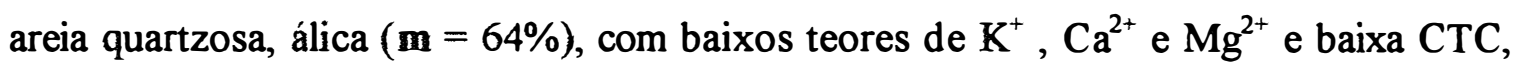
contendo $85 \%$ de areia, $11 \%$ de argila e $4 \%$ de silte.

Os tratamentos obedeceram ao delineamento experimental de blocos casualizados, com 10 tratamentos e 5 repetições, sendo que cada parcela foi constituida 
por 7 linhas de cana-de-açúcar de 20 metros de comprimento, espaçadas de 1,0 metro; foram consideradas úteis somente as 3 linhas centrais.

Foram utilizados os seguintes produtos : calcário calcítico, calcário magnesiano, calcário dolomítico, magnesita e gesso agrícola, testando-os separadamente e em misturas. Com exceção do gesso, as doses dos corretivos e misturas foram calculadas a fim de elevar o índice de saturação por bases (V \%) a $70 \%$, na profundidade de 0 a $40 \mathrm{~cm}$; a dose de gesso foi calculada com o objetivo de elevar o teor de $\mathrm{Ca}^{2+}$ a 2 meq $/ 100 \mathrm{~cm}^{3}$, na profundidade 20 a $40 \mathrm{~cm}$.

A aplicação dos produtos foi manual, imediatamente antes do plantio e sua incorporação foi feita com arado de aiveca, incorporando-se os produtos a uma profundidade aproximada de $40 \mathrm{~cm}$. Amostragens de solo foram realizadas com sonda amostradora, na linha e na entrelinha da cana-de-açúcar, nas profundidades $0-25 \mathrm{~cm}, 25$ $-50 \mathrm{~cm}, 50-75 \mathrm{~cm}$ e $75-100 \mathrm{~cm}$, aos 6 meses após a aplicação dos produtos e após as colheitas da cana planta e das duas primeiras socas, determinando-se o $\mathrm{pH} \mathrm{em} \mathrm{CaCl}_{2}$ e os teores de $\mathrm{P}, \mathrm{K}^{+}, \mathrm{Ca}^{2+}, \mathrm{Mg}^{2+}, \mathrm{S}^{2} \mathrm{SO}_{4}{ }^{2-}$ e $\mathrm{Al}^{3+}$.

As plantas foram amostradas aos 6 meses após a aplicação dos produtos e aos 4 meses após o culivo das duas primeiras soqueiras, coletando-se a folha +3 e sendo analisados os teores porcentuais dos macronutrientes e de Mn e Al. Na colheita da cana planta e das socas foram determinados o "stand" final, a produtividade agrícola e a qualidade da matéria prima obtida.

Mediante os resultados obtidos, pode-se tirar as seguintes conclusões : 
a) a aplicação de corretivos de acidez do solo e do gesso agrícola, com exceção da magnesita aplicada isoladamente, permitiram a obtenção de altas produtividades de cana-de-açúcar até o $3^{\circ}$ corte; neste contexto, a mistura de gesso agrícola ( $85 \%$ ) com magnesita (15\%) se destacou dentre os tratamentos, chegando a produzir o dobro da testemunha na segunda soca;

b) no solo, ao longo do tempo, os teores de $\mathrm{S}_{-} \mathrm{SO}_{4}{ }^{2-}, \mathrm{Ca}^{2+} \mathrm{e} \mathrm{Mg}^{2+}$ foram os mais afetados pelos tratamentos realizados e, em maior proporção, pela mistura de gesso agricola com magnesita, na camada arável;

c) a entrelinha da cana-de-açúcar apresentou maiores teores de $\mathrm{S}_{-} \mathrm{SO}_{4}{ }^{2-}$, em todo o perfil do solo e ao longo do tempo e de $\mathrm{Ca}^{2+}$, somente na camada arável e até a colheita da cana planta;

d) na planta, houve maior influência dos tratamentos nos teores foliares (\%) de $\mathrm{S} \mathrm{e} \mathrm{Mg}$, sendo mais acentuado na mistura de gesso agrícola com magnesita;

e) não houve influência dos corretivos e do gesso agrícola na qualidade da matéria prima, expressa em têrmos de pol \% cana, fibra \% cana e pureza, nos 3 cortes estudados. 


\title{
EFFECTS OF SOIL ACIDITY CORRECTIVE PRODUCTS AND \\ PHOSPHOGYPSUM ON THE SOIL CHEMICAL ATTRIBUTES, ON THE \\ NUTRITION AND PRODUCTION OF SUGARCANE
}

\author{
Author : JOSÉ CARLOS ROLIM \\ Adviser : Prof. Dr. GODOFREDO CESAR VITTI
}

SUMMARY

A three-year long experiment was conducted to evaluate the efficiency of liming, applied alone and in mixture with phosphogypsum and magnesite, applied in total area in sugarcane field. The experiment was carried out at Cocal mill, in Paraguaçu Paulista, located in the west of São Paulo State $\left(22^{\circ} 30^{\prime} \mathrm{S} ; 50^{\circ} 22^{\prime} \mathrm{W}\right)$. The soil of the area is a quartzpsaments, alic $(\mathrm{m}=64 \%)$, with low contents of $\mathrm{K}^{+}, \mathrm{Ca}^{2+}$, and $\mathrm{Mg}^{2+}$ and low cation exchangeable capacity, extremely sandy ( $85 \%$ sand).

The statistic design was randomized complete blocks, with 10 treatments and 5 replications. Each plot was constituted by 7 rows of sugarcane , $20 \mathrm{~m}$ long and 1.0 $\mathrm{m}$ between rows; only the 3 central rows were considered as effective area.

The following products were used : calcitic, magnesian, and dolomitic limestone, magnesite, and phosphogypsum, alone and in mixtures. The rates of the liming 
products and their mixtures were calculated with the purpose of increasing the soil base saturation to $70 \%$, on the pedon situated in $0-40 \mathrm{~cm}$ soil depth. The phosphogypsum rate was calculated with the aim of increasing the $\mathrm{Ca}^{2+}$ contents to $2 \mathrm{meq} / 100 \mathrm{~cm}^{3}$, in the same depth.

The products were applied manually, just before planting; incorporation was made with a moldboard plow, to a depth of $40 \mathrm{~cm}$.

Soil samples were collected in the following sites : sugarcane rows and inter-rows, both in depths of $0-25 \mathrm{~cm}, 25-50 \mathrm{~cm}, 50-75 \mathrm{~cm}$, and $75-100 \mathrm{~cm}$. Sampling was repeated 4 times : 6 months after products application, after harvesting the plant cane and two ratoons. The $\mathrm{pH}$ in $\mathrm{CaCl}_{2}$ and $\mathrm{P}, \mathrm{K}^{+}, \mathrm{Ca}^{2+}, \mathrm{S}-\mathrm{SO}_{4}{ }^{2-}$, and $\mathrm{Al}^{3+}$ contents were analyzed.

In plant cane, sugarcane leaves $(+3)$ were sampled 6 months after products application; the two ratoons were sampled 4 months after cultivation. Mineral macronutrient status (\%), manganese, and aluminum (ppm) were analyzed. In all harvests the number of stalks per linear meter, the yield, and the sugarcane quality were determined.

Considering the results obtained, the following conclusions can be withdrawn :-

a) except for magnesite, all the products tested increased the yield of the sugarcane crop up to the $3^{\text {rd }}$ harvest; the mixture phosphogypsum (85\%) plus magnesite (15\%) was the best treatment, giving yield two times higher than the control in the $3^{\text {rd }}$ harvest; 
b) from all the soil chemical parameters analyzed, $\mathrm{S}-\mathrm{SO}_{4}{ }^{2-}, \mathrm{Ca}^{2+}$, and $\mathrm{Mg}^{2+}$ contents were the most affected by the treatments. This effect was higher in the phosphogypsum-magnesite treatment, in the plowing layer;

c) soil in inter-rows showed higher $\mathrm{S}-\mathrm{SO}_{4}{ }^{2-}$ contents, with depth and over time; on the other hand, higher $\mathrm{Ca}^{2+}$ contents were observed in soil in inter-rows only in the plowing layer in the first harvest;

d) the S and $\mathrm{Mg}$ foliar contents ( $\%$ ) were highly influenced by all treatments, particularly by the phosphogypsum-magnesite mixture;

e) sugarcane quality, expressed in pol \% cane, fiber $\%$ cane, and purity, was not affected by limestone and phosphogypsum. 


\section{INTRODUÇÃO}

O Brasil sempre se situou entre os paises maiores produtores de cana-deaçúcar (Saccharum spp.) do mundo, mesmo na fase em que o interesse maior residia no açúcar. Em 1975, 1.969.000 ha era a área colhida com cana-de-açúcar, com a produção de 91,5 milhões de toneladas de colmos, 6,0 milhões de toneladas de açúcar e $625.000 \mathrm{~m}^{3}$ de álcool; o que se visava era a produção de açúcar, que era controlada pelo Instituto do Açúcar e do Álcool (IAA), para atender o consumo interno e a quota de exportação.

Como resultado da primeira crise do petróleo, por volta de 1970, foi criado no Brasil o Programa Nacional do Álcool - PROÁlCOOL, visando amenizar o consumo de óleo pela introdução do álcool etílico (etanol) hidratado como combustível. Sendo um Programa novo e ambicioso, estabeleceu-se como meta, a ser atingida em 1985, uma produção de 10,7 bilhões de litros de álcool, que foi realmente atingida no ano seguinte. Houve, para tanto, grande expansão da cultura da cana-de-açúcar, acompanha da ampliação das destilarias anexas às usinas e da instalação de numerosas destilarias autônomas, que visavam à produção exclusivamente do álcool. Dados do IBGE, do Censo Agrícola de 1990, indicam que a área colhida de cana-de-açúcar no Brasil foi de 
4,1 milhões de ha, com uma produção de 262 milhões de toneladas de colmos industrializáveis.

Com isto, a área de cana-de-açúcar, que até a década de 70 era confinada às proximidades das usinas processadoras, sendo cultivadas em regiões de solos de alta fertilidade, representadas, em geral, pelos latossolos roxos eutróficos, contendo alta capacidade de troca de íons e elevada saturação por bases, teve que ser ampliada. Com a expansão rápida da cultura, os novos canaviais foram também instalados em solos de baixa fertilidade, distróficos e/ou álicos, na maior parte das vezes; dentre tais solos, predominaram os latossolos vermelho escuros textura média, os podzólicos vermelho amarelos e as areias quartzosas.

A cultura da cana-de-açúcar passou, então, a necessitar de maior tecnificação, exigida também pela adoção do sistema de pagamento da matéria prima baseada em seu teor de sacarose, a partir de 1975. A melhoria do nível de tecnologia utilizado nos canaviais vem se sentindo nos últimos anos através da adoção de diversas inovações tecnológicas, dentre as quais se destaca a referente à fertilização da cultura, responsável por grande parte dos incrementos de produtividade alcançados, especialmente no Estado de São Paulo.

Dentro dos esforços para obtenção de maiores produtividades da cultura via fertilização, assume importância fundamental a correção da acidez dos solos, tanto em sua camada arada como em subsuperficie e em camadas mais profundas, onde o acúmulo de $\mathrm{Al}^{3+}$ vem prejudicando sensivelmente o sistema radicular da cana-de-açúcar. 
Por outro lado, novos tipos de corretivos surgiram no mercado, ampliando as possibilidades de utilização mais racional desta classe de produtos; assim, a magnesita, como subproduto da indústria de refratários, pode permitir um melhor balanceamento dos teores de $\mathrm{Ca}^{2+}$ e de $\mathrm{Mg}^{2+}$ existentes nos demais corretivos e o gesso agrícola, subproduto da indústria do ácido fosfórico, além de inativar $\mathrm{o} \mathrm{Al}^{3+} \mathrm{em}$ profundidade, fomece $\mathrm{Ca}^{2+}$ e $\mathrm{S}^{-\mathrm{SO}_{4}{ }^{2-}}$ às plantas. Pode-se inferir que o uso de tais produtos, associados ou não aos calcários tradicionais, possa trazer melhorias nos resultados finais da calagem.

Os objetivos deste trabalho se resumem na avaliação da eficiência de alguns produtos corretivos da acidez do solo, aplicados isoladamente e em misturas com magnesita e gesso agrícola, na cultura da cana-de-açúcar, tanto no que diz respeito à sua produtividade agrícola e às suas características tecnológicas, como nos efeitos que os produtos venham a ter nas características químicas do solo, tanto na camada arável como em subsuperficie, ao longo do tempo. 


\section{REVISÃO BIBLIOGRÁFICA}

\subsection{Solos cultivados com a cultura da cana-de-açúcar no Brasil}

A cultura canavieira, sendo cultivada em mais de 4 milhões de ha, distribuidos pela maioria dos estados brasileiros, abrange os mais variados tipos de solos. A grande variabilidade de solos nos quais são plantados esta cultura é atestada por KOFFLER \& DONZELI (1987). Já CARVALHO (1983) cita que a cana-de-açúcar se expandiu em direção às áreas de campo cerrado, cerrado, cerradão e tabuleiros a partir da implementação do PROÁLCOOL, na década de 70. Lembra o autor que, embora a canade-açúcar seja uma planta muito rústica, é óbvio que a economicidade de sua produção agroindustrial é gradativamente prejudicada à medida que as características ambientais tornam-se mais hostis, incluindo-se nestas condições os solos sujeitos à inundações, ou altamente erodiveis, ou declivosos, ou pedregosos e os solos de fertilidade muito baixa em que a cultura passou a ser explorada.

MARINHO \& ALBUQUERQUE (1983) comentam que os solos brasileiros apresentan acidez média ( $\mathrm{pH} \mathrm{5,5}$ ), sendo que os solos sob cerrado tem acidez ainda maior ( $\mathrm{pH}$ entre 4,8 e 5,2). 
Apresentando as características gerais dos solos mais representativos com a cultura canavieira no Brasil, KOFFLER \& DONZELI (1987) destacam os latossolos e os podzólicos. Segundo os autores, dentre os latossolos, o latossolo roxo eutrófico vem proporcionando bons resultados à canavicultura, devendo-se verificar localmente a presença de condições restritivas. Os solos podzólicos (especialmente os arenitos com cimento calcário), por sua vez, são, em geral, distróficos, de textura média ou argilosa; são solos de baixa fertilidade natural, sendo este o principal fator limitante ao uso agrícola. Nestes solos, a acidez elevada, associada a niveis tóxicos de $\mathrm{Al}$ e Mn e a baixos teores de $\mathrm{P}$ é muito comum, fatores estes relevantes para a baixa produtividade da cana-de-açúcar.

Os latossolos possuem teor de argila em profundidade pouco variável, entre 15 e $25 \%$, drenagem interna boa, com teores de bases extremamente baixo, em tomo dos $10-20 \%$ da CTC. A saturação com $\mathrm{Al}^{3+}$ aumenta em profundidade, atingindo valores superiores a $60 \%$. A CTC para os horizontes superficiais está entre 3 a 5 meq/100g; os teores de $\mathrm{Ca}^{2+}$ e de $\mathrm{Mg}^{2+}$ perfazem um total de 50 a $60 \%$ da CTC, em toda a extensão do perfil. $\mathrm{O}$ teor de $\mathrm{K}^{+}$é relativamente elevado para tais solos, devido à presença de ortoclásios na fração areia; ocorrem em relevo de plano a suavemente ondulado, ocupando as posições mais elevadas.

Dentre os fatores limitantes que contribuem para reduzir a produtividade da cana-de-açúcar, podem ser destacados : a) baixa fertilidade dos solos : os latossolos possuem teor de bases extremamente baixo, ao longo do perfil; apesar da cultura da canade-açúcar ser tida como pouco exigente em fertilidade, variedades mais novas, ricas em 
sacarose, são extremamente exigentes (COPERSUCAR, 1984, 1986; IAAPPLANALSUCAR, 1982, 1983); b) elevada saturação em Al : normalmente superior a 50\%; os resultados obtidos por ZAMBELLO JÚNIOR \& ORLANDO FILHO (1981), com dados de São Paulo e Alagoas são equivalentes aos dados obtidos por MARINHO \& ALBUQUERQUE (1981), MARINHO \& ARAUJO FILHO (1981) e MARINHO et al. (1981) em Alagoas, que indicam o valor de $40 \%$ de saturação com $\mathrm{Al}^{3+}$ correspondente a $90 \%$ de produção relativa e os teores de $\mathrm{Al}^{3+}$ de 1,0 a $2,0 \mathrm{meq} / 100 \mathrm{ml}$ de solo, correspondentes a 90 e $80 \%$ de produção relativa, respectivamente; c) restrição ao desenvolvimento radicular devido ao bloqueio químico : a falta de nutrientes em profundidade ou o elevado teor de $\mathrm{Al}^{3+}$ podem agir como verdadeiras barreiras químicas contra o desenvolvimento radicular e o pouco volume de solo explorado pelo sistema radicular é um dos fatores que tem agido contra o aumento da produtividade da cana-deaçúcar. No Brasil, de modo geral, constata-se que o sistema radicular da cana-de-açúcar explora efetivamente cerca de $60 \mathrm{~cm}$ de espessura de solo; a literatura internacional (KOFLER, 1986) aponta para valores significativamente superiores, entre 120 e $200 \mathrm{~cm}$.

\subsection{Níveis de nutrientes na cana-de-açúcar}

Nas condições brasileiras, diversos autores têm procurado caracterizar a planta da cana-de-açúcar no que diz respeito aos teores normais de nutrientes, em determinados estágios de seu desenvolvimento, com vistas à determinação de suas deficiências e possíveis correções através de adubações balanceadas, que podem ser 
realizadas tanto no solo como por via foliar. Independentemente da questão varietal, parâmetro inportante na determinação destes níveis na planta, diversos estudos vêm sendo conduzidos para caracterizar níveis críticos ou teores mais adequados dos nutrientes nas plantas de cana-de-açúcar.

Assim, GALLO et al. (1968) foram um dos primeiros autores nacionais a proceder a um levantamento nutricional de canaviais paulistas, indicando estes autores os seguintes teores existentes em amostras de folhas de cana-de-açúcar : plantas deficientes em $\mathrm{N}$ possuiam de 1,08 a $1,60 \%$ deste nutriente em suas folhas; deficiência de $\mathrm{P}$, entre 0,07 e $0,12 \%$; deficiência de $\mathrm{K}$, entre 0,34 e 1,20 \%; deficiência de Ca, entre 0,23 e 0,30 $\%$; plantas deficientes em Mg acusaram teores entre 0,04 e 0,15\%.

MALAVOLTA et al. (1974) cita dados obtidos por outros autores, a nível internacional, que podem servir como padrão para comparação dos dados obtidos por outros pesquisadores; desta forma, o autor comenta os dados obtidos por Dutoit ${ }^{(1)}$ (1953), que, trabalhando na África do Sul, amostrando a $3^{\mathrm{a}}$ folha, com 7 a 11 meses de idade, contendo a nervura central, considerou adequados para aquela região teores foliares de $\mathrm{N}$ entre 1,45 e 1,65\%, denominando de deficientes as plantas que possuiam teores foliares de $\mathrm{N}$ menores que $1,25 \%$; plantas deficientes em $\mathrm{P}$ foram aquelas que possuiam, segundo o autor, teores inferiores a $0,12 \%$, considerando adequados os níveis entre 0,12 e $0,16 \%$ de $\mathrm{P}$ foliar; já para o $\mathrm{K}$, este autor considera como níveis adequados os teores entre 1,33 e 1,50\%, encontrando-se a planta em estado de deficiência quando apresentasse abaixo de $0,83 \%$ de $\mathrm{K}$ nas folhas.

\footnotetext{
${ }^{1}$ - DUTOIT, J.L. Proc. International Society of Sugarcane Technologists Conference. Barbados. 1953. 40p.
} 


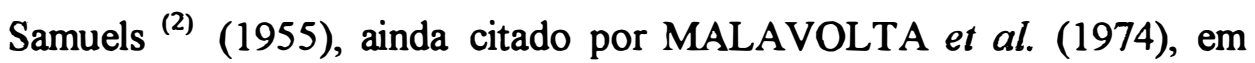
Porto Rico, trabalhou com as $4^{\mathrm{a}}, 5^{\mathrm{a}}$ e $6^{\mathrm{a}}$ folhas de cana-de-açúcar, com a idade de 3 meses, encontrando os seguintes valores : para o $\mathrm{N}$, teores adequados, entre 2,00 e 2,50 $\%$ e teores deficientes, abaixo de $1,50 \%$; para o $\mathrm{P}$, considerou teores adequados os níveis entre 0,18 e 0,25\%, encontrando-se plantas deficientes quando apresentassem teores inferiores a $0,10 \%$; ainda segundo este autor, os teores adequados de $\mathrm{K}$ foliar se situam entre 1,15 e $2,0 \%$ e o nível de deficiência se encontra em teores abaixo de 1,00 $\%$.

Por sua vez, Evans ${ }^{(3)}$ (1959), também citado por MALAVOLTA et al. (1974), trabalhando nas Ilhas Maurício, detectou que folhas de cana-de-açúcar deficientes em Mn apresentavam, quando cloróticas, 24 ppm do elemento e quando sadias, 40 ppm de Mn foliar.

Trabalhando em nossas condições, MALAVOLTA (1980) indicou os níveis críticos dos nutrientes, considerando como tal o teor mínimo aceitável existente na folha, abaixo do qual ocorrem perdas de produção. Assim, para o N, considera como adequados os teores entre 1,50 e $2,50 \%$, sendo $1,50 \%$ o nível crítico deste nutriente; 0,20\%, segundo o autor, é o nível crítico de $\mathrm{P}$ foliar, estando a planta com teores adequados quando possuir entre 0,20 e $0,25 \%$ deste nutriente nas folhas; para o $\mathrm{K}$, considera o valor de $1,00 \%$ como nível crítico, encontrando-se plantas com teores adequados numa faixa mais ampla, entre 1,00 e 2,25 \% de $\mathrm{K}$ foliar. Plantas com teores foliares de $\mathrm{Ca}$ abaixo de $0,50 \%$ foram consideradas como deficientes neste nutriente,

\footnotetext{
2 - SAMUELS, G. Agricultural Experiment Station of the University of Puerto Rico Bulletin. 1955. 123 p. - EVANS, H. Proc. 10 th. International Society of Sugarcane Technologists Congress. 1959. 473 p.
} 
considerando o autor a faixa adequada entre 0,50 e $1,0 \%$; para o $\mathrm{Mg}$, o nível crítico estabelecido foi de $0,15 \%$ e os níveis adequados, entre 0,15 e $0,30 \%$. Similarmente, para o S, o autor estabeleceu o nível de 0,15\% como crítico para a cana-de-açúcar, encontrando-se a planta com teor adequado quando se situasse na faixa entre 0,15 e 0,20 \%; já para o Mn, 50 ppm nas folhas foi o nível crítico encontrado por este autor, que considerou ainda, que plantas que se encontrassem na faixa entre 50 e $150 \mathrm{ppm}$ de $\mathrm{Mn}$ nas folhas estariam numa faixa ótima com relação a este micronutriente.

O mesmo autor e colaboradores - MALAVOLTA et al. (1989) -, posteriormente, propôs alguns novos valores para os níveis críticos de nutrientes nas folhas de cana-de-açúcar. Trabalhando com a folha +3 , com a $1^{a}$ lígula, têrço mediano e excluindo a nervura central, estes autores determinaram os seguintes teores adequados para os diversos nutrientes : para o $\mathrm{N}$ - cana planta $=1,90$ a $2,10 \%$ e cana soca $=2,00 \mathrm{a}$ $2,20 \%$; para o P - cana planta $=0,20$ a $0,24 \%$ e cana soca $=0,18$ a $0,20 \%$; para o $\mathrm{K}$ cana planta $=1,10$ a $1,30 \%$ e cana soca $=1,30$ a $1,50 \%$; para o $\mathrm{Ca}$ - cana planta $=0,80$ a $1,00 \%$ e cana soca $=0,50$ a $0,70 \%$; para o $\mathrm{Mg}$ - cana planta $=0,20$ a $0,30 \%$ e cana soca $=0,20$ a $0,25 \%$; para o S - cana planta e cana soca $=0,25$ a $0,30 \%$.

BATAGLIA \& DECHEN (1986) indicam, também, teores bastante similares aos já citados por outros autores; dentro do conceito de nível crítico, estes autores citam ser os seguintes os teores mínimos aceitáveis dos nutrientes em folhas de cana-de-açúcar : $\mathrm{N}=1,60 \% ; \mathrm{P}=0,12 \% ; \mathrm{K}=1,20 \% ; \mathrm{Ca}=0,20 \% ; \mathrm{Mg}=0,20 \% ; \mathrm{S}=$ $0,20 \% ;$ e $\mathrm{Mn}=50 \mathrm{ppm}$ 
Mais recentemente, RAU (1994) propôs trabalhar com faixas de teores considerados adequados às culturas; assim, para a cana-de-açúcar, considera as seguintes faixas de teores foliares de nutrientes como adequadas : $\mathrm{N}$ - entre 1,60 e $2,00 \% ; \mathrm{P}$ entre 0,12 e $0,16 \% ; \mathrm{K}$ - entre 1,20 e 1,40\%; Ca - entre 0,70 e 0,80\%; Mg - entre 0,20 e $0,35 \%$; S - entre 0,17 e 0,30\%; e Mn - entre 100 e $150 \mathrm{ppm}$.

\subsection{Corretivos da acidez dos solos}

Uma das maneiras de se melhorar a fertilidade do solo e racionalizar a recomendação da adubação é a utilização de corretivos do solo, através da prática da calagem. Esta técnica tem o objetivo básico de proporcionar maior suprimento de $\mathrm{Ca}^{2+} \mathrm{e}$ de $\mathrm{Mg}^{2+}$ como nutrientes das plantas e eliminar os efeitos nocivos da acidez do solo, pela neutralização do $\mathrm{Al}^{3+} \mathrm{e} \mathrm{Mn}^{2+}$ tóxicos aos vegetais.

ALCARDE (1986) lembra que os produtos considerados corretivos da acidez dos solos são aqueles que contêm como "constituinte neutralizante" ou "princípio ativo", carbonatos, óxidos, hidróxidos ou silicatos de $\mathrm{Ca}^{2+}$ e/ou de $\mathrm{Mg}^{2+}$. Assim, são corretivos de acidez : calcário moído, cal virgem, cal hidratada ou extinta, calcário calcinado, escória de siderúrgia e outros materiais de menor importância. Em função do teor de $\mathrm{MgCO}_{3}$ presente nos calcários estes são classificados em : calcíticos, quando o teor de $\mathrm{Mg}^{2+}$ é baixo, não excedendo a $5 \%$ (ou 2,5\% de $\mathrm{MgO}$ ); magnesianos, quando o teor de $\mathrm{MgCO}_{3}$ é de 5 a $20 \%$; dolomíticos, quando o teor de $\mathrm{MgCO}_{3}$ é maior do que 20 $\%$ (ou $11,0 \%$ de $\mathrm{MgO}$ ). 
A neutralização da acidez dos solos pelos corretivos de acidez é feita em decorrência da base química contida em seus constituintes neutralizantes. A prática da calagem tem se fundamentado em duas características dos corretivos: reatividade e efeito residual. Reatividade de um corretivo é a sua velocidade de ação no solo, o que é traduzido na rapidez com que a acidez é corrigida; a reatividade depende de vários fatores : da natureza química dos neutralizantes; da granulometria, das condições de solo e clima. Efeito residual de um corretivo é o tempo de duração da calagem efetuada; é fator primordial no manejo de solos ácidos e na economicidade da calagem; estas características são antagônicas. Tisdale \& $\operatorname{Nelson}^{(4)}$ (1975), citados por ALCARDE (1986), afirmam que os materiais finamente divididos reagem rapidamente no solo, mas seus efeitos são mantidos por um período mais curto do que os materiais que contém uma razoável quantidade de partículas mais grossas.

$\mathrm{O}$ poder de neutralização (PN) de um calcário indica a capacidade potencial do corretivo em neutralizar a acidez do solo, ou o teor total de neutralizantes do corretivo. O desempenho efetivo dessa capacidade depende basicamente de sua composição granulométrica; a partir dessas 2 características de qualidade idealizou-se um índice que aglutina essas duas avaliações : o Poder Relativo de Neutralização Total (PRNT), indice este que permite ajustar a quantidade de corretivo recomendada à qualidade dos produtos disponíveis no mercado.

${ }^{4}$ - TISDALE, S.L. \& NELSON, W.L. Soil Fertility and Fertilizers. 3rd. ed. 1975. 694 p. Macmillan Pub. Co. New York. 
A prática da calagem em solos cultivados com cana-de-açúcar é antiga, como relata Black ${ }^{(5)}$, citado por MARINHO (1983), que indica que no começo deste século a calagem já era realizada nas ilhas havaianas.

Os solos das regiões canavieiras brasileiras apresentam, na sua maioria, reação ácida, e o uso da calagem deveria se tornar, de acordo com IAAPLANALSUCAR (1989), uma prática indispensável para o aumento da produtividade.

Não obstante a isso, ALCARDE (1986) relata que as pesquisas conduzidas a nivel de Brasil sobre a eficiência dos diferentes corretivos são ainda muito escassas, conduzindo à utilização de parâmetros insuficientes para sua avaliação e perfeita recomendação do produto e doses mais adequadas para cada situação.

\subsection{Efeitos do calcário nas características químicas do solo}

O efeito residual de um corretivo é o tempo de duração da calagem efetuada; é primordial no manejo de solos ácidos e na economicidade da calagem, segundo diversos autores - FREITAS \& RAIJ (1974); MIELNICZUK (1983) e RAIJ \& QUAGGIO (1984).

O efeito residual da calagem está relacionado com a reatividade do corretivo que, por sua vez, depende da qualidade do mesmo, das doses aplicadas, da textura do solo e do clima. Em geral, materiais mais finos são mais reativos, com efeito

\footnotetext{
${ }^{5}$ - BLACK, C.A. Soil-plant relationships. 2nd. ed. 1968. 729 p. John Wiley. New York.
} 
residual menor, como foi confirmado por BARROS et al. (1985) para as condições brasileiras.

A velocidade de reação do calcário no solo é relativamente lenta e depende de vários fatores. EMBRAPA (1981) afirma que quantidades suficientes de calcário para atingir pH 5,5 a 6,0 levam em torno de 100 dias para alcançar estes valores. Entre os fatores que afetam a velocidade da reação estão a quantidade e a granulometria mais fina do calcário (GARGANTINI et al. - 1957), enquanto a textura e a matéria orgânica são citados por ROSS et al. (1964) e FAGERIA (1984) como influenciadores da velocidade da reação.

RITCHEY et al. (1980) observaram que o $\mathrm{Ca}^{2+}$ do calcário é muito lentamente lixiviado, provavelmente devido ao fato de que o ânion $\mathrm{CO}_{3}{ }^{2-}$ reage com os ácidos do solo, em pH baixo, sendo transformado em $\mathrm{CO}_{2}$, o qual se perde na atmosfera.

NASCIMENTO et al. (1983), estudando amostras de solo tomadas 300 dias após a calagem, nas profundidades $0-20$ e $20-40 \mathrm{~cm}$, detectaram que os valores de $\mathrm{pH}$ obtidos na profundidade $0-20 \mathrm{~cm}$ foram significativamente diferentes em função dos tratamentos, enquanto que na profundidade $20-40 \mathrm{~cm}$ não se verificou diferença, o mesmo acontecendo com o $\mathrm{Al}$; os teores de $\mathrm{Ca}+\mathrm{Mg}$ não diferiram, na superfície e em profundidade, da testemunha. Também não apresentaram diferenças significativas o $\mathrm{K}$ (com tendência de diminuição com o aumento da dose), o P solúvel e a CTC efetiva, que apresentaram valores, na camada $0-20 \mathrm{~cm}$ cerca de $30 \%$ maiores que os da camada 20 $40 \mathrm{~cm}$. Os valores de V\% nos tratamentos que receberam calcário foram estatisticamente diferentes da testemunha, ao nivel de $1 \%$ de probabilidade, na camada de $0-20 \mathrm{~cm}$. 
QUAGGIO et al. (1982) verificaram que, após 30 meses da incorporação ao solo, o tratamento que recebeu $12 \mathrm{t} / \mathrm{ha}$ de calcário, com $\mathrm{PRNT}=57 \%$, ainda apresentava $1 / 3$ do calcário não reagido.

ZAMBELLO JÚNIOR et al. (1983), visando estudar os efeitos de aplicação de calcário e de superfosfato triplo sobre a cana-de-açúcar, variedade CB-4176, em cana planta e seu efeito residual em 3 soqueiras subsequentes, instalaram ensaio em solo PVa, na região canavieira de Piracicaba (SP). As doses de calcário foram de 0,4 e 8 tha, sendo aplicados 0,75 e $150 \mathrm{~kg} / \mathrm{ha}$ de $\mathrm{P}_{2} \mathrm{O}_{5}$, na forma de superfosfato triplo. Foram observadas respostas às aplicações dos dois insumos considerados, bem como interação positiva entre os mesmos. O calcário mostrou elevado efeito residual, de $94,70 \%, 89,68$ $\%$ e $84,39 \%$, respectivamente para a primeira, segunda e terceira socas; já para o superfosfato triplo, o elevado efeito residual inicial decresceu rapidamente de $82,30 \%$ para $55,74 \%$ da primeira para a terceira soca, enquanto na segunda soca o valor residual foi de $67,73 \%$, tais efeitos sendo evidenciados por superficies de resposta. A perda de

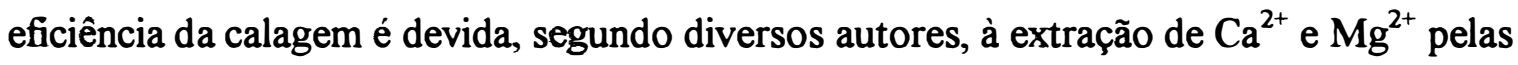
plantas, à lixiviação destes nutrientes e à adição de adubos que promovem a acidificação do solo, seja pela lixiviação das bases ou pela produção de íons $\mathrm{H}^{+}$.

NASCIMENTO et al. (1983) e FREITAS et al. (1984) verificaram em latossolos argilosos que, após 30 e 48 meses da aplicação do calcário, as maiores dosagens provocaram alterações nas propriedades químicas do solo, até essas épocas.

AZEVEDO et al. (1981) mencionaram que em solos onde teores de Ca e/ou de $\mathrm{Mg}$ forem insuficientes para suprir as necessidades da cana-de-açúcar, a aplicação 
de calcário seria recomendável por trazer aumento significativo na produção, independentemente do nível de $\mathrm{Al}$ nesses solos, e que, a partir de teores de $\mathrm{Ca}$ menores que $0,8 \mathrm{meq} / 100 \mathrm{~cm}^{3}$ de solo e de $\mathrm{Mg}$ inferiores a $0,6 \mathrm{meq} / 100 \mathrm{~cm}^{3}$, as possibilidades de se obter bons resultados com a prática da calagem são bastante consideráveis.

LEON et al. (1986), em Cuba, trabalharam com $\mathrm{CaCO}_{3}$ entre 0 e 14 t/ha, calculados com o fim de neutralizar o hidrogênio do solo extraído com acetato de sódio IN (acidez hidrolítica). Como consequência das aplicações do material, se reduziu a acidez hidrolítica, obtendo-se os menores valores após 2 anos de aplicado o material corretivo, recuperando-se os valores iniciais após 4 anos; o efeito sobre o pH se manifestou mais lentamente e foi mais duradouro. $\mathrm{O} \mathrm{Ca}^{2+}$ aumentou, mas o $\mathrm{K}^{+}, \mathrm{Na}^{+} \mathrm{e}$ $\mathrm{Mg}^{2+}$ não sofreram variações notáveis devido às aplicações do calcário. Apesar das variações observadas no solo, não se obteve em 4 colheitas analisadas, aumentos nas variáveis cana/ha e pol/ha. Em solos similares ao deste estudo, concluiram os autores pela não recomendação da prática de aplicação de calcário, independentemente de sua reação ácida.

PINA et al. (1986), em áreas de 4 complexos agroindustrais de Cuba, selecionaram campos de cana-de-açúcar que possuiam condições similares quanto ao tipo de solo, variedade, fertilização mineral aplicada, método de cultivo, etc, mas que diferiam por terem sido calcareados ou não, amostrando-se o solo de cada um deles para sua análise. A calagem aumentou geralmente o conteúdo de $\mathrm{Ca}^{2+}$ trocável, o $\mathrm{pH}$, a soma de bases e a saturação por bases, conquanto diminuiu a acidez hidrolítica e de troca. Em alguns solos com niveis de $\mathrm{K}^{+}$e/ou de $\mathrm{Mg}^{2+}$ trocáveis próximos ao limite de insuficiência 
a calagem com materiais ricos em Ca poderá induzir a deficiência destes nutrientes. Não obtiveram evidências que justifiquem a generalização da prática da calagem nos solos ácidos canavieiros das províncias centrais de Cuba.

MARINHO \& ALBUQUERQUE (1981) citam que, para a cana-deaçúcar, em condições de baixa CTC, teores de $\mathrm{Ca}^{2+}+\mathrm{Mg}^{2+}$ em torno de $1,9 \mathrm{meq} / 100 \mathrm{ml}$ de solo são considerados suficientes. Lembram os autores que, do ponto de vista da absorção de $\mathrm{Ca}^{2+}$ e $\mathrm{Mg}^{2+}$, a cultura da cana-de-açúcar é considerada como pouco exigente em relação às outras culturas.

MORELLI et al. (1986) notaram, em solos arenosos, que a aplicação de calcário em área total, incorporado ou não, proporcionou sensíveis aumentos no V\% apenas na superficie do solo. Na dose de 2,0 t/ha, não incorporado, observaram que a saturação de bases passou de $21 \%$ para $32 \%$ na superficie do solo após 18 meses da instalação do ensaio. Na segunda camada, o calcário praticamente não alterou as características químicas do solo. Quando a mesma dose de calcário foi aplicada no sulco de plantio, os autores verificaram que a saturação de bases atingiu valores em torno de 60 $\%$ na superficie, tendo reflexo também na subsuperficie.

BENEDINI \& KORNDORFER (1992) citam que a soma dos teores de $\mathrm{Ca}^{2+}+\mathrm{Mg}^{2+}$ e $\circ \mathrm{Ca}^{2+}$ isoladamente foram, entre as variáveis estudadas, aqueles que apresentaram os mais altos graus de correlação com a produção relativa $\left(r=0,73^{*}\right)$, constituindo-se nos melhores parâmetros para recomendação de calcário para cana-deaçúcar. A saturação em bases (V\%) e a saturação em Al $(r=0,22$ e $r=0,12$, respectivamente), segundo os autores, não são bons critérios para estimar a necessidade 
de calcário para a cana-de-açúcar, principalmente quando a CTC do solo é elevada. Recomendam os autores que estudos que visem correlacionar a saturação de bases (V\%) com a necessidade de calcário para a cultura de cana-de-açúcar devam ser cuidadosamente analisados, procurando sempre que possivel isolar o efeito do $\mathrm{Ca}^{2+} \mathrm{e}$ do $\mathrm{Mg}^{2+}$ ao interpretar os resultados.

Com a aplicação de calcário, além da correção da acidez, os teores de

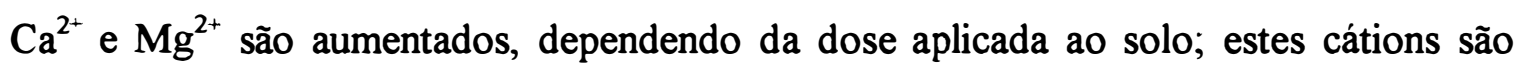
necessários como nutrientes para a maioria das culturas e mesmo doses baixas, como 1,0 t/ha de calcário aumenta significativamente os teores de $\mathrm{Ca}^{2+}$ e $\mathrm{Mg}^{2+}$ no solo, como detectou GONZÁLEZ \& RICO (1976).

A calagem profunda e bem feita, por demais dispendiosa, e o uso de variedades resistentes à acidez do subsolo, são alternativas propostas para a redução da toxidez de Al nas camadas subsuperficiais por ALVES \& LOPES (1983).

MIKKELSEN et al. (1962) já comentavam que a incorporação profunda do calcário em solos de baixa fertilidade no Estado de São Paulo vinha trazendo aumento de produtividade para algumas culturas. Porém, adicionavam os autores, muito embora esta observação pudesse ser um fato concreto, a aplicação do calcário em maiores profundidades (abaixo de $40 \mathrm{~cm}$ ) seria muito dificil, agronômicamente e econômicamente inexequível.

STOLF et al. (1988), estudando o problema de incorporação mecânica dos corretivos, propuseram uma metodologia que promove regiões de incorporação 
profunda (zona de sulco) alternadas com regiões de incorporação semelhantes às obtidas na incorporação convencional com grade (zona da entrelinha).

Devido às dificuldades de incorporação do calcário além da camada arável, não se consegue, em curto prazo, corrigir os problemas de baixo $\mathrm{pH}$, baixa CTC, proporções inadequadas de bases e alta saturação de $\mathrm{Al}$ nas camadas mais profundas ou subsuperficiais. Assim sendo, o sistema radicular das plantas fica limitado à zona corrigida pelo calcário, não se desenvolvendo em profundidade e diminuindo a capacidade de resistência destas plantas às estiagens prolongadas, conforme salientam FERREIRA et al. (1987). Segundo estes autores, a prática da utilização do gesso em mistura com o calcário poderia "corrigir" em parte as camadas subsuperficiais do solo, devido à maior mobilidade do mesmo no perfil do solo, chegando até as zonas onde o calcário praticamente não tem efeito.

RAIJ (1988) relata que a acidez de subsuperficie é devida à deficiência de bases disponiveis, principalmente $\mathrm{Ca}$ e ao excesso de $\mathrm{Al}$ tóxico. Por sua vez, os íons amônio e nitrato, ao serem absorvidos pelas plantas, afetam a acidez, pois as raizes das plantas liberam $\mathrm{H}^{+}$, acidificando o solo.

VARGAS (1989) verificou que o aumento nas profundidades de incorporação de calcário influencia positivamente na produção de cana-de-açúcar, aumentando o peso das raízes das plantas e promovendo melhoria das qualidades tecnólogicas, não interferindo nas características fisicas do solo; por sua vez, as características químicas do solo, ao longo do tempo, são melhoradas. Observou também, efeito residual do calcário até três anos após a aplicação. 
Trabalhando com diferentes fontes de cálcio, DAL BÓ et al. (1986) não detectaram movimentação apreciável de $\mathrm{Ca}^{2+}$ a $20-25 \mathrm{~cm}$ de profundidade quando a fonte foi apenas $\mathrm{CaCO}_{3} ;$ o $\mathrm{CaSO}_{4}$ provocou movimentação intermediária $(45-60 \mathrm{~cm}$ de profundidade) e o $\mathrm{CaCl}_{2}$ provocou intensa movimentação ( $150 \mathrm{~cm}$ de profundidade).

BRAUNER \& GARCEZ (1981), em três solos do Rio Grande do Sul, verificaram que os níveis de calagens e a natureza dos solos influenciaram as perdas de $\mathrm{K}^{+}$ e $\mathrm{Ca}^{2+}$ por lixiviação, o mesmo não ocorrendo com o $\mathrm{Mg}^{2+}$, enquanto que QUAGGIO et al. (1982) observaram que a lixiviação de bases provocada pela calagem é um processo lento, gradual, ocorrendo lixiviação de $\mathrm{Ca}^{2+}$ e de $\mathrm{Mg}^{2+}$ até a camada de 40-60 $\mathrm{cm}$ já 6 meses após a calagem, com reflexo pequeno no $\mathrm{pH}$.

BATAGLIA et al. (1985) observaram que a calagem promoveu elevação

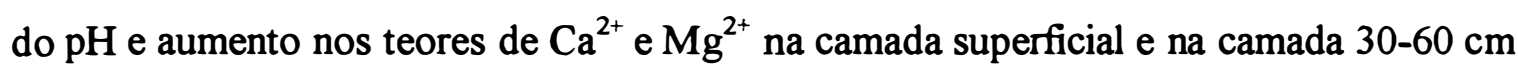
de profundidade; após 36 meses da aplicação do calcário, na camada superficial o efeito havia praticamente desaparecido na dose mais baixa.

SUZUKI (1989) observou em latossolo húmico distrófico que até $50 \mathrm{~cm}$

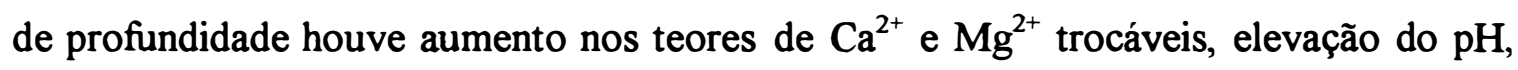
diminuição do Al trocável, em função das doses e da incorporação profunda do calcário.

\subsection{Efeitos do calcário na cultura da cana-de-açúcar}

A resposta das culturas à calagem depende de uma série de fatores ligados à planta, ao solo e ao corretivo empregado; QUAGGIO (1986) cita que a 
conjugação destes fatores, corretamente considerados, leva à obtenção da máxima eficiência desta prática agrícola.

A magnitude da influência das relações entre $\mathrm{Ca}^{2+}, \mathrm{Mg}^{2+}$ e $\mathrm{K}^{+}$na produtividade das culturas varia em função da cultura e a relação entre estes nutrientes assume importância em condições em que há uma elevação dos teores dos nutrientes desproporcionalmente entre si.

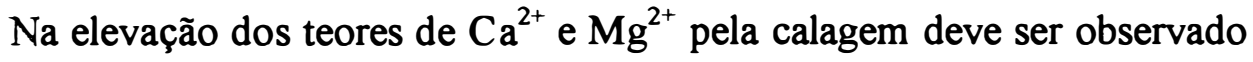
a relação $\mathrm{Ca} / \mathrm{Mg} / \mathrm{K}$ ou a porcentagem de saturação de $\mathrm{Ca}^{2+}$ na $\mathrm{CTC}$ efetiva do solo (Ca $\% \mathrm{~T})$.

Segundo RAIJ (1994), somente nas condições de teores baixos a muito baixos de um dos nutrientes, a limitação por deficiência passa a ser mais importante que a relação que estes nutrientes expressam entre si.

BULL (1986) cita que, nas culturas produtoras de açúcar e amido, as exigências de $\mathrm{Mg}^{2+}$ parecem ser a metade das de $\mathrm{Ca}^{2+}$.

Estudos desenvolvidos por PEIXOTO (1980), em casa de vegetação, revelaram que a relação $\mathrm{Ca} / \mathrm{Mg}>5,5$ poderia induzir uma deficiência de $\mathrm{Mg}^{2+}$, limitando a produção da cana-de-açúcar. Em condições de relações situadas entre 1,0 e 3,0, o autor não detectou diferenças significativas entre as produções finais. $\mathrm{O}$ autor detectou ainda que o aumento do teor de $\mathrm{Mg}^{2+}$ no solo causou decréscimo na produção, determinando que cerca de 1,0 meq de $\mathrm{Mg}^{2+} / 100 \mathrm{~g}$ de solo foram adequados para o máximo de produção. 
Embora a cana-de-açúcar seja muito tolerante às condições de acidez e alcalinidade, desenvolvendo-se bem, segundo SCHMEHEL \& HUMBERT (1964), em solos com pH entre 4,0 e 8,3, inúmeros experimentos demonstram elevação da produtividade com a prática da calagem.

RAIJ (1986) comenta que a calagem tem um efeito residual prolongado, que perdura por vários anos, sendo o retorno deste investimento, por consequencia, cumulativo.

MARINHO \& ALBUQUERQUE (1981) apresentaram resultados de mais de vinte experimentos de campo realizados em Alagoas, com aplicação de calcário dolomítico em cana-de-açúcar, sendo que, na maior parte deles foram obtidos acréscimos de cana/ha superiores a 5 toneladas no primeiro corte; observaram, ainda, resposta à aplicação de calcário em área total incorporado ao solo, no sulco de plantio e aplicado em cobertura. Porém, os autores relembram que no mundo inteiro, nas áreas canavieiras, a prática da calagem é de dificil previsão quanto às reais necessidades e quantidades, sendo que a maior dificuldade, segundo os autores, referem-se aos métodos de avaliação das necessidades de calagem, se devem ser baseadas nas deficiências de $\mathrm{Ca}$ e/ou de $\mathrm{Mg}$, ou se na necessidade de correção dos efeitos tóxicos de $\mathrm{Al}$, ou, ainda, na elevação da porcentagem de saturação de bases ( $\mathrm{V} \%)$ a um valor adequado.

MALAVOLTA (1986) relata que as maiores respostas da cana-de-açúcar à costumam ser obtidas quando o solo possui acima de 0,4 meq de $\mathrm{Al}^{3+} / 100 \mathrm{ml}$ ou quando tem menos de 1 meq de $\mathrm{Ca}^{2+} / 100 \mathrm{ml}$. Considera que a calagem deve ser feita 
sempre que o índice de saturação de bases seja menor que $60 \%$ em solos de textura média e argilosa e menor que $70 \%$ em solos arenosos.

$\mathrm{O}$ peso dos colmos está altamente correlacionado com os teores de $\mathrm{Mg}^{2+}$ no solo, segundo SANCHEZ \& CLEMENTS (1974), sendo que CORDEIRO (1978) afirma que os incrementos de produção proporcionados pela calagem devem ser atribuidos mais a uma ação nutritiva do $\mathrm{Mg}^{2+}$ do que mesmo a uma ação do $\mathrm{Ca}^{2+}$.

De acordo com ORLANDO FILHO \& ZAMBELLO JÚNIOR (1980), no Havaí, o nível crítico para $\mathrm{Ca}^{2+}$ é de $1,15 \mathrm{meq} / 100 \mathrm{~g}$ de solo e para $\mathrm{Mg}^{2+}$ é de 0,25 meq/100 g de solo; na África do Sul, os níveis críticos são de 0,75 e 0,21 meq/100 g de

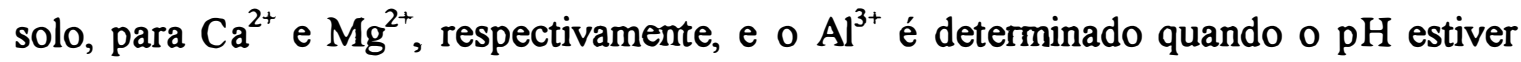
abaixo de 5,5. Na Austrália, esses níveis são de 0,85 e 0,42 meq/100g de solo, para $\mathrm{Ca}^{2+}$ e $\mathrm{Mg}^{2+}$, respectivamente.

No Brasil, os níveis críticos para o Estado de São Paulo foram encontrados por ESPIRONELO \& OLIVEIRA (1972), como sendo de 0,50 meq/100 g de solo para o $\mathrm{Al}^{3+}$; por CORDEIRO (1978), 0,28 e 0,25 meq/100 g de solo, para $\mathrm{Ca}^{2+}$ e $\mathrm{Mg}^{2+}$, respectivamente; por ZAMBELLO JÚNIOR \& ORLANDO FILHO (1984), 1,0 meq/100 $\mathrm{g}$ de solo de $\mathrm{Al}^{3+}, 0,75$ e $0,67 \mathrm{meq} / 100 \mathrm{~g}$ de solo para $\mathrm{Ca}^{2+}$ e $\mathrm{Mg}^{2+}$, respectivamente.

BENEDINI (1988) comenta que a cana-de-açúcar é citada na literatura como tolerante à acidez do solo e aos altos teores de $\mathrm{Al}^{3+}$ trocável. Este autor, com base em diversos ensaios de campo, nos Estados de São Paulo e do Paraná, propôs um novo conceito para a recomendação de calcário, baseado nos teores de $\mathrm{Ca}^{2+}+\mathrm{Mg}^{2+}$ do solo, e 
preconiza este método em substituição ao método que eleva o índice de saturação em bases (V\%). Define, como nível crítico de $\mathrm{Ca}^{2+}+\mathrm{Mg}^{2+}$ no solo, $1,4 \mathrm{meq} / 100 \mathrm{~cm}^{3}$ e de

$\mathrm{Ca}^{2+}$ isoladamente, $1,0 \mathrm{meq} / 100 \mathrm{~cm}^{3}$ de solo. De acordo com este autor, a relação Ca/Mg de 2,5 : 1,0 assegura $97 \%$ da produção máxima possível, sendo necessário, em termos econômicos, que a lavoura produza no mínimo 5 toneladas a mais de cana para cada tonelada de calcário aplicada ao solo, a firm de que se cubram os investimentos com a prática da calagem.

Mais recentemente, MAZZA (1993) determinou que o calcário promoveu aumentos significativos nos teores de $\mathrm{Ca}^{2+}, \mathrm{Mg}^{2+}$, valor $\mathrm{S}, \mathrm{V} \% \mathrm{e} \mathrm{pH}$, principalmente na camada superficial do solo, detectando também que os efeitos benéficos nos atributos químicos do solo prolongaram-se até o $2^{\circ}$ corte da cultura.

\subsection{Efeitos do gesso agrícola nas propriedades químicas do solo e na cultura da cana-de-açúcar}

O gesso agrícola, também chamado de fosfogesso, é originário da reação do ácido sulfúnico sobre rocha fosfatada e concentrada, objetivando a separação e concentração do ácido fosfórico; este subproduto é produzido na razão de 5 toneladas de gesso por 1 tonelada de $\mathrm{P}_{2} \mathrm{O}_{5}$ de ácido fosfórico (VITTI, $1988 \mathrm{~b}$ ).

A prática da gessagem vem tendo grande repercussão nos ambientes dos técnicos e dos produtores; sendo seu efeito muito complexo e sua ação favorável sobre o ambiente radicular devido à um conjunto de fatores dificeis de isolar, mesmo tendo 
passado mais de uma década desde as primeiras observações, ainda existem muito mais dúvidas do que certezas em relação ao uso do gesso agrícola.

Os primeiros trabalhos envolvendo a movimentação do gesso agrícola em profundidade foram realizados na África do Sul por REEVE \& SUMNER (1972); estes autores compararam a eficiência do $\mathrm{Ca}(\mathrm{OH})_{2}$ com a do $\mathrm{CaSO}_{4} \cdot 2 \mathrm{H}_{2} \mathrm{O}$ na redução da saturação do $\mathrm{Al}^{3+}$ do subsolo, demonstando também que as aplicações elevadas de gesso (acima de 3,0 meq/100 g solo) causaram perdas significativas do $\mathrm{Mg}^{2+}$ nativo do solo.

Trabalhando no Brasil, LOPES \& ALVES (1981) compararam cinco materiais, a saber : - superfosfato simples, óxido de cálcio, calcário calcítico comercial e micropulverizado, além do gesso agrícola, verificando que os tratamentos mais eficientes na redução do $\mathrm{Al}^{3+}$ do subsolo foram o superfosfato simples e o gesso.

A aplicação isolada de gesso agrícola, em ensaios conduzidos tanto em colunas como no campo, pela EMBRAPA (1982), promoveu uma lixiviação de $\mathrm{K}^{+}$, mais intensa do que quando foi aplicado a mistura de calcário com gesso, fato este atribuido ao aumento da CTC do solo.

KIEHL \& FRANCO (1984), em laboratório, estudando de que forma e em que tempo o gesso modifica o $\mathrm{pH}$ e os teores de $\mathrm{Al}^{3+}$ trocável, $\mathrm{Ca}^{2+}$ trocável e $\mathrm{S}_{-} \mathrm{SO}_{4}{ }^{2-}$ solúvel de quatro solos de variadas texturas, observaram, no início, leve efeito acidificante do gesso, e decréscimos de até $41 \%$ no teor de $\mathrm{Al}^{3+}$ trocável, com a incubação. $\mathrm{O}$ teor de $\mathrm{Ca}^{2+}$ trocável em todos os solos aumentou imediatamente após a adição de gesso, tendo os aumentos sido, em média, quantitativamente iguais ao conteúdo de $\mathrm{Ca}^{2+}$ do material aplicado. 
PAVAN et al. (1984), trabalhando em latossolo roxo distrófico, com acidez de subsuperficie, determinaram que a aplicação de gesso agrícola, em quantidade equivalente a 1,5 vezes a calagem, reduziu os níveis de $\mathrm{Al}^{3+}$ e de $\mathrm{Mg}^{2+}$ trocáveis por todos os $100 \mathrm{~cm}$ de profundidade do perfil do solo, aumentando o $\mathrm{Ca}^{2+}$ trocável, não interferindo nos valores de $\mathrm{pH}$ e de CTC.

VITTI (1987) comenta que a associação de gesso agrícola com calcário dolomítico pode ser uma prática mais apropriada para o tratamento de solos com concentração de $\mathrm{Al}^{3+}$ tóxicos em subsuperficie, dispensando, adicionalmente, pelo efeito do gesso, a incorporação profunda da mistura.

O uso do gesso agrícola na cultura canavieira não deixa de ser uma boa alternativa de manejo para aumentar a produtividade de solos pouco férteis, como demonstra trabalho pioneiro nessa cultura realizado por MORELLI et al. (1986); segundo estes autores, a associação de calcário e gesso agrícola proporcionou um aumento na saturação por bases na superficie e um decréscimo na saturação de $\mathrm{Al}^{3+}$ em profundidade.

YAMADA (1988) encontrou, por sua vez, resultados positivos da aplicação do gesso agrícola em latossolos, porém não observou nenhum efeito em podzólicos.

LORENZETTI et al. (1992), trabalhando com soqueiras de cana-deaçúcar (variedade NA-5679), usaram calcário (2 t/ha), gesso agrícola (2 e 4 t/ha) e fósforo ( $35 \mathrm{~kg} \mathrm{P}_{2} \mathrm{O}_{5} / \mathrm{ha}$ ), em solos de textura média a arenosa e de baixa fertilidade. Os produtos foram aplicados a lanço, logo após a brotação da soqueira e incorporados 
ligeiramente com o cultivador. Doze meses após, detectou-se que a ação do $\mathrm{Ca}^{2+}{\mathrm{e} \mathrm{Mg}^{2+}}^{2+}$ ficou restrita à camada superficial; a ação do gesso propiciou um razoável aumento de bases em profundidade, apesar de ter removido parcialmente $0 \mathrm{Mg}^{2+}$. A associação do calcário com o gesso possibilitou uma melhor distribuição das bases em profundidade mantendo ainda $0 \mathrm{Mg}^{2+}$ em níveis normais na superficie. A produtividade da cana nas parcelas que receberam gesso foi superior quando comparado com as parcelas que receberam somente calcário. A associação do gesso com calcário sempre produziu mais do que as parcelas que receberam somente calcário. $\mathrm{O}$ aumento da produção de cana na faixa dos 10 a $15 \%$, obtido principalmente com gesso, mostrou, segundo os autores, ser razoável, pois além do rápido aumento na produtividade alcançado, permitiu maior longevidade da soqueira.

MAZZA (1993), trabalhando em solos latossólicos e em podzólicos, encontrou que o gesso agrícola acelerou o fornecimento de $\mathrm{Ca}^{2+}$, além de promover sua incorporação, juntamente com $\circ \mathrm{Mg}^{2+}$ e $\circ \mathrm{S} \mathrm{SO}_{4}{ }^{2-}$, a maiores profundidades. A utilização de doses elevadas de gesso agrícola, segundo este autor, não provocou problemas com outros cátions básicos ao longo do perfil do solo. O produto porém, apesar de trazer beneficios nos atributos químicos do podzólico, propiciou efeitos depreciativos na produtividade agrícola naquele solo. Quando utilizado nos latossolos o gesso elevou a produtividade da cultura no $1^{\circ}$ e $2^{\circ}$ cortes, sendo, entretanto, inferior ao calcário quanto à eficiência em prolongar seus efeitos a longo prazo.

Verifica-se, portanto, que a aplicação do gesso agrícola ainda levanta dúvidas sobre possíveis efeitos colaterais prejudiciais, especialmente no que concerne à 
movimentação excessiva de bases através do perfil do solo; na realidade, ainda não existem dados experimentais conclusivos que sirvam de parâmetros para definição das quantidades de gesso a aplicar, isoladamente ou em misturas com produtos corretivos da acidez dos solos, com a finalidade de melhorar o ambiente radicular dos subsolos cultivados pelas diversas culturas de interesse agrícola. 


\section{MATERIAL E MÉTODOS}

\subsection{Localização e descrição da área experimental}

A região de Paraguaçú Paulista/SP é caracterizada por apresentar verão quente e úmido, com médias de temperatura em torno de $25^{\circ} \mathrm{C}$ e um inverno seco. $\mathrm{O}$ índice pluviométrico está em torno de $1500 \mathrm{~mm}$ anuais e a estação seca ocorre entre os meses de maio a setembro, sendo julho o mes em que atinge a maior intensidade; o regime de umidade do solo é classificado como ústico e o de temperatura, como isotérmico.

Os latossolos de textura média são os predominantes na região, representando aproximadamente $70 \%$ da área, os PVs, $25 \%$ e os solos rasos, $5 \%$.

Nestas condições, as características climáticas da região, em termos de precipitação, temperatura, radiação solar, etc., são propícias à cultura da cana-de-açúcar; entretanto, a produtividade normalmente não é muito elevada, ficando em torno das 65 t/ha como média ponderada de 4,5 cortes.

O clima da região, segundo a classificação de Koeppen, é do tipo CWa (isotérmico, com verão quente chuvoso e inverno seco), sendo que as precipitações 
pluviais (em mm) durante o transcorrer do ensaio, demaio de 1991 a agosto de 1994, está indicada na Tabela 1.

Tabela 1. Precipitações pluviométricas (em mm) ocorridas durante o desenvolvimento do experimento.

\begin{tabular}{|c|cccc|}
\hline \multirow{2}{*}{ MÊS } & \multicolumn{4}{|c|}{ ANO } \\
\cline { 2 - 5 } & $\mathbf{1 9 9 1}$ & $\mathbf{1 9 9 2}$ & $\mathbf{1 9 9 3}$ & $\mathbf{1 9 9 4}$ \\
\hline JANEIRO & --- & 40 & 224 & 202 \\
FEVEREIRO & --- & 77 & 487 & 106 \\
MARÇO & --- & 194 & 111 & 100 \\
ABRIL & --- & 192 & 49 & 130 \\
MAIO & 35 & 174 & 94 & 69 \\
JUNHO & 81 & 28 & 48 & 55 \\
JULHO & 12 & 13 & 19 & 14 \\
AGÔSTO & zero & 46 & 37 & zero \\
SETEMBRO & 62 & 241 & 94 & --- \\
OUTUBRO & 45 & 117 & 53 & --- \\
NOVEMBRO & 80 & 126 & 71 & --- \\
\hline DEZEMBRO & 152 & 16 & 254 & 676 \\
\hline TOTAIS & 467 & 1264 & 1541 & \\
\hline
\end{tabular}

Portanto, nas condições do ensaio, na cana planta ocorreram $1231 \mathrm{~mm}$, na primeira soca, $1569 \mathrm{~mm}$ e na segunda soca, $1134 \mathrm{~mm}$.

Note-se que o ano de 1991 foi extremamente anormal, ocorrendo sêca pronunciada durante os 6 primeiros meses após a instalação do ensaio.

O experimento foi instalado em solo classificado como areia quartzosa, álica $(\mathbf{m}=64 \%)$, com baixa CTC, contendo $85 \%$ de areia, $11 \%$ de argila e $4 \%$ de silte, 
situado na fazenda São Sebastião, pertencente à Destilaria Cocal, no município de Paraguaçú Paulista/SP, latitude $22^{\circ} 30^{\prime} \mathrm{S}$, longitude $50^{\circ} 22^{\prime}$ W e altitude de 625 metros.

$\mathrm{Na}$ área experimental já havia sido implantada anteriormente, por um ciclo, a cultura da cana-de-açúcar, que foi reformada após o $3^{\circ}$ corte devido à baixa produtividade conseguida (em torno de $50 \mathrm{t} / \mathrm{ha}$ ). As principais características químicas do solo acham-se apresentadas na Tabela 2 , onde se pode destacar os baixíssimos teores de $\mathrm{K}^{+}, \mathrm{Ca}^{2+} \mathrm{e} \mathrm{Mg}^{2+}$.

Tabela 2. Principais características químicas do solo na área experimental da Destilaria Cocal (Paraguaçú Paulista/SP).

\begin{tabular}{|c|c|c|c|c|c|c|c|c|c|}
\hline PROFUNDIDADE & pH & $\overline{\mathbf{P}}$ & $\overline{\mathbf{K}}$ & $\mathbf{C a}$ & $\mathbf{M g}$ & $\mathbf{S}$ & $\mathbf{T}$ & $\mathbf{V}$ & $\mathbf{m}$ \\
\hline (cm) & $\mathrm{CaCl}_{2}$ & ppm & & & $q / 10$ & & & $\%$ & $\%$ \\
\hline $0-25$ & 4,0 & 4 & 0,05 & 0,4 & 0,1 & 0,5 & 3,6 & 14 & 64 \\
\hline $25-50$ & 4,0 & 3 & 0,04 & 0,3 & 0,2 & 0,5 & 2,5 & 20 & 61 \\
\hline
\end{tabular}

\subsection{Delineamento experimental e tratamentos}

Os tratamentos obedeceram ao delineamento experimental de blocos casualizados, com 5 repetições, totalizando 50 parcelas.

Cada parcela foi constituida de 7 linhas de cana-de-açúcar de 20,0 metros de comprimento, espaçadas de 1,0 metro, sendo consideradas úteis as 3 linhas centrais; a área total da parcela foi, portanto, de $140 \mathrm{~m}^{2} \mathrm{e}$ a área útil de $60 \mathrm{~m}^{2}$.

As características fisico-químicas dos produtos corretivos da acidez do solo, bem como do gesso e da magnesita e das misturas estudadas estão indicadas na 
Tabela 3, que indica os teores percentuais de $\mathrm{CaO}, \mathrm{MgO}, \mathrm{PN}$ (poder de neutralização) e de PRNT (poder relativo de neutralização total).

O gesso foi considerado apenas como condicionador do ambiente radicular do subsolo.

A magnesita, nome comercial do subproduto proveniente da calcinação controlada do minério magnesiano $\mathrm{MgCO}_{3}$, em uso pela indústria de refratários, vem sendo destinada recentemente em estudos para sua utilização agrícola.

Tabela 3. Teores percentuais de $\mathrm{CaO}, \mathrm{MgO}, \mathrm{PN}$ e $\mathrm{PRNT}$ dos produtos corretivos e misturas utilizadas.

\begin{tabular}{|l|cccc|}
\hline \multicolumn{1}{|c|}{ PRODUTOS/MISTURAS } & CaO & MgO & PN & PRNT \\
\cline { 2 - 5 } & \multicolumn{4}{|c}{$\%$} \\
\hline Calcário calć́tico & 49,0 & 4,0 & 94 & 83 \\
Calcário magnesiano & 39,0 & 12,0 & 91 & 76 \\
Calcário dolomítico 1 (70\%) + gesso (30\%) & 36,0 & 23,0 & 98 & 92 \\
Calcário dolomítico 2 & 40,0 & 15,0 & 100 & 95 \\
Magnesita & 0,7 & 91,5 & 206 & 204 \\
Magnesita (25\%) + calc.calcítico (75\%) & 37,2 & 23,5 & 122 & 113 \\
Magnesita (15\%) + calc.calcítico (85\%) & 41,9 & 15,7 & 111 & 101 \\
Magnesita (15\%) + gesso (85\%) & 22,0 & 12,3 & 70 & 31 \\
Gesso & 26,0 & -- & -- & - \\
\hline
\end{tabular}

A magnesita apresenta as seguintes características típicas :

Dados fisicos :-

$\%$ máxima retida em peneira 65 mesh $=25 \%$;

$\%$ máxima de umidade $=1,0 \%$. 
Análise química :

Perda ao fogo : 4,5\%; $\mathrm{SiO}_{2}: 0,9 \% ; \mathrm{Al}_{2} \mathrm{O}_{3}: 0,6 \% ; \mathrm{Fe}_{2} \mathrm{O}_{3}: 1,8 \% ; \mathrm{CaO}$ : 0,7\%; $\mathrm{MgO}: 91,5 \% ; \mathrm{Mg}$ contido : $55,2 \%$.

As doses dos corretivos e misturas utilizadas, com exceção do gesso, foram calculadas para elevar o índice de saturação por bases (V\%) a $70 \%$, na profundidade 0 a $40 \mathrm{~cm}$; para tanto, na fórmula da necessidade de calagem, utilizou-se o fator de calagem $f=2,0$. A dose de gesso foi aplicada com o objetivo de elevar o teor de $\mathrm{Ca}^{2+}$ a $2 \mathrm{meq} / 100 \mathrm{~cm}^{3}$, na profundidade de 20 a $40 \mathrm{~cm}$, levando-se em consideração o teor de $\mathrm{Ca}^{2+}$ nesta camada.

Desta forma, foram aplicadas, de cada produto/mistura, as quantidades indicadas na Tabela 4, que se constituiram nos tratamentos estudados.

Tabela4. Doses dos produtos/misturas utilizados como tratamentos (em t/ha).

TRATAMENTO

T 1. Calcário calcítico

T 2. Calcário magnesiano

T 3. Calcário dolomítico $1(70 \%)+$ gesso (30\%)

T 4. Calcário dolomítico 2

T 5. Magnesita

T 6. Magnesita (25\%) + calcário calcítico (75\%)

T 7. Magnesita (15\%) + calcário calcítico (85\%)

T 8. Magnesita (15\%) + gesso (85\%)

T 9. Gesso
DOSE (T/HA)

4,86

5,30

$4,38+3,54$

4,24

1,98

$0,90+2,67$

$0,60+3,38$

$1,98+3,54$

$3,54^{(*)}$

T 10. Testemunha sem calcário

(*) $-1 \mathrm{t} /$ ha gesso $=0,48 \mathrm{meq} \mathrm{Ca}^{2+} / 100 \mathrm{~cm}^{3}$ 


\subsection{Instalação e condução do experimento}

O preparo do solo, após a gradagem pesada para a eliminação da soqueira antiga, consistiu de aração seguida de gradagem leve.

A aplicação dos produtos foi efetuada imediatamente antes do plantio, que foi realizado nos dias 3 e 4 de maio de 1991, tendo sido plantada a variedade de cana-de-açúcar RB72454, uma das mais plantadas na Destilaria Cocal e em todo o oeste do Estado de São Paulo na atualidade, devido a sua boa adaptabilidade aos solos da região, utilizando-se mudas de 12 meses de idade e densidade de plantio de 18 gemas $/ \mathrm{m}$ linear de sulco, gastando-se cerca de $12 \mathrm{t} / \mathrm{ha}$ de mudas.

A aplicação dos produtos e misturas foi manual e a lanço, sendo sua incorporação realizada com arado de aiveca, objetivando-se incorporar os produtos a uma maior profundidade possível (aproximadamente $40 \mathrm{~cm}$ ).

Todos os tratamentos receberam, de acôrdo com a análise de solo, adubação NPK no sulco de plantio, através da fórmula $4-28-20$, na dose de $600 \mathrm{~kg} / \mathrm{ha}$, o que forneceu $24-168-120 \mathrm{~kg} / \mathrm{ha}$ de $\mathrm{N}-\mathrm{P}_{2} \mathrm{O} s-\mathrm{K}_{2} \mathrm{O}$, respectivamente, conforme recomendação de ZAMBELLO JÚNIOR et al. (1981). Foram adicionados $30 \mathrm{~kg}$ de $\mathrm{N}$ em cobertura, aos 5 meses após o plantio, usando-se o sulfato de amônio, na dose de 150 $\mathrm{kg} / \mathrm{ha}$, visando o fornecimento de $\mathrm{S}$ a todos os tratamentos.

Decorridos 6 meses após o plantio foram realizadas amostragens de solo, com sonda amostradora, nas profundidades $0-25,25-50,50-75$ e $75-100 \mathrm{~cm}$, nas linhas e nas entrelinhas da cana-de-açúcar, e amostragens de folhas, coletando-se a folha 
+3. Novas amostragens de solo, seguindo a mesma metodologia, foram realizadas logo após as colheitas da cana planta e das duas primeiras socas.

O primeiro corte se deu em setembro de 1992 (16 meses após o plantio), o segundo corte em setembro de 1993 e o terceiro corte em setembro de 1994; em todas as ocasiões, a cana foi queimada e colhida manualmente.

A área útil das parcelas foi colhida com garra hidrálica acoplada a carregadeira de cana, e as pesagens foram realizadas com dinamômetro Chatillon, com capacidade de $500 \mathrm{~kg}$.

As soqueiras receberam os tratos culturais normais, sendo a adubação realizada de acôrdo com a análise inicial dos solos; assim, cada soca foi adubada com 300 $\mathrm{kg}$ ha da fórmula 20 - 00 - 30, como preconiza ZAMBELLO JÚNIOR et al. (1981); aos 4 meses após este cultivo, foram novamente amostradas folhas +3 , para serem submetidas às novas análises foliares.

\subsection{Parâmetros analisados}

Os parâmetros que foram avaliados para se identificar os efeitos dos tratamentos aplicados ao solo foram os seguintes :

a) no solo : foram retiradas, em tôdas as ápocas de amostragem, 6 subamostras de cada local (linha e entrelinha), em cada parcela, nas profundidades $0-25,25$ - 50, $50-75$ e $75-100 \mathrm{~cm}$, sendo efetuadas as determinações de $\mathrm{pH}$ em $\mathrm{CaCl}_{2}, \mathrm{P}$ (resina), $\mathrm{K}^{+}, \mathrm{Ca}^{2+}, \mathrm{Mg}^{2+}, \mathrm{Al}^{3+}$ em KCl 1,0 N, segundo metodologia descrita por RAIJ \& 
QUAGGIO (1983); $\mathrm{S}^{-\mathrm{SO}_{4}}{ }^{2-}$ em $\mathrm{NH}_{4} \mathrm{OAc} 0,5 \mathrm{~N}$, segundo VITTI (1988a); foram calculados os valores da capacidade de troca catiônica (CTC), de saturação por bases (V\%) e de saturação em $\mathrm{Al}^{3+}$ (m\%).

b) na planta : as amostras de folhas foram constituidas de 15 folhas +3 por parcela, excluindo-se a nervura central e secando-as em estufa a $70^{\circ} \mathrm{C}$, até peso constante; em seguida, foram trituradas e analisadas, sendo determinados os teores de $\mathrm{N}$, P, K, Ca, Mg, Mn e Al, segundo JøRGENSEN (1977) e os teores de S, segundo VITTI $(1988 a)$

$\mathrm{Na}$ colheita da cana planta e das socas foram determinados : a) o número de colmos úteis para industrialização ("stand"), através da contagem do número de colmos nas 3 linhas centrais de cada parcela; b) a produtividade agricola (t/ha), sendo realizada a pesagem dos colmos de cada parcela através do uso de dinamômetro de precisão com garra hidráulica acoplados a uma carregadeira de cana e, c) a qualidade da matéria prima obtida através da determinação da pol \% cana, fibra \% cana e pureza, de amostras compostas por 10 colmos retirados aleatoriamente de cada parcela, segundo COPERSUCAR (1980).

\subsection{Métodos estatísticos}

Os dados obtidos foram submetidos à análises estatísticas que obedeceram à análise de variância indicada a seguir :- 


\begin{tabular}{|c|c|}
\hline CAUSA DE VARIAÇAO & GRAUS DE LIBERDADE \\
\hline Blocos & 4 \\
\hline Tratamentos & 9 \\
\hline Resíduo & 36 \\
\hline TOTÁ & 49 \\
\hline
\end{tabular}

Para verificar a significância estatística foi considerado o teste $\mathrm{F}$ e para comparação de médias dos tratamentos utilizou-se o teste de Tukey, ao nível de $10 \%$ de probabilidade, como preconiza CAMPOS (1984), especificamente para o caso da canade-açúcar.

Procurou-se também correlacionar alguns resultados das análises de solo e de planta com as produtividades agrícolas obtidas nos 3 cortes, através do coeficiente de correlação simples $\mathbf{r}$, o qual foi testado pelo teste $\mathbf{t}$. 


\section{RESULTADOS E DISCUSSÃO}

Cada parâmetro estudado é apresentado e discutido individualmente, à modida em que foram obtidos, ao longo do tempo, na linha e na entrelinha da cana-deaçúcar e através do perfil de solo amostrado, conforme a metodologia seguida.

\subsection{Efeitos nas características químicas do solo}

\subsection{1. pH}

Aos 6 meses após aplicação dos produtos (ver Tabela 5) notou-se diferença significativa no $\mathrm{pH}$, na camada arável, de todos os tratamentos quando comparados à testemunha e ao tratamento com gesso aplicado isoladamente, nas amostras retiradas na linha; na entrelinha, o mesmo se repetiu, com exceção da mistura de calcário dolomítico e gesso agrícola, que apresentou valores que não foram diferentes estatísticamente do gesso aplicado isoladamente. Menores valores no $\mathrm{pH}$ foram detectados em profundidade, em todos os tratamentos.

Deve ser salientado que estes valores foram obtidos mesmo com a ocorrência de poucas chuvas (235 mm, de maio a outubro de 1991) na área experimental; com a fraca precipitação ocorrida no período, poderia se esperar menor 
reatividade dos corretivos de acidez do solo e do próprio gesso agrícola. Em subsuperficie (na camada $0-25 \mathrm{~cm}$ ), as misturas de magnesita (a 25\%) com calcário calcítico e magnesita com gesso agrícola, bem como o calcário dolomítico e a magnesita aplicados isoladamente, apresentaram valores de $\mathrm{pH}$ significativamente diferentes do gesso agricola e da testemunha, alcançando os maiores valores de $\mathrm{pH}$; tais valores, porém, ainda são indicativos de acidez do solo nestas camadas.

Tabela 5. Resultados da análise de solo para $\mathrm{pH}$ em $\mathrm{CaCl}_{2}$ aos 6 meses após a aplicação dos produtos na linha e na entrelinha, ao longo do perfil do solo; dados médios de 5 repetições.

\begin{tabular}{|c|c|c|c|c|c|c|c|c|}
\hline \multirow{2}{*}{$\begin{array}{r}\text { TRATA } \\
\text { MENTO }\end{array}$} & \multicolumn{2}{|c|}{$0-25 \mathrm{~cm}$} & \multicolumn{2}{|c|}{$25-50 \mathrm{~cm}$} & \multicolumn{2}{|c|}{$50-75 \mathrm{~cm}$} & \multicolumn{2}{|c|}{$\begin{array}{r}75-\begin{array}{c}100 \\
\mathrm{~cm}\end{array} \\
\end{array}$} \\
\hline & $\mathbf{L}$ & $\mathbf{E L}$ & $\overline{\mathbf{L}}$ & $\mathbf{E L}$ & $\mathbf{L}$ & $\overline{\mathbf{E L}}$ & $\overline{\mathbf{L}}$ & $\mathbf{E L}$ \\
\hline T1 & $4,5 a b$ & $4,7 a b c$ & $3,5 b c$ & $3,5 b$ & $3,5 b$ & 3,7 & $3,5 c$ & 3,8 \\
\hline T 2 & $4,5 a b$ & 4,9 & $3,5 b c$ & $3,5 b$ & $3,5 b$ & 3,7 & $3,5 c$ & 3,7 \\
\hline T 3 & $4,4 a b$ & $4,2 b c d$ & $3,5 b c$ & $3,4 b c$ & $3,5 b$ & 3,8 & $3,5 c$ & 3,8 \\
\hline T 4 & $4,6 a b$ & $5,7 a$ & $3,6 b c$ & $3,7 a$ & $3,5 b$ & 3,8 & $3,5 c$ & 3,8 \\
\hline T 5 & $4,7 a b$ & $5,7 a$ & $4,1 a$ & $3,7 a$ & $3,5 b$ & ,7 & $3,5 c$ & 3,8 \\
\hline T 6 & $5,0 a$ & $5,4 c$ & $4,0 a$ & $3,7 a$ & $3,6 a$ & 3,8 & $3,6 b$ & 3,8 \\
\hline T 7 & $4,2 b$ & $4,9 a b$ & $3,5 b c$ & $3,5 b$ & $3,4 c$ & 3,7 & $3,5 c$ & 3,8 \\
\hline T 8 & $4,5 a b$ & $5,7 a$ & $3,7 b$ & $3,8 a$ & $3,5 b$ & 3,7 & $3,7 a$ & 3,7 \\
\hline Т 9 & $3,4 c$ & 3,5 & $3,4 b c$ & $3,4 b c$ & $3,5 b$ & 3 & $3,5 c$ & 3,8 \\
\hline T 10 & $3,3 c$ & & $3,3 c$ & & $3,5 b$ & 3,7 & $3,5 c$ & 3,7 \\
\hline $\mathbf{F}$ & $7,50^{* *}$ & $7,62^{* *}$ & $5,40^{* *}$ & $7,74^{* *}$ & $2,01^{+}$ & 0,93 & $2,61^{*}$ & 0,90 \\
\hline dms & 0,8 & 1,3 & 0,4 & 0,2 & 0,1 & 0,2 & 0,1 & 0,1 \\
\hline CV(\%) & 10,0 & 14,8 & 6,6 & 3,9 & 2,3 & 2,9 & 2,1 & 2,3 \\
\hline
\end{tabular}

LEGENDA:

$\mathrm{T} 1=$ calc.calcítico

T 6 = magnesita $(25 \%)+$ calc.calcítico $(75 \%)$

T 2 = calc.magnesiano

$\mathrm{T} 7=$ magnesita $(15 \%)+$ calc.calcítico $(85 \%)$

T 3 = calc.dolomítico $1(70 \%)+$ gesso

T 4 = calc. dolomítico 2

T $8=$ magnesita $(15 \%)+$ gesso $(85 \%)$

T $5=$ magnesita

$\mathrm{T} 9=$ gesso

$\mathrm{T} 10=$ testemunha

Médias seguidas da mesma letra, na vertical, não diferem entre si (Tukey a 10\%). 
Estas mesmas considerações, de um modo geral, são válidas para os dados obtidos na colheita da cana planta e das duas primeiras socas, conforme pode ser observado nas Tabelas 6 a 8 . Nota-se que os maiores valores de $\mathrm{pH}$ foram encontrados nas camadas mais superficiais do solo, tanto na linha quanto na entrelinha da cana-deaçúcar. A mistura da magnesita com gesso agrícola proporcionou obter valores de $\mathrm{pH}$ significativamente diferentes do que o gesso aplicado isoladamente, na camada arável e na linha da cana-de-açúcar, até a colheita da primeira soca, e na entrelinha, em todas as épocas analisadas.

Tabela 6. Resultados da análise de solo para $\mathrm{pH}$ em $\mathrm{CaCl}_{2}$ na colheita da cana planta na linha e na entrelinha, ao longo do perfil do solo; dados médios de 5 repetições.

\begin{tabular}{|c|cc|cc|cc|cc|}
\hline TRATA & \multicolumn{2}{|c|}{$\mathbf{0}-\mathbf{2 5} \mathbf{c m}$} & \multicolumn{2}{c|}{$\mathbf{2 5}-\mathbf{5 0} \mathbf{~ c m}$} & \multicolumn{2}{c|}{$\mathbf{5 0}-\mathbf{7 5} \mathbf{~ c m}$} & \multicolumn{2}{c|}{$\mathbf{7 5}-\mathbf{1 0 0} \mathbf{~ c m}$} \\
\cline { 2 - 9 } MENTO & $\mathbf{L}$ & $\mathbf{E L}$ & $\mathbf{L}$ & $\mathbf{E L}$ & $\mathbf{L}$ & $\mathbf{E L}$ & $\mathbf{L}$ & $\mathbf{E L}$ \\
\hline T 1 & $4,4 a$ & $4,3 b c$ & $3,8 a b c$ & $3,6 a b$ & $3,5 a b$ & $3,5 c$ & 3,5 & 3,5 \\
T 2 & $4,1 a b$ & $4,5 a b$ & $3,7 a b c$ & $3,6 a b$ & $3,5 a b$ & $3,6 b$ & 3,5 & 3,6 \\
T 3 & $4,4 a$ & $4,1 b c$ & $3,8 a b c$ & $3,5 b$ & $3,4 b$ & $3,5 c$ & 3,5 & 3,5 \\
T 4 & $4,4 a$ & $4,7 a b$ & $3,8 a b c$ & $3,6 a b$ & $3,4 b$ & $3,5 c$ & 3,5 & 3,5 \\
T 5 & $4,3 a b$ & $5,2 a$ & $4,2 a$ & $3,7 a$ & $3,6 a$ & $3,6 b$ & 3,5 & 3,5 \\
T 6 & $4,4 a$ & $4,2 b c$ & $4,0 a b$ & $3,5 b$ & $3,6 a$ & $3,6 b$ & 3,5 & 3,6 \\
T 7 & $4,4 a$ & $4,6 a b$ & $3,8 a b c$ & $3,6 a b$ & $3,5 a b$ & $3,6 b$ & 3,5 & 3,6 \\
T 8 & $4,6 a$ & $4,9 a b$ & $4,0 a b$ & $3,7 a$ & $3,6 a$ & $3,7 a$ & 3,5 & 3,6 \\
T 9 & $3,6 b$ & $3,6 c$ & $3,5 c$ & $3,5 b$ & $3,4 b$ & $3,5 c$ & 3,5 & 3,5 \\
T 10 & $3,5 b$ & $3,6 c$ & $3,5 c$ & $3,5 b$ & $3,4 b$ & $3,4 d$ & 3,5 & 3,6 \\
\hline F & $4,66 *$ & $5,89 * *$ & $2,76^{*}$ & $1,91^{+}$ & $1,41^{+}$ & $2,78 *$ & - & 1,29 \\
& $*$ & & & & & & & \\
dms & 0,7 & 0,9 & 0,5 & 0,2 & 0,2 & 0,1 & - & 0,2 \\
CV(\%) & 9,1 & 11,0 & 7,2 & 4,1 & 3,6 & 2,7 & - & 2,3 \\
\hline
\end{tabular}

LEGENDA :

$\mathrm{T} 1$ = calc.calcítico

$\mathrm{T} 2$ = calc.magnesiano

T 3 = calc.dolomítico $1(70 \%)+$ gesso

$\mathrm{T} 4=$ calc. dolomítico 2

T 5 = magnesita
T 6 = magnesita $(25 \%)+$ calc.calcítico $(75 \%)$

$\mathrm{T} 7$ = magnesita $(15 \%)+$ calc.calcítico $(85 \%)$

T 8 = magnesita $(15 \%)+$ gesso $(85 \%)$

$\mathrm{T} 9=$ gesso

$\mathrm{T} 10=$ testemunha

Médias seguidas da mesma letra, na vertical, não diferem entre si (Tukey a 10\%). 
$\mathrm{Na}$ colheita da cana planta, na camada arável, o gesso agrícola aplicado isoladamente só não diferiu significativamente da magnesita, do calcário magnesiano e da testemunha, que foram os tratamentos com menores valores de $\mathrm{pH}$; este fato foi notado principalmente na linha da cana-de-açúcar.

$\mathrm{Na}$ entrelinha, na mesma época e camada citadas, o gesso agrícola apresentou o mesmo valor que o obtido na amostra retirada na linha, porém não diferiu significativamente do calcário calcítico, do calcário magnesiano e das misturas de calcário dolomítico com gesso e da magnesita (a 25\%) com calcário calcítico, além da testemunha.

Tabela 7. Resultados da análise de solo para $\mathrm{pH}$ em $\mathrm{CaCl}_{2}$ na colheita da primeira soca na linha e na entrelinha, ao longo do perfil do solo; dados médios de 5 repetições.

\begin{tabular}{|c|cc|cc|cc|cc|}
\hline TRATA & \multicolumn{2}{|c|}{$\mathbf{0}-\mathbf{2 5} \mathbf{~ c m}$} & \multicolumn{2}{c|}{$\mathbf{2 5}-\mathbf{5 0} \mathbf{~ c m}$} & \multicolumn{2}{c|}{$\mathbf{5 0}-\mathbf{7 5} \mathbf{~ c m}$} & \multicolumn{2}{c|}{$\mathbf{7 5}-\mathbf{1 0 0} \mathbf{~ c m}$} \\
\cline { 2 - 10 } MENTO & $\mathbf{L}$ & $\mathbf{E L}$ & $\mathbf{L}$ & $\mathbf{E L}$ & $\mathbf{L}$ & $\mathbf{E L}$ & $\mathbf{L}$ & $\mathbf{E L}$ \\
\hline T 1 & $4,5 a$ & $4,3 b c$ & $4,2 a$ & $4,0 b c$ & $4,1 b c$ & 4,1 & $3,9 c$ & 4,0 \\
T 2 & $4,3 a b$ & $4,4 b c$ & $4,2 a$ & $4,1 b$ & $4,0 c d$ & 4,0 & $3,9 c$ & 4,0 \\
T 3 & $4,7 a$ & $4,3 b c$ & $4,3 a$ & $4,0 b c$ & $4,0 c d$ & 3,9 & $3,9 c$ & 3,9 \\
T 4 & $4,3 a b$ & $4,3 b c$ & $4,1 a b$ & $4,0 b c$ & $3,9 d e$ & 3,9 & $3,9 c$ & 4,1 \\
T 5 & $4,4 a$ & $4,6 a b$ & $4,1 a b$ & $4,2 a b$ & $4,0 c d$ & 4,0 & $3,9 c$ & 4,0 \\
T 6 & $4,5 a$ & $4,5 b$ & $4,4 a$ & $4,2 a b$ & $4,2 a b$ & 4,0 & $4,0 b$ & 4,0 \\
T 7 & $4,5 a$ & $4,3 b c$ & $4,2 a$ & $4,0 b c$ & $4,0 c d$ & 4,0 & $4,0 b$ & 3,9 \\
T 8 & $4,4 a$ & $5,1 a$ & $4,4 a$ & $4,4 a$ & $4,3 a$ & 4,0 & $4,2 a$ & 4,1 \\
T 9 & $3,9 b c$ & $3,9 c d$ & $3,8 b$ & $3,8 c$ & $3,9 d e$ & 3,8 & $3,9 c$ & 3,9 \\
T 10 & $3,8 c$ & $3,7 d$ & $3,8 b$ & $3,8 c$ & $3,8 e$ & 3,8 & $3,8 d$ & 3,9 \\
\hline F & $5,27^{* *}$ & $5,96 * *$ & $4,56 * *$ & $6,31 * *$ & $4,07 * *$ & 1,56 & $5,76 * *$ & 1,11 \\
dms & 0,5 & 0,6 & 0,4 & 0,3 & 0,2 & 0,4 & 0,1 & 0,3 \\
CV(\%) & 6,1 & 8,0 & 5,2 & 4,2 & 3,7 & 3,6 & 2,3 & 3,9 \\
\hline
\end{tabular}

LEGENDA :

$\mathrm{T} 1$ = calc.calcítico

T $6=$ magnesita $(25 \%)+$ caic.calcítico $(75 \%)$

T 2 = calc.magnesiano

T $7=$ magnesita $(15 \%)+$ calc.calcítico $(85 \%)$

T 3 = calc.dolomítico $1(70 \%)+$ gesso

T $4=$ calc. dolomítico 2

T $8=$ magnesita $(15 \%)+$ gesso $(85 \%)$

$\mathrm{T} 9=$ gesso

T $5=$ magnesita

T $10=$ testemunha

Médias seguidas da mesma letra, na vertical, não diferem entre si (Tukey a 10\%). 
O gesso agricola aplicado isoladamente apresentou os menores valores de $\mathrm{pH}$, não diferindo estatisticamente dos valores obtidos na testemunha, indicando que este produto não interferiu no $\mathrm{pH}$ do solo, em todas as camadas analisadas e durante $\mathrm{o}$ decorrer do experimento.

Tabela 8. Resultados da análise de solo para $\mathrm{pH} \mathrm{em} \mathrm{CaCl}_{2}$ na colheita da segunda soca na linha e na entrelinha, ao longo do perfil do solo; dados médios de 5 repetições.

\begin{tabular}{|c|cc|cc|cc|cc|}
\hline TRATA & \multicolumn{2}{|c|}{$\mathbf{0}-\mathbf{2 5} \mathbf{~ c m}$} & \multicolumn{2}{|c|}{$\mathbf{2 5}-\mathbf{5 0} \mathbf{~ c m}$} & \multicolumn{2}{c|}{$\mathbf{5 0}-\mathbf{7 5} \mathbf{~ c m}$} & \multicolumn{2}{|c|}{$\mathbf{7 5}-\mathbf{1 0 0} \mathbf{~ c m}$} \\
\cline { 2 - 9 } MENTO & $\mathbf{L}$ & $\mathbf{E L}$ & $\mathbf{L}$ & $\mathbf{E L}$ & $\mathbf{L}$ & $\mathbf{E L}$ & $\mathbf{L}$ & $\mathbf{E L}$ \\
\hline T 1 & 4,0 & $4,1 b c$ & 4,1 & $4,0 c d e$ & 4,0 & $4,0 b c$ & 4,1 & 4,0 \\
T 2 & 4,2 & $4,7 a b$ & 4,2 & $4,2 a b c$ & 4,0 & $4,1 a b c$ & 4,0 & 4,0 \\
T 3 & 4,3 & $4,4 b c$ & 4,2 & $4,1 b c d$ & 3,9 & $4,0 b c$ & 3,9 & 4,1 \\
T 4 & 4,5 & $4,7 a b$ & 4,2 & $4,2 b c$ & 4,0 & $4,1 a b c$ & 3,9 & 4,1 \\
T 5 & 4,3 & $4,6 a b$ & 4,3 & $4,3 a b$ & 3,9 & $4,2 a b$ & 3,9 & 4,1 \\
T 6 & 4,5 & $4,4 b c$ & 4,1 & $4,2 b c$ & 4,3 & $4,1 a b c$ & 4,1 & 4,0 \\
T 7 & 4,3 & $4,3 b c$ & 4,1 & $4,0 c d e$ & 4,2 & $4,0 b c$ & 4,1 & 4,0 \\
T 8 & 4,6 & $5,1 a$ & 4,2 & $4,5 a$ & 4,1 & $4,3 a$ & 4,1 & 4,1 \\
T 9 & 4,0 & $3,9 c$ & 4,1 & $3,9 d e$ & 4,1 & $3,9 c$ & 4,1 & 4,0 \\
T 10 & 3,9 & $3,8 c$ & 4,0 & $3,8 e$ & 3,9 & $3,9 c$ & 3,9 & 3,9 \\
\hline F & 1,60 & $5,27 * *$ & 0,44 & $5,83 * *$ & 1,90 & $2,48 *$ & 1,18 & 1,06 \\
dms & 0,8 & 0,7 & 0,5 & 0,3 & 0,3 & 0,3 & 0,3 & 0,3 \\
CV(\%) & 9,0 & 8,6 & 6,5 & 4,7 & 4,9 & 4,2 & 4,8 & 2,9 \\
\hline
\end{tabular}

LEGENDA :

T 1 = calc.calcítico

T 6 = magnesita $(25 \%)+$ calc.calcítico $(75 \%)$

$\mathrm{T} 2$ = calc.magnesiano

T 7 = magnesita $(15 \%)+$ calc.calcítico $(85 \%)$

T 3 = calc.dolomítico $1(70 \%)+$ gesso $\quad$ T $8=$ magnesita $(15 \%)+$ gesso $(85 \%)$

$\mathrm{T} 4$ = calc. dolomítico 2

T $9=$ gesso

T 5 = magnesita

$\mathrm{T} 10=$ testemunha

Médias seguidas da mesma letra, na vertical, não diferem entre si (Tukey a 10\%).

Maiores valores de $\mathrm{pH}$ na camada superficial também foram obtidos por NASCIMENTO et al. (1983), que, porém, não detectaram nenhuma diferença entre valores de $\mathrm{pH}$ em subsuperficie. Estes resultados também são concordantes com os obtidos por BATAGLIA et al. (1985) e por SUZUKI (1989), que também notaram 
aumento no $\mathrm{pH}$ até $50-60 \mathrm{~cm}$ de profundidade, que perdurou, na camada superficial, até os 36 meses após a aplicação dos produtos.

\subsection{2. $P$}

Os resultados obtidos para $\mathrm{P}$, no perfil do solo, na linha e na entrelinha da cana-de-açúcar e ao longo do tempo são encontrados nas Tabelas 9 a 12.

Tabela 9. Resultados de análise do solo para $P\left(\mu \mathrm{g} / \mathrm{cm}^{3}\right)$ aos 6 meses após a aplicação dos produtos, na linha e na entrelinha, ao longo do perfil do solo; dados médios de 5 repetições.

\begin{tabular}{|c|cc|cc|cc|cc|}
\hline TRATA & \multicolumn{2}{|c|}{$\mathbf{0}-\mathbf{2 5} \mathbf{~ c m}$} & \multicolumn{2}{c|}{$\mathbf{2 5}-\mathbf{5 0} \mathbf{~ c m}$} & \multicolumn{2}{c|}{$\mathbf{5 0}-\mathbf{7 5} \mathbf{~ c m}$} & \multicolumn{2}{c|}{$\mathbf{7 5}-\mathbf{1 0 0} \mathbf{~ c m}$} \\
\cline { 2 - 9 } MENTO & $\mathbf{L}$ & $\mathbf{E L}$ & $\mathbf{L}$ & $\mathbf{E L}$ & $\mathbf{L}$ & $\mathbf{E L}$ & $\mathbf{L}$ & $\mathbf{E L}$ \\
\hline T 1 & 31 & $\mathbf{8}$ & 22 & 5 & 4 & 3 & 2 & 2 \\
T 2 & 48 & $\mathbf{1 5}$ & 20 & 4 & 4 & 3 & 2 & 2 \\
T 3 & 37 & 6 & 13 & 4 & 3 & 2 & 2 & 2 \\
T 4 & 42 & 5 & 15 & 3 & 3 & 2 & 3 & 2 \\
T 5 & 41 & 5 & 19 & 6 & 3 & 3 & 3 & 2 \\
T 6 & 40 & 10 & 26 & 4 & 4 & 3 & 2 & 2 \\
T 7 & 49 & 15 & 24 & 5 & 4 & 3 & 3 & 2 \\
T 8 & 59 & 13 & 22 & 3 & 4 & 2 & 3 & 2 \\
T 9 & 32 & 7 & 21 & 5 & 3 & 3 & 2 & 2 \\
T 10 & 42 & 5 & 15 & 4 & 5 & 2 & 2 & 2 \\
\hline F & 0,56 & 1,31 & 0,88 & 0,50 & 1,11 & 1,28 & 1,22 & - \\
dms & 47 & 15 & 19 & 5 & 2 & 1 & 1 & - \\
CV(\%) & 58,4 & 85,9 & 50,5 & 57,7 & 31,6 & 19,0 & 18,4 & - \\
\hline
\end{tabular}

\section{LEGENDA :}

$\mathrm{T} 1$ = calc.calcítico

T 6 = magnesita $(25 \%)+$ calc.calcítico $(75 \%)$

T 2 = calc.magnesiano

T $7=$ magnesita $(15 \%)+$ calc.calcítico $(85 \%)$

T 3 = calc.dolomítico $1(70 \%)+$ gesso

T 4 = calc. dolomítico 2

T $8=$ magnesita $(15 \%)+$ gesso $(85 \%)$

T 5 = magnesita

$\mathrm{T} 9=$ gesso

$\mathrm{T} 10=$ testemunha

Médias seguidas da mesma letra, na vertical, não diferem entre si (Tukey a 10\%).

Não foram observadas diferenças significativas entre os tratamentos efetuados quando se analisou o fósforo; encontrou-se apenas o que já era esperado, ou 
seja, maiores teores do elemento na linha da cana-de-açúcar e na primeira camada estudada, teores estes provenientes da adubação de sulco realizada e que podem ser considerados como aceitáveis para a cultura, do ponto de vista nutricional, pelo menos até o segundo corte realizado, quando se leva em consideração os teores foliares encontrados e as exigências da cultura.

Tabela 10. Resultados da análise de solo para $\mathrm{P}\left(\mu \mathrm{g} / \mathrm{cm}^{3}\right)$ na colheita da cana planta, na linha e na entrelinha, ao longo do perfil do solo; dados médios de 5 repetições.

\begin{tabular}{|c|cc|cc|cc|cc|}
\hline TRATA & \multicolumn{2}{|c|}{$\mathbf{0}-\mathbf{2 5} \mathbf{~ c m ~}$} & \multicolumn{2}{|c|}{$\mathbf{2 5}-\mathbf{5 0} \mathbf{~ c m}$} & \multicolumn{2}{|c|}{$\mathbf{5 0}-\mathbf{7 5} \mathbf{~ c m}$} & \multicolumn{2}{|c|}{$\mathbf{7 5}-\mathbf{1 0 0} \mathbf{~ c m}$} \\
\cline { 2 - 9 } MENTO & $\mathbf{L}$ & $\mathbf{E L}$ & $\mathbf{L}$ & $\mathbf{E L}$ & $\mathbf{L}$ & $\mathbf{E L}$ & $\mathbf{L}$ & $\mathbf{E L}$ \\
\hline T 1 & 32 & $3 c$ & 11 & 3 & 5 & 3 & 2 & 3 \\
T 2 & 42 & $3 c$ & 6 & 3 & 5 & 3 & 3 & 3 \\
T 3 & 41 & $3 c$ & 10 & 5 & 4 & 4 & 3 & 3 \\
T 4 & 38 & $3 c$ & 14 & 4 & 5 & 3 & 2 & 3 \\
T 5 & 35 & $4 b c$ & 12 & 3 & 5 & 2 & 3 & 3 \\
T 6 & 39 & $4 b c$ & 8 & 6 & 5 & 3 & 3 & 3 \\
T 7 & 37 & $4 b c$ & 12 & 4 & 4 & 2 & 3 & 4 \\
T 8 & 46 & $6 a$ & 20 & 3 & 5 & 2 & 3 & 2 \\
T 9 & 28 & $5 a b$ & 11 & 3 & 6 & 3 & 3 & 3 \\
T 10 & 35 & $3 c$ & 11 & 3 & 4 & 3 & 2 & 3 \\
\hline F & 0,38 & $2,47 *$ & 1,14 & 0,86 & 0,50 & 1,18 & 0,59 & 0,95 \\
dms & 37 & 2 & 14 & 5 & 3 & 2 & 1 & 2 \\
CV(\%) & 50,8 & 36,9 & 62,1 & 68,6 & 37,0 & 35,8 & 25,2 & 33,5 \\
\hline
\end{tabular}

\section{LEGENDA :}

T 1 = calc.calcítico

$\mathrm{T} 2$ = calc.magnesiano

T $6=$ magnesita $(25 \%)+$ calc.calcítico $(75 \%)$

T 3 = calc.dolomítico $1(70 \%)+$ gesso

T 4 = calc. dolomítico 2

T $7=$ magnesita $(15 \%)+$ calc.calcítico $(85 \%)$

T $5=$ magnesita

T $8=$ magnesita $(15 \%)+$ gesso $(85 \%)$

T $9=$ gesso

$\mathrm{T} 10=$ testemunha

Médias seguidas da mesma letra, na vertical, não diferem entre si (Tukey a 10\%). 
Tabela 11. Resultados da análise de solo para $\mathrm{P}\left(\mu \mathrm{g} / \mathrm{cm}^{3}\right)$ na colheita da primeira soca, na linha e na entrelinha, ao longo do perfil do solo; dados médios de 5 repetições.

\begin{tabular}{|c|cc|cc|cc|cc|}
\hline \multirow{2}{*}{ TRATA } & \multicolumn{2}{|c|}{$\mathbf{0}-\mathbf{2 5} \mathbf{~ c m}$} & \multicolumn{2}{|c|}{$\mathbf{2 5}-\mathbf{5 0} \mathbf{~ c m}$} & \multicolumn{2}{|c|}{$\mathbf{5 0}-\mathbf{7 5} \mathbf{~ c m}$} & \multicolumn{2}{|c|}{$\mathbf{7 5}-\mathbf{1 0 0} \mathbf{~ c m}$} \\
\cline { 2 - 8 } MENTO & $\mathbf{L}$ & $\mathbf{E L}$ & $\mathbf{L}$ & $\mathbf{E L}$ & $\mathbf{L}$ & $\mathbf{E L}$ & $\mathbf{L}$ & $\mathbf{E L}$ \\
\hline T 1 & 42 & 3 & 13 & 3 & 4 & 1 & 1 & 1 \\
T 2 & 30 & 3 & 7 & 1 & 1 & 1 & 1 & 1 \\
T 3 & 30 & 3 & 13 & 2 & 1 & 1 & 2 & 1 \\
T 4 & 35 & 2 & 10 & 1 & 1 & 1 & 1 & 1 \\
T 5 & 32 & 2 & 10 & 2 & 1 & 1 & 1 & 1 \\
T 6 & 32 & 4 & 9 & 1 & 1 & 1 & 1 & 1 \\
T 7 & 36 & 3 & 20 & 4 & 2 & 1 & 1 & 1 \\
T 8 & 29 & 4 & 9 & 1 & 2 & 1 & 1 & 1 \\
T 9 & 29 & 4 & 9 & 1 & 1 & 1 & 1 & 1 \\
T 10 & 31 & 8 & 12 & 1 & 1 & 1 & 1 & 1 \\
\hline F & 0,23 & 0,68 & 1,63 & 1,33 & 1,51 & - & 1,32 & - \\
dms & 36 & $\mathbf{8}$ & 13 & 3 & 3 & - & 1 & - \\
CV(\%) & 56,8 & 98,9 & 55,4 & 93,0 & 72,2 & - & 60,5 & - \\
\hline
\end{tabular}

\section{LEGENDA :}

$\mathrm{T} 1$ = calc.calcítico

T 2 = calc.magnesiano

T $3=$ calc.dolomítico $1(70 \%)+$ gesso

T $4=$ calc. dolomítico 2

T 5 = magnesita
T 6 = magnesita $(25 \%)+$ calc.calcítico $(75 \%)$

T $7=$ magnesita $(15 \%)+$ calc.calcítico $(85 \%)$

T $8=$ magnesita $(15 \%)+$ gesso $(85 \%)$

T $9=$ gesso

$\mathrm{T} 10=$ testemunha

Médias seguidas da mesma letra, na vertical, não diferem entre si (Tukey a 10\%). 
Tabela 12. Resultados da análise de solo para $P\left(\mu \mathrm{g} / \mathrm{cm}^{3}\right)$ na colheita da segunda soca, na linha e na entrelinha, ao longo do perfil do solo; dados médios de 5 repetições.

\begin{tabular}{|c|cc|cc|cc|cc|}
\hline TRATA & \multicolumn{2}{|c|}{$\mathbf{0}-\mathbf{2 5} \mathbf{~ c m ~}$} & \multicolumn{2}{|c|}{$\mathbf{2 5}-\mathbf{5 0} \mathbf{~ c m}$} & \multicolumn{2}{|c|}{$\mathbf{5 0}-\mathbf{7 5} \mathbf{~ c m}$} & \multicolumn{2}{|c|}{$\mathbf{7 5}-\mathbf{1 0 0} \mathbf{~ c m}$} \\
\cline { 2 - 8 } MENTO & $\mathbf{L}$ & $\mathbf{E L}$ & $\mathbf{L}$ & $\mathbf{E L}$ & $\mathbf{L}$ & $\mathbf{E L}$ & $\mathbf{L}$ & EL \\
\hline T 1 & 33 & 5 & 9 & 4 & 3 & 2 & 3 & 2 \\
T 2 & 10 & 7 & 5 & 2 & 3 & 2 & 2 & 2 \\
T 3 & 26 & 12 & 11 & 4 & 3 & 2 & 2 & 2 \\
T 4 & 10 & 8 & 4 & 4 & 3 & 2 & 2 & 2 \\
T 5 & 10 & 15 & 6 & 7 & 3 & 2 & 3 & 2 \\
T 6 & 11 & 7 & 11 & 3 & 4 & 2 & 3 & 2 \\
T 7 & 14 & 5 & 5 & 5 & 3 & 2 & 3 & 2 \\
T 8 & 32 & 13 & 14 & 12 & 5 & 3 & 4 & 2 \\
T 9 & 22 & 4 & 5 & 4 & 3 & 2 & 3 & 2 \\
T 10 & 15 & 11 & 4 & 4 & 4 & 3 & 2 & 2 \\
\hline F & 1,19 & 0,96 & 1,23 & 1,39 & 0,89 & 1,80 & 1,89 & - \\
dms & 30 & 12 & 13 & 10 & 2 & 1 & 2 & - \\
CV(\%) & 99,5 & 99,7 & 89,2 & 95,1 & 48,6 & 25,8 & 35,5 & - \\
\hline
\end{tabular}

LEGENDA :

T 1 = calc.calcítico

T 2 = calc. magnesiano

T 3 = calc.dolomítico $1(70 \%)+$ gesso

T 4 = calc. dolomítico 2

T 5 = magnesita

Médias seguidas da mesma letra, na vertical, não diferem entre si (Tukey a 10\%).
T $6=$ magnesita $(25 \%)+$ calc.calcítico $(75 \%)$

T $7=$ magnesita $(15 \%)+$ calc.calcítico $(85 \%)$

T $8=$ magnesita $(15 \%)+$ gesso $(85 \%)$

T $9=$ gesso

$\mathrm{T} 10=$ testemunha

\subsection{3. $\mathrm{K}^{+}$}

Aos 6 meses após a aplicação dos produtos, maiores teores de $\mathrm{K}^{+}$foram encontrados, como já era esperado, na linha e na camada $0-25 \mathrm{~cm}$, como resultado da adubação potássica praticada neste local, por ocasião do plantio; porém, todos os tratamentos apresentaram, ainda, baixos teores deste elemento. Abaixo da camada arável, na linha e, em todo o perfil do solo na entrelinha, todos os tratamentos indicaram possuir muito baixos teores de $\mathrm{K}^{+}$. 
Porém, quando comparados com os teores inicialmente existentes no solo, os valores encontrados na linha a $0-25 \mathrm{~cm}$ podem ser considerados como relativamente altos, ainda na colheita da cana planta. $\mathrm{Na}$ ápoca da colheita das duas primeiras socas, em todo o perfil do solo, em qualquer ponto amostrado, independentemente do tratamento realizado, encontrou-se teores baixos a muito baixos deste nutriente.

Tabela 13. Resultados da análise de solo para $\mathrm{K}^{+}\left(\mathrm{meq} / 100 \mathrm{~cm}^{3}\right)$ aos 6 meses após a aplicação dos produtos, na linha e na entrelinha, ao longo do perfil do solo; dados médios de 5 repetições.

\begin{tabular}{|c|cc|cc|cc|cc|}
\hline TRATA & \multicolumn{2}{|c|}{$\mathbf{0 -} \mathbf{2 5} \mathbf{~ c m}$} & \multicolumn{2}{c|}{$\mathbf{2 5}-\mathbf{5 0} \mathbf{~ c m}$} & \multicolumn{2}{c|}{$\mathbf{5 0}-\mathbf{7 5} \mathbf{~ c m}$} & \multicolumn{2}{c|}{$\mathbf{7 5}-\mathbf{1 0 0} \mathbf{~ c m}$} \\
\cline { 2 - 8 } MENTO & $\mathbf{L}$ & $\mathbf{E L}$ & $\mathbf{L}$ & $\mathbf{E L}$ & $\mathbf{L}$ & $\mathbf{E L}$ & $\mathbf{L}$ & $\mathbf{E L}$ \\
\hline T 1 & 0,08 & 0,05 & 0,06 & 0,04 & 0,05 & 0,04 & 0,04 & 0,03 \\
T 2 & 0,11 & 0,05 & 0,06 & 0,04 & 0,06 & 0,04 & 0,04 & 0,03 \\
T 3 & 0,09 & 0,04 & 0,05 & 0,04 & 0,04 & 0,04 & 0,03 & 0,03 \\
T 4 & 0,10 & 0,04 & 0,06 & 0,04 & 0,05 & 0,04 & 0,05 & 0,03 \\
T 5 & 0,10 & 0,05 & 0,07 & 0,04 & 0,04 & 0,03 & 0,04 & 0,03 \\
T 6 & 0,09 & 0,05 & 0,06 & 0,04 & 0,05 & 0,03 & 0,04 & 0,03 \\
T 7 & 0,09 & 0,04 & 0,06 & 0,04 & 0,05 & 0,03 & 0,04 & 0,03 \\
T 8 & 0,09 & 0,04 & 0,05 & 0,03 & 0,04 & 0,03 & 0,05 & 0,03 \\
T 9 & 0,09 & 0,05 & 0,05 & 0,04 & 0,06 & 0,03 & 0,05 & 0,03 \\
T 10 & 0,10 & 0,05 & 0,05 & 0,04 & 0,03 & 0,03 & 0,04 & 0,03 \\
\hline F & 0,39 & 1,24 & 1,52 & 0,64 & 1,70 & 1,51 & 0,66 & -- \\
dms & 0,06 & 0,02 & 0,02 & 0,01 & 0,03 & 0,01 & 0,02 & -- \\
CV(\%) & 32,1 & 25,1 & 22,0 & 22,1 & 34,0 & 15,2 & 30,8 & -- \\
\hline
\end{tabular}

LEGENDA :

$\mathrm{T} 1$ = calc. calcítico

$\mathrm{T} 2$ = calc.magnesiano

T 6 = magnesita $(25 \%)+$ calc. calcítico $(75 \%)$

T 3 = calc.dolomítico $1(70 \%)+$ gesso

$\mathrm{T} 4$ = calc. dolomítico 2

T 7 = magnesita $(15 \%)+$ calc. calcítico $(85 \%)$

T $5=$ magnesita

T 8 = magnesita $(15 \%)+$ gesso $(85 \%)$

$\mathrm{T} 9=$ gesso

$\mathrm{T} 10=$ testemunha

Médias seguidas da mesma letra, na vertical, não diferem entre si (Tukey a 10\%).

Estes resultados indicam que não houve influência dos corretivos e do gesso sobre $\mathrm{o} \mathrm{K}^{+}$, ao longo do perfil de solo e durante o transcorrer do tempo, pelo 
menos neste solo paupérrimo em $\mathrm{K}^{+}$. Estes dados, que podem ser visualizados nas Tabelas 13 a 16, são concordantes com os obtidos por LEON et al. (1986), que também não observaram variação nos teores de $\mathrm{K}^{+}$, ao longo do perfil do solo, em avaliações efetuadas 2 anos após a aplicação dos produtos corretivos.

Tabela 14. Resultados da análise de solo para $\mathrm{K}^{+}\left(\mathrm{meq} / 100 \mathrm{~cm}^{3}\right)$ na colheita da cana planta, na linha e na entrelinha, a o longo do perfil do solo; dados médios de 5 repetições.

\begin{tabular}{|c|c|c|c|c|c|c|c|c|}
\hline \multirow{2}{*}{$\begin{array}{r}\text { TRATA } \\
\text { MENTO }\end{array}$} & \multicolumn{2}{|c|}{$0-25 \mathrm{~cm}$} & \multicolumn{2}{|c|}{$25-50 \mathrm{~cm}$} & \multicolumn{2}{|c|}{$50-75 \mathrm{~cm}$} & \multicolumn{2}{|c|}{$\begin{array}{c}75-100 \\
\mathrm{~cm}\end{array}$} \\
\hline & $\mathbf{L}$ & EL & $\mathbf{L}$ & EL & $\mathbf{L}$ & EL & $\mathbf{L}$ & EL \\
\hline T 1 & 0,10 & 0,06 & 0,03 & 0,03 & 0,04 & 0,01 & 0,05 & 0,01 \\
\hline T 2 & 0,11 & 0,05 & 0,03 & 0,02 & 0,04 & 0,02 & 0,02 & 0,01 \\
\hline T 3 & 0,08 & 0,06 & 0,03 & 0,02 & 0,03 & 0,01 & 0,02 & 0,01 \\
\hline T 4 & 0,11 & 0,05 & 0,03 & 0,03 & 0,03 & 0,01 & 0,02 & 0,01 \\
\hline T 5 & 0,12 & 0,04 & 0,05 & 0,03 & 0,04 & 0,01 & 0,02 & 0,01 \\
\hline T 6 & 0,11 & 0,05 & 0,04 & 0,03 & 0,03 & 0,01 & 0,02 & 0,01 \\
\hline T 7 & 0,11 & 0,06 & 0,04 & 0,02 & 0,04 & 0,01 & 0,02 & 0,01 \\
\hline T 8 & 0,12 & 0,05 & 0,03 & 0,02 & 0,02 & 0,01 & 0,02 & 0,01 \\
\hline Т 9 & 0,11 & 0,04 & 0,04 & 0,03 & 0,03 & 0,02 & 0,03 & 0,01 \\
\hline T 10 & 0,11 & 0,05 & 0,04 & 0,02 & 0,03 & 0,01 & 0,02 & 0,01 \\
\hline 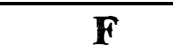 & 0,86 & 1,54 & 2,05 & 0,83 & 1,48 & 1,35 & 1,01 & - \\
\hline dms & 0,04 & 0,02 & 0,02 & 0,01 & 0,02 & 0,01 & 0,04 & -- \\
\hline CV(\%) & 22,4 & 23,5 & 27,6 & 28,0 & 31,7 & 49,3 & 80,2 & -- \\
\hline
\end{tabular}

LEGENDA :

T $1=$ calc.calcítico

T 6 = magnesita $(25 \%)+$ calc.calcítico $(75 \%)$

T 2 = calc.magnesiano

T $7=$ magnesita $(15 \%)+$ calc.calcítico $(85 \%)$

T 3 = calc.dolomítico $1(70 \%)+$ gesso

T $4=$ calc. dolomítico 2

T $8=$ magnesita $(15 \%)+$ gesso $(85 \%)$

T 5 = magnesita

T $9=$ gesso

$\mathrm{T} 10=$ testemunha

Médias seguidas da mesma letra, na vertical, não diferem entre si (Tukey a 10\%). 
Tabela 15. Resultados da análise de solo para $\mathrm{K}^{+}\left(\mathrm{meq} / 100 \mathrm{~cm}^{3}\right)$ na colheita da primeira soca, na linha e na entrelinha, ao longo do perfil do solo; dados médios de 5 repetições.

\begin{tabular}{|c|cc|cc|cc|cc|}
\hline \multirow{2}{*}{ TRATA } & \multicolumn{2}{|c|}{$\mathbf{0}-\mathbf{2 5} \mathbf{~ c m}$} & \multicolumn{2}{|c|}{$\mathbf{2 5}-\mathbf{5 0} \mathbf{~ c m}$} & \multicolumn{2}{c|}{$\mathbf{5 0}-\mathbf{7 5} \mathbf{~ c m}$} & \multicolumn{2}{c|}{$\mathbf{7 5}-\mathbf{1 0 0} \mathbf{~ c m}$} \\
\cline { 2 - 9 } MENTO & L & EL & L & EL & L & EL & L & EL \\
\hline T 1 & 0,05 & 0,04 & 0,01 & $0,03 a b$ & 0,01 & $0,02 a$ & 0,01 & 0,01 \\
T 2 & 0,04 & 0,04 & 0,02 & $0,03 a b$ & -- & $0,02 a$ & -- & -- \\
T 3 & 0,04 & 0,04 & 0,01 & $0,02 a b c$ & -- & $0,01 a b$ & - & - \\
T 4 & 0,05 & 0,05 & 0,01 & $0,02 a b c$ & 0,01 & $0,01 a b$ & -- & -- \\
T 5 & 0,04 & 0,04 & 0,01 & $0,04 a$ & 0,01 & $0,02 a$ & -- & 0,01 \\
T 6 & 0,04 & 0,03 & 0,02 & $0,03 a b$ & -- & $0,02 a$ & -- & -- \\
T 7 & 0,04 & 0,05 & 0,01 & $0,02 a b c$ & -- & $0,01 a b$ & -- & - \\
T 8 & 0,04 & 0,03 & 0,01 & $0,00 c$ & -- & $0,00 b$ & -- & -- \\
T 9 & 0,05 & 0,03 & 0,01 & $0,01 b c$ & -- & $0,01 a b$ & - & 0,01 \\
T 10 & 0,05 & 0,04 & 0,02 & $0,02 a b c$ & 0,01 & $0,01 a b$ & -- & 0,01 \\
\hline F & 0,69 & 0,94 & 0,91 & $3,99 * *$ & -- & $2,48 *$ & -- & -- \\
dms & 0,03 & 0,03 & 0,01 & 0,02 & -- & 0,01 & -- & -- \\
CV(\%) & 39,7 & 39,3 & 76,4 & 44,7 & -- & 53,1 & -- & -- \\
\hline
\end{tabular}

LEGENDA :

$\mathrm{T} 1$ = calc.calcítico

$\mathrm{T} 2$ = calc.magnesiano

T 3 = calc.dolomítico I (70\%)+gesso

T 4 = calc. dolomítico 2

T $5=$ magnesita
T 6 = magnesita $(25 \%)+$ calc.calcítico $(75 \%)$

T $7=$ magnesita $(15 \%)+$ calc.calcítico $(85 \%)$

T $8=$ magnesita $(15 \%)+$ gesso $(85 \%)$

T $9=$ gesso

$\mathrm{T} 10=$ testemunha

Médias seguidas da mesma letra, na vertical, não diferem entre si (Tukey a 10\%). 
Tabela 16. Resultados da análise de solo para $\mathrm{K}^{+}\left(\mathrm{meq} / 100 \mathrm{~cm}^{3}\right)$ na colheita da segunda soca, na linha e na entrelinha, ao longo do perfil do solo; dados médios de 5 repetições.

\begin{tabular}{|c|cc|cc|cc|cc|}
\hline TRATA & \multicolumn{2}{|c|}{$\mathbf{0}-\mathbf{2 5} \mathbf{~ c m}$} & \multicolumn{2}{|c|}{$\mathbf{2 5}-\mathbf{5 0} \mathbf{~ c m}$} & \multicolumn{2}{|c|}{$\mathbf{5 0}-\mathbf{7 5} \mathbf{~ c m}$} & \multicolumn{2}{|c|}{$\mathbf{7 5}-\mathbf{1 0 0} \mathbf{~ c m}$} \\
\cline { 2 - 8 } MENTO & $\mathbf{L}$ & $\mathbf{E L}$ & $\mathbf{L}$ & $\mathbf{E L}$ & $\mathbf{L}$ & $\mathbf{E L}$ & $\mathbf{L}$ & $\mathbf{E L}$ \\
\hline T 1 & 0,03 & $0,03 a b$ & 0,01 & $0,02 a b$ & 0,01 & $0,02 b$ & 0,00 & 0,01 \\
T 2 & 0,03 & $0,02 b$ & 0,02 & $0,01 b$ & 0,01 & $0,01 b$ & 0,01 & 0,00 \\
T 3 & 0,03 & $0,03 a b$ & 0,01 & $0,01 b$ & 0,00 & $0,02 b$ & 0,00 & 0,01 \\
T 4 & 0,03 & $0,03 a b$ & 0,02 & $0,02 a b$ & 0,01 & $0,01 b$ & 0,00 & 0,01 \\
T 5 & 0,03 & $0,03 a b$ & 0,03 & $0,04 a$ & 0,01 & $0,05 a$ & 0,00 & 0,02 \\
T 6 & 0,02 & $0,04 a$ & 0,02 & $0,02 a b$ & 0,01 & $0,02 b$ & 0,01 & 0,00 \\
T 7 & 0,03 & $0,02 b$ & 0,02 & $0,02 a b$ & 0,02 & $0,01 b$ & 0,00 & 0,00 \\
T 8 & 0,02 & $0,02 b$ & 0,01 & $0,01 b$ & 0,01 & $0,01 b$ & 0,00 & 0,00 \\
T 9 & 0,03 & $0,03 a b$ & 0,01 & $0,01 b$ & 0,01 & $0,01 b$ & 0,01 & 0,01 \\
T 10 & 0,03 & $0,02 b$ & 0,02 & $0,02 a b$ & 0,01 & $0,02 b$ & 0,00 & 0,01 \\
\hline F & 0,44 & $1,91^{+}$ & 0,80 & $2,21^{*}$ & 1,27 & $5,89 * *$ & 1,69 & $2,45 *$ \\
dms & 0,02 & 0,01 & 0,02 & 0,02 & 0,01 & 0,02 & 0,01 & 0,01 \\
CV(\%) & 36,1 & 30,4 & 69,5 & 59,3 & 63,8 & 53,9 & 99,3 & 67,0 \\
\hline
\end{tabular}

\section{LEGENDA :}

$\mathrm{T} 1$ = calc.calcítico

T 2 = calc. magnesiano

T 3 = calc.dolomítico $1(70 \%)+$ gesso

T 4 = calc. dolomítico 2

T 5 = magnesita

Médias seguidas da mesma letra, na vertical, não diferem entre si (Tukey a $10 \%$ ).

\subsection{4. $\mathrm{Ca}^{2+}$}

Como se verifica pela análise dos dados constantes da Tabela 17, aos 6 meses após a aplicação dos produtos, teores significativamente diferentes de $\mathrm{Ca}^{2+}$ foram obtidos na linha, na camada arável, nos tratamentos que receberam calcário calcítico, calcário magnesiano e a mistura de magnesita (a $25 \%$ ) com calcário calcítico, que apresentaram os maiores teores de $\mathrm{Ca}^{2+}$, estatisticamente diferentes do gesso agrícola e da magnesita aplicados isoladamente e da testemunha. 
Tabela 17. Resultados da análise de solo para $\mathrm{Ca}^{2+}\left(\mathrm{meq} / 100 \mathrm{~cm}^{3}\right)$ aos 6 meses após a aplicação dos produtos, na linha e na entrelinha, ao longo do perfil do solo; dados médios de 5 repetições.

\begin{tabular}{|c|cc|cc|cc|cc|}
\hline \multirow{2}{*}{ TRATA } & \multicolumn{2}{|c|}{$\mathbf{0}-\mathbf{2 5} \mathbf{~ c m}$} & \multicolumn{2}{|c|}{$\mathbf{2 5}-\mathbf{5 0} \mathbf{~ c m}$} & \multicolumn{2}{|c|}{$\mathbf{5 0}-\mathbf{7 5} \mathbf{~ c m}$} & \multicolumn{2}{|c|}{$\mathbf{7 5}-\mathbf{1 0 0} \mathbf{~ c m}$} \\
\cline { 2 - 9 } MENTO & $\mathbf{L}$ & $\mathbf{E L}$ & $\mathbf{L}$ & $\mathbf{E L}$ & $\mathbf{L}$ & $\mathbf{E L}$ & $\mathbf{L}$ & $\mathbf{E L}$ \\
\hline T 1 & $1,56 a$ & $3,30 a b$ & $0,42 a b$ & $0,50 a b c$ & $0,18 b$ & 0,28 & 0,24 & 0,12 \\
T 2 & $1,58 a$ & $3,08 a b$ & $0,30 a b$ & $0,48 a b c$ & $0,14 b$ & 0,18 & 0,18 & 0,12 \\
T 3 & $0,98 a b c$ & $1,16 b c$ & $0,34 a b$ & $0,26 b c$ & $0,22 a b$ & 0,28 & 0,20 & 0,12 \\
T 4 & $1,02 a b c$ & $2,14 a b c$ & $0,24 a b$ & $0,50 a b c$ & $0,24 a b$ & 0,34 & 0,24 & 0,16 \\
T 5 & $0,18 c$ & $0,36 c$ & $0,10 b$ & $0,18 c$ & $0,10 b$ & 0,14 & 0,16 & 0,10 \\
T 6 & $1,58 a$ & $2,42 a b c$ & $0,28 a b$ & $0,48 a b c$ & $0,14 b$ & 0,24 & 0,20 & 0,18 \\
T 7 & $0,96 a b c$ & $2,08 a b c$ & $0,36 a b$ & $0,52 a b$ & $0,18 b$ & 0,22 & 0,18 & 0,12 \\
T 8 & $1,16 a b$ & $3,92 a$ & $0,48 a$ & $0,72 a$ & $0,38 a$ & 0,24 & 0,24 & 0,12 \\
T 9 & $0,44 b c$ & $1,14 b c$ & $0,26 a b$ & $0,54 a b$ & $0,22 a b$ & 0,18 & 0,24 & 0,20 \\
T 10 & $0,22 c$ & $0,26 c$ & $0,12 b$ & $0,22 b c$ & $0,16 b$ & 0,16 & 0,12 & 0,10 \\
\hline F & $6,73 * *$ & $4,29 * *$ & $2,42 *$ & $5,14^{* *}$ & $3,80 * *$ & 1,43 & 1,46 & 0,68 \\
dms & 0,90 & 2,60 & 0,33 & 0,32 & 0,17 & 0,22 & 0,14 & 0,17 \\
CV(\%) & 47,8 & 67,5 & 59,2 & 37,6 & 45,3 & 51,6 & 38,0 & 68,4 \\
\hline
\end{tabular}

LEGENDA :

$\mathrm{T} 1$ = calc.calcítico

T 2 = calc.magnesiano

T 3 = calc.dolomítico $1(70 \%)+$ gesso

T 4 = calc. dolomítico 2

T 5 = magnesita

Médias seguidas da mesma letra, na vertical, não diferem entre si (Tukey a 10\%).

Maiores teores foram obtidos, ainda na camada arável, na entrelinha da cana-de-açúcar, especialmente no tratamento que recebeu a mistura de magnesita com gesso agrícola, que foi significativamente superior à magnesita e ao gesso aplicados isolados, à mistura de calcário dolomítico com gesso, além da testemunha.

Em subsuperficie, até os $75 \mathrm{~cm}$ de profundidade e na linha da cana-deaçúcar, a mistura de magnesita e gesso agrícola apresentou valores de $\mathrm{Ca}^{2+}$ significativamente diferentes da aplicação isolada de magnesita e da testemunha, principalmente. 
Nesta mesma época, na camada de $75-100 \mathrm{~cm}$, não se notou diferenças significativas entre os tratamentos estudados, tanto na linha quanto na entrelinha da cana-de-açúcar.

Tabela 18. Resultados da análise de solo para $\mathrm{Ca}^{2+}\left(\mathrm{meq} / 100 \mathrm{~cm}^{3}\right)$ na colheita da cana planta, na linha e na entrelinha, ao longo do perfil do solo; dados médios de 5 repetições.

\begin{tabular}{|c|cc|cc|cc|cc|}
\hline TRATA & \multicolumn{2}{|c|}{$\mathbf{0}-\mathbf{2 5} \mathbf{~ c m}$} & \multicolumn{2}{|c|}{$\mathbf{2 5}-\mathbf{5 0} \mathbf{~ c m}$} & \multicolumn{2}{|c|}{$\mathbf{5 0}-\mathbf{7 5} \mathbf{~ c m}$} & \multicolumn{2}{|c|}{$\mathbf{7 5}-\mathbf{1 0 0} \mathbf{~ c m}$} \\
\cline { 2 - 9 } MENTO & $\mathbf{L}$ & $\mathbf{E L}$ & $\mathbf{L}$ & $\mathbf{E L}$ & $\mathbf{L}$ & $\mathbf{E L}$ & $\mathbf{L}$ & $\mathbf{E L}$ \\
\hline T 1 & $1,72 a$ & $2,00 a b$ & 0,38 & $0,22 b$ & 0,12 & 0,12 & 0,10 & 0,10 \\
T 2 & $0,80 a b$ & $2,34 a b$ & 0,14 & $0,30 a b$ & 0,12 & 0,28 & 0,12 & 0,12 \\
T 3 & $0,80 a b$ & $1,04 b c$ & 0,24 & $0,16 b$ & 0,14 & 0,10 & 0,10 & 0,10 \\
T 4 & $0,72 b$ & $1,42 a b c$ & 0,22 & $0,16 b$ & 0,10 & 0,10 & 0,10 & 0,10 \\
T 5 & $0,28 b$ & $0,32 c$ & 0,36 & $0,14 b$ & 0,24 & 0,10 & 0,10 & 0,10 \\
T 6 & $0,88 a b$ & $1,02 b c$ & 0,24 & $0,20 b$ & 0,18 & 0,10 & 0,10 & 0,10 \\
T 7 & $0,96 a b$ & $2,30 a b$ & 0,18 & $0,18 b$ & 0,12 & 0,10 & 0,18 & 0,10 \\
T 8 & $0,98 a b$ & $2,82 a$ & 0,44 & $0,52 a$ & 0,22 & 0,10 & 0,18 & 0,16 \\
T 9 & $0,18 b$ & $1,84 a b$ & 0,10 & $0,26 a b$ & 0,18 & 0,14 & 0,10 & 0,10 \\
T 10 & $0,36 b$ & $0,24 c$ & 0,10 & $0,12 b$ & 0,12 & 0,10 & 0,10 & 0,10 \\
\hline F & $4,13 * *$ & $6,73^{* *}$ & 1,61 & $3,11^{* *}$ & 0,65 & 0,90 & 3,25 & 0,91 \\
dms & 0,94 & 1,46 & 0,40 & 0,28 & 0,25 & 0,25 & 0,08 & 0,08 \\
CV(\%) & 63,2 & 49,0 & 87,2 & 65,5 & 86,2 & 86,7 & 34,9 & 41,7 \\
\hline
\end{tabular}

LEGENDA :

$\mathrm{T} 1$ = calc.calcítico

T 2 = calc.magnesiano

T 3 = calc.dolomítico $1(70 \%)+$ gesso

$\mathrm{T} 4=$ calc. dolomítico 2

T $5=$ magnesita
T $6=$ magnesita $(25 \%)+$ calc.calcítico $(75 \%)$

T $7=$ magnesita $(15 \%)+$ calc.calcítico $(85 \%)$

T 8 = magnesita $(15 \%)+$ gesso $(85 \%)$

T $9=$ gesso

$\mathrm{T} 10=$ testemunha

Médias seguidas da mesma letra, na vertical, não diferem entre si (Tukey a 10\%).

Observou-se na colheita da cana planta que, na camada arável, tanto na linha quanto na entrelinha da cultura, a magnesita apresentou os menores teores de $\mathrm{Ca}^{2+}$, não diferentes estatisticamente da testemunha. Nesta camada, principalmente na entrelinha, a mistura de gesso agrícola com a magnesita apresentou teores 
significativamente superiores aos obtidos pela magnesita aplicada isoladamente, fato este que persistiu até os $50 \mathrm{~cm}$ de profundidade.

Alíás, neste nível do perfil do solo, só foram obtidos teores similares de $\mathrm{Ca}^{2+}$ (aos da mistura gesso + magnesita) nos tratamentos que receberam calcário magnesiano e gesso agrícola, este aplicado isoladamente.

Tabela 19. Resultados da análise de solo para $\mathrm{Ca}^{2+}\left(\mathrm{meq} / 100 \mathrm{~cm}^{3}\right)$ na colheita da primeira soca, na linha e na entrelinha, ao longo do perfil do solo; dados médios de 5 repetições.

\begin{tabular}{|c|cc|cc|cc|cc|}
\hline \multirow{2}{*}{ TRATA } & \multicolumn{2}{|c|}{$\mathbf{0}-\mathbf{2 5} \mathbf{~ c m}$} & \multicolumn{2}{|c|}{$\mathbf{2 5}-\mathbf{5 0} \mathbf{~ c m}$} & \multicolumn{2}{c|}{$\mathbf{5 0}-\mathbf{7 5} \mathbf{~ c m}$} & \multicolumn{2}{|c|}{$\mathbf{7 5}-\mathbf{1 0 0} \mathbf{~ c m}$} \\
\cline { 2 - 9 } MENTO & $\mathbf{L}$ & $\mathbf{E L}$ & $\mathbf{L}$ & $\mathbf{E L}$ & $\mathbf{L}$ & $\mathbf{E L}$ & $\mathbf{L}$ & $\mathbf{E L}$ \\
\hline T 1 & $1,37 a$ & $1,08 a b$ & $0,83 a$ & $0,43 a b$ & $0,41 a b$ & $0,37 a b$ & $0,45 a$ & $0,30 b c$ \\
T 2 & $1,06 a b$ & $0,83 b$ & $0,72 a$ & $0,43 a b$ & $0,35 a b$ & $0,37 a b$ & $0,28 a b$ & $0,26 c$ \\
T 3 & $1,04 a b$ & $0,72 b c$ & $0,70 a$ & $0,45 a b$ & $0,43 a b$ & $0,39 a b$ & $0,39 a b$ & $0,34 a b c$ \\
T 4 & $1,00 a b$ & $0,79 b$ & $0,60 a b$ & $0,41 b$ & $0,33 a b$ & $0,31 a b$ & $0,35 a b$ & $0,35 a b c$ \\
T 5 & $0,41 c$ & $0,33 c d$ & $0,31 c$ & $0,28 b$ & $0,28 b$ & $0,28 b$ & $0,22 b$ & $0,30 b c$ \\
T 6 & $0,97 a b$ & $0,97 b$ & $0,66 a$ & $0,39 b$ & $0,45 a b$ & $0,37 a b$ & $0,33 a b$ & $0,26 c$ \\
T 7 & $1,00 a b$ & $0,83 b$ & $0,58 b$ & $0,37 b$ & $0,32 a b$ & $0,37 a b$ & $0,33 a b$ & $0,28 b c$ \\
T 8 & $1,25 a$ & $1,46 a$ & $0,72 a$ & $0,62 a$ & $0,55 a$ & $0,45 a$ & $0,43 a$ & $0,41 a b$ \\
T 9 & $0,56 b c$ & $0,72 b c$ & $0,39 b c$ & $0,43 a b$ & $0,47 a b$ & $0,39 a b$ & $0,33 a b$ & $0,47 a$ \\
T 10 & $0,43 c$ & $0,28 d$ & $0,41 b c$ & $0,28 b$ & $0,28 b$ & $0,24 b$ & $0,28 a b$ & $0,24 c$ \\
\hline F & $7,90 * *$ & $12,2 * *$ & $8,23 * *$ & $3,97 * *$ & $2,62 *$ & $2,50 *$ & $2,73 *$ & $4,29 * *$ \\
dms & 0,51 & 0,42 & 0,25 & 0,20 & 0,24 & 0,16 & 0,18 & 0,15 \\
CV(\%) & 28,9 & 27,1 & 22,4 & 25,7 & 31,6 & 24,0 & 27,7 & 23,6 \\
\hline
\end{tabular}

LEGENDA :

$\mathrm{T} 1$ = calc. calcítico

$\mathrm{T} 6=$ magnesita $(25 \%)+$ calc.calcítico $(75 \%)$

T 2 = calc.magnesiano

T 3 = calc.dolomítico $1(70 \%)+$ gesso

T $4=$ calc. dolomítico 2

$\mathrm{T} 7$ = magnesita $(15 \%)+$ calc.calcítico $(85 \%)$

T 5 = magnesita

T 8 = magnesita $(15 \%)+$ gesso $(85 \%)$

$\mathrm{T} 9=$ gesso

Médias seguidas da mesma letra, na vertical, não diferem entre si (Tukey a 10\%).

A mistura de gesso com magnesita apresentou os maiores teores de $\mathrm{Ca}^{2+}$ até os 50-75 $\mathrm{cm}$ de profundidade, fato este provavelmente devido à rápida disponibilidade do $\mathrm{Ca}^{2+}$ do gesso, como cita KIEHL \& FRANCO (1984). 
Os maiores teores de $\mathrm{Ca}^{2+}$ encontrados nas amostras retiradas na entrelinha deve ser creditado ao fato de existir menor interação deste nutriente, neste local, com outros cátions, que, por ocasião da adubação de plantio, são colocados no fundo do sulco.

A obtenção de maiores teores de $\mathrm{Ca}^{2+}$, na primeira camada analisada, concorda com os dados obtidos por GONZÁLEZ et al. (1976), discordando, porém, dos resultados conseguidos por NASCIMENTO et al. (1983).

Menores teores foram achados nas camadas mais profundas do solo, sendo que, a partir dos $50 \mathrm{~cm}$ de profundidade, a mistura de gesso agrícola com magnesita apresentou teores significativamente diferentes da testemunha sem aplicação; esta tendência foi notada até a época da colheita da segunda soca, como se pode observar nas Tabelas 19 e 20.

A magnesita aplicada isoladamente proporcionou baixos teores de $\mathrm{Ca}^{2+}$ comparáveis aos da testemunha, em todo o perfil do solo, em qualquer ponto amostrado e para todas as ápocas de avaliação deste parâmetro.

Os teores encontrados na camada arável, em todas as ápocas de avaliação, em todos os tratamentos estudados, com exceção dos já citados anteriormente, foram iguais ou superiores aos dos níveis críticos mencionados por ESPIRONELLO \& OLIVEIRA (1972), CORDEIRO (1978), ORLANDO FILHO e ZAMBELLO JÚNIOR (1980), ZAMBELLO JÚNIOR e ORLANDO FILHO (1981) e BENEDINI (1988). 
Ao longo do perfil do solo observou-se uma certa lixiviação do $\mathrm{Ca}^{2+}$, como um processo lento e gradual, que se iniciou aos 6 meses após a aplicação dos produtos, concordando com os resultados obtidos e relatados por RITCHEY et al. (1980), QUAGGIO et al. (1982) e que também foi detectado por LORENZETTI et al. (1992) e por VITTI et al. (1993).

Tabela 20. Resultados da análise de solo para $\mathrm{Ca}^{2+}\left(\mathrm{meq} / 100 \mathrm{~cm}^{3}\right)$ na colheita da segunda soca, na linha e na entrelinha, ao longo do perfil do solo; dados médios de 5 repetições.

\begin{tabular}{|c|cc|cc|cc|cc|}
\hline TRATA & \multicolumn{2}{|c|}{$\mathbf{0}-\mathbf{2 5} \mathbf{~ c m}$} & \multicolumn{2}{|c|}{$\mathbf{2 5}-\mathbf{5 0} \mathbf{~ c m}$} & \multicolumn{2}{|c|}{$\mathbf{5 0}-\mathbf{7 5} \mathbf{~ c m}$} & \multicolumn{2}{|c|}{$\mathbf{7 5}-\mathbf{1 0 0} \mathbf{~ c m}$} \\
\cline { 2 - 9 } MENTO & $\mathbf{L}$ & $\mathbf{E L}$ & $\mathbf{L}$ & $\mathbf{E L}$ & $\mathbf{L}$ & $\mathbf{E L}$ & $\mathbf{L}$ & $\mathbf{E L}$ \\
\hline T 1 & $1,31 a b c d$ & $1,08 a b$ & $0,87 a b$ & $0,49 a$ & $0,56 a b$ & $0,18 a b$ & $0,41 b$ & $0,14 b$ \\
T 2 & $0,97 b c d e$ & $0,75 b$ & $0,66 a b c$ & $0,30 a b$ & $0,51 a b$ & $0,18 a b$ & $0,53 a b$ & $0,14 b$ \\
T 3 & $1,48 a b$ & $0,53 b$ & $0,77 a b c$ & $0,20 b$ & $0,53 a b$ & $0,16 a b$ & $0,49 a b$ & $0,16 b$ \\
T 4 & $1,12 b c d e$ & $0,58 b$ & $0,68 a b c$ & $0,22 a b$ & $0,49 a b$ & $0,14 a b$ & $0,41 b$ & $0,10 b$ \\
T 5 & $0,45 d e$ & $0,20 b$ & $0,39 c$ & $0,14 b$ & $0,41 b$ & $0,10 b$ & $0,37 b$ & $0,06 b$ \\
T 6 & $1,31 a b c d$ & $0,79 b$ & $0,66 a b c$ & $0,35 a b$ & $0,55 a b$ & $0,12 b$ & $0,47 a b$ & $0,12 b$ \\
T 7 & $1,44 a b c$ & $0,60 b$ & $0,79 a b c$ & $0,26 a b$ & $0,55 a b$ & $0,14 a b$ & $0,51 a b$ & $0,12 b$ \\
T 8 & $2,00 a$ & $2,46 a$ & $0,93 a$ & $0,49 a$ & $0,77 a$ & $0,37 a$ & $0,66 a$ & $0,43 a$ \\
T 9 & $0,58 c d e$ & $0,12 b$ & $0,51 b c$ & $0,12 b$ & $0,43 b$ & $0,10 b$ & $0,52 a b$ & $0,14 b$ \\
T 10 & $0,41 e$ & $0,22 b$ & $0,41 c$ & $0,22 a b$ & $0,33 b$ & $0,20 a b$ & $0,39 b$ & $0,16 b$ \\
\hline F & $6,49 * *$ & $3,17^{* *}$ & $3,66 * *$ & $3,95 * *$ & $2,80 *$ & 1,96 & $2,86^{*}$ & $4,12^{* *}$ \\
dms & 0,87 & 1,65 & 0,41 & 0,28 & 0,30 & 0,24 & 0,22 & 0,21 \\
CV(\%) & 40,4 & 95,4 & 32,0 & 52,3 & 30,2 & 73,2 & 24,4 & 69,6 \\
\hline
\end{tabular}

\section{LEGENDA :}

$\mathrm{T} 1$ = calc.calcítico

$\mathrm{T} 2$ = calc.magnesiano

T 3 = calc.dolomítico $1(70 \%)+$ gesso

T 4 = calc. dolomítico 2

T 5 = magnesita
T 6 = magnesita $(25 \%)+$ calc.calcítico $(75 \%)$

T 7 = magnesita $(15 \%)+$ calc.calcítico $(85 \%)$

T $8=$ magnesita $(15 \%)+$ gesso $(85 \%)$

$\mathrm{T} 9=$ gesso

T $10=$ testemunha

Médias seguidas da mesma letra, na vertical, não diferem entre si (Tukey a 10\%). 


\subsection{5. $\mathrm{Mg}^{2+}$}

Teores altos deste elemento foram encontrados aos 6 meses após a aplicação dos produtos na camada $0-25 \mathrm{~cm}$, na linha e na entrelinha, nos tratamentos que receberam calcário dolomítico e, especialmente, a magnesita, aplicada isoladamente ou em mistura com o gesso; este último tratamento manteve os teores elevados até os 50 cm de profundidade. A partir daí, em qualquer ponto de amostragem, os teores mantiveram-se baixos; os dados apresentados nas Tabelas 21 a 24 ilustram estes fatos.

Tabela 21. Resultados da análise de solo para $\mathrm{Mg}^{2+}\left(\mathrm{meq} / 100 \mathrm{~cm}^{3}\right)$ aos 6 meses após a aplicação dos produtos, na linha e na entrelinha, ao longo do perfil do solo; dados médios de 5 repetições.

\begin{tabular}{|c|cc|cc|cc|cc|}
\hline TRATA & \multicolumn{2}{|c|}{$\mathbf{0}-\mathbf{2 5} \mathbf{~ c m}$} & \multicolumn{2}{|c|}{$\mathbf{2 5}-\mathbf{5 0} \mathbf{~ c m}$} & \multicolumn{2}{c|}{$\mathbf{5 0}-\mathbf{7 5} \mathbf{~ c m}$} & \multicolumn{2}{|c|}{$\mathbf{7 5}-\mathbf{1 0 0} \mathbf{~ c m}$} \\
MENTO & $\mathbf{L}$ & $\mathbf{E L}$ & $\mathbf{L}$ & $\mathbf{E L}$ & $\mathbf{L}$ & $\mathbf{E L}$ & $\mathbf{L}$ & $\mathbf{E L}$ \\
\hline T 1 & $0,30 c d$ & $0,50 c$ & $0,12 c$ & $0,14 c$ & $0,10 b$ & $0,12 b$ & $0,10 b$ & 0,10 \\
T 2 & $0,54 b c d$ & $0,92 b c$ & $0,16 c$ & $0,16 c$ & $0,10 b$ & $0,12 b$ & $0,12 b$ & 0,10 \\
T 3 & $0,78 a b c$ & $0,74 b c$ & $0,18 c$ & $0,16 c$ & $0,14 b$ & $0,16 a b$ & $0,16 b$ & 0,10 \\
T 4 & $0,84 a b c$ & $1,94 a b$ & $0,24 b c$ & $0,40 b c$ & $0,14 b$ & $0,20 a b$ & $0,18 a b$ & 0,14 \\
T 5 & $1,20 a$ & $2,36 a$ & $0,64 a$ & $0,56 b$ & $0,12 b$ & $0,18 a b$ & $0,20 a b$ & 0,10 \\
T 6 & $1,02 a b$ & $1,82 a b$ & $0,50 a b$ & $0,42 b c$ & $0,16 b$ & $0,14 b$ & $0,18 a b$ & 0,12 \\
T 7 & $0,46 c d$ & $0,92 b c$ & $0,22 b c$ & $0,28 b c$ & $0,10 b$ & $0,12 b$ & $0,14 b$ & 0,10 \\
T 8 & $0,84 a b c$ & $2,50 a$ & $0,38 a b c$ & $1,04 a$ & $0,32 a$ & $0,26 a$ & $0,28 a$ & 0,10 \\
T 9 & $0,12 d$ & $0,12 c$ & $0,10 c$ & $0,18 c$ & $0,14 b$ & $0,12 b$ & $0,12 b$ & 0,12 \\
T 10 & $0,14 d$ & $0,14 c$ & $0,10 c$ & $0,12 c$ & $0,12 b$ & $0,10 b$ & $0,10 b$ & 0,10 \\
\hline F & $8,45^{* *}$ & $\mathbf{8 , 6 8 * *}$ & $7,31 * *$ & $12,6 * *$ & $4,18 * *$ & $2,84^{*}$ & $4,26 * *$ & 1,29 \\
dms & 0,55 & 1,31 & 0,29 & 0,34 & 0,13 & 0,12 & 0,11 & 0,05 \\
CV (\%) & 45,6 & 56,4 & 57,6 & 51,8 & 49,4 & 42,9 & 37,9 & 25,4 \\
\hline
\end{tabular}

LEGENDA:

T 1 = calc.calcítico

T 2 = calc.magnesiano

T $6=$ magnesita $(25 \%)+$ calc.calcítico $(75 \%)$

T 3 = calc.dolomítico $1(70 \%)+$ gesso

T 4 = calc. dolomítico 2

T 7 = magnesita $(15 \%)+$ calc.calcítico $(85 \%)$

T $5=$ magnesita

T $8=$ magnesita $(15 \%)+$ gesso $(85 \%)$

T $9=$ gesso

T $10=$ testemunha

Médias seguidas da mesma letra, na vertical, não diferem entre si (Tukey a 10\%). 
Estes resultados concordam com os obtidos por GONZÁLEZ et al. (1976), QUAGGIO et al. (1982), BATAGLIA et al. (1985) e SUZUKI (1989), diferindo em parte dos citados por NASCIMENTO et al. (1983) e por LEON et al. (1986).

Tabela 22. Resultados de análise de solo para $\mathrm{Mg}^{2+}\left(\mathrm{meq} / 100 \mathrm{~cm}^{3}\right)$ na colheita da cana planta, na linha e na entrelinha, ao longo do perfil do solo; dados médios de 5 repetições.

\begin{tabular}{|c|cc|cc|cc|cc|}
\hline TRATA & \multicolumn{2}{|c|}{$\mathbf{0}-\mathbf{2 5} \mathbf{~ c m}$} & \multicolumn{2}{|c|}{$\mathbf{2 5}-\mathbf{5 0} \mathbf{~ c m}$} & \multicolumn{2}{|c|}{$\mathbf{5 0 -} \mathbf{7 5} \mathbf{~ c m}$} & \multicolumn{2}{c|}{$\mathbf{7 5}-\mathbf{1 0 0} \mathbf{~ c m}$} \\
\cline { 2 - 9 } MENTO & $\mathbf{L}$ & $\mathbf{E L}$ & $\mathbf{L}$ & $\mathbf{E L}$ & $\mathbf{L}$ & $\mathbf{E L}$ & $\mathbf{L}$ & $\mathbf{E L}$ \\
\hline T 1 & $0,30 b c$ & $0,30 c$ & $0,10 c$ & $0,10 c$ & 0,10 & 0,10 & 0,10 & $0,10 b$ \\
T 2 & $0,32 b c$ & $0,78 b c$ & $0,10 c$ & $0,16 b c$ & 0,10 & 0,12 & 0,10 & $0,12 b$ \\
T 3 & $0,50 b c$ & $0,62 b c$ & $0,16 b c$ & $0,12 b c$ & 0,10 & 0,16 & 0,10 & $0,10 b$ \\
T 4 & $0,54 a b$ & $1,16 b c$ & $0,20 b c$ & $0,16 b c$ & 0,30 & 0,14 & 0,10 & $0,12 b$ \\
T 5 & $0,94 a$ & $2,26 a$ & $0,64 a$ & $0,40 b$ & 0,24 & 0,24 & 0,10 & $0,18 b$ \\
T 6 & $0,46 b c$ & $0,78 b c$ & $0,42 a b$ & $0,14 b c$ & 0,18 & 0,10 & 0,10 & $0,10 b$ \\
T 7 & $0,38 b c$ & $0,90 b c$ & $0,20 b c$ & $0,16 b c$ & 0,12 & 0,12 & 0,10 & $0,10 b$ \\
T 8 & $0,50 b c$ & $1,42 a b$ & $0,26 b c$ & $0,74 a$ & 0,16 & 0,26 & 0,10 & $0,36 a$ \\
T 9 & $0,10 c$ & $0,12 c$ & $0,10 c$ & $0,12 b c$ & 0,16 & 0,14 & 0,10 & $0,10 b$ \\
T 10 & $0,22 b c$ & $0,24 c$ & $0,10 c$ & $0,10 c$ & 0,10 & 0,10 & 0,10 & $0,12 b$ \\
\hline F & $5,68 * *$ & $6,66 * *$ & $5,87^{* *}$ & $\mathbf{8 , 3 6 * *}$ & 0,92 & 1,55 & -- & $5,74 * *$ \\
dms & 0,41 & 1,07 & 0,31 & 0,30 & 0,31 & 0,20 & -- & 0,14 \\
CV (\%) & 50,1 & 64,5 & 71,2 & $\mathbf{7 1 , 1}$ & 92,1 & 69,7 & -- & 54,0 \\
\hline
\end{tabular}

LEGENDA :

$\mathrm{T} 1$ = calc.calcítico

T $6=$ magnesita $(25 \%)+$ calc.calcítico $(75 \%)$

$\mathrm{T} 2$ = calc.magnesiano

$\mathrm{T} 7=$ magnesita $(15 \%)+$ calc.calcítico $(85 \%)$

T 3 = calc.dolomítico $1(70 \%)+$ gesso

T $4=$ calc. dolomítico 2

T $8=$ magnesita $(15 \%)+$ gesso $(85 \%)$

T 5 = magnesita

$\mathrm{T} 9=$ gesso

$\mathrm{T} 10=$ testemunha

Médias seguidas da mesma letra, na vertical, não diferem entre si (Tukey a 10\%).

Na época da colheita da cana planta, tal fato se repetiu :- os tratamentos com magnesita aplicada isoladamente ou em mistura com gesso conduziram a teores altos de $\mathrm{Mg}^{2+}$ no solo, situando-se especialmente na camada arável das amostras retiradas na entrelinha. 
Nesta época, na camada arável, o tratamento que recebeu exclusivamente a magnesita proporcionou os maiores teores de $\mathrm{Mg}^{2+}$, significativamente diferentes de todos os tratamentos, à exceção do calcário dolomítico; na entrelinha da cultura, os teores de $\mathrm{Mg}^{2+}$ obtidos foram ainda maiores, na camada superficial, somente comparáveis aos encontrados na mistura de gesso agrícola com magnesita.

Tabela 23. Resultados de análise de solo para $\mathrm{Mg}^{2+}\left(\mathrm{meq} / 100 \mathrm{~cm}^{3}\right)$ na colheita da primeira soca, na linha e na entrelinha, ao longo do perfil do solo; dados médios de 5 repetições.

\begin{tabular}{|c|c|c|c|c|c|c|c|c|}
\hline \multirow{2}{*}{$\begin{array}{l}\text { TRATA } \\
\text { MENTO }\end{array}$} & \multicolumn{2}{|c|}{$0-25 \mathrm{~cm}$} & \multicolumn{2}{|c|}{$25-50 \mathrm{~cm}$} & \multicolumn{2}{|c|}{$50-75 \mathrm{~cm}$} & \multicolumn{2}{|c|}{ 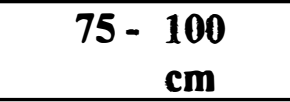 } \\
\hline & $\mathbf{L}$ & $\mathbf{E L}$ & $\mathbf{L}$ & EL & $\mathbf{L}$ & EL & $\mathbf{L}$ & EL \\
\hline T 1 & $0,21 c d$ & $0,31 b c$ & $0,10 c d$ & $0,07 d$ & $0,06 c$ & $0,05 b$ & $0,06 b c$ & $0,05 c$ \\
\hline T 2 & $0,27 c d$ & $0,18 c$ & $0,15 c d$ & $0,10 c d$ & $0,08 b c$ & $0,07 b$ & $0,06 b c$ & $0,05 c$ \\
\hline T 3 & $0,50 b$ & $0,39 b c$ & $0,27 b c$ & $0,13 c d$ & $0,14 b$ & $0,09 b$ & $0,10 b$ & $0,06 c$ \\
\hline T 4 & $0,49 b$ & $0,43 b c$ & $0,27 b c$ & $0,13 c d$ & $0,11 b c$ & $0,08 b$ & $0,08 b c$ & $0,09 b c$ \\
\hline T 5 & $0,71 a$ & $0,96 a$ & $0,45 a$ & $0,53 a$ & $0,22 a$ & $0,25 a$ & $0,14 a$ & $0,14 b$ \\
\hline T 6 & $0,39 b c$ & $0,42 b c$ & $0,37 a b$ & $0,29 b c$ & $0,28 a$ & $0,12 b$ & $0,10 b$ & $0,06 c$ \\
\hline $\mathbf{T} 7$ & $0,30 c$ & $0,21 c$ & $0,23 b c d$ & $0,13 c d$ & $0,11 b c$ & $0,08 b$ & $0,08 b c$ & $0,06 c$ \\
\hline T 8 & $0,53 a b$ & $0,67 a b$ & $0,33 a b$ & $0,40 a b$ & $0,22 a$ & $0,25 a$ & $0,18 a$ & $0,29 a$ \\
\hline T 9 & $0,10 d$ & $0,05 c$ & $0,06 d$ & $0,05 d$ & $0,06 c$ & $0,05 b$ & $0,05 c$ & $0,05 c$ \\
\hline T 10 & $0,11 d$ & $0,05 c$ & $0,07 d$ & $0,05 d$ & $0,05 c$ & $0,05 b$ & $0,05 c$ & $0,05 c$ \\
\hline $\mathbf{F}$ & $18,9 * *$ & $8,67^{* *}$ & $9,95 * *$ & $10,3^{* *}$ & $16,5^{* *}$ & $9,40 * *$ & $10,2^{* *}$ & $15,7^{* *}$ \\
\hline dms & 0,19 & 0,41 & 0,18 & 0,22 & 0,08 & 0,10 & 0,05 & 0,08 \\
\hline CV $(\%)$ & 28,0 & 57,6 & 40,4 & 59,9 & 31,6 & 50,0 & 30,9 & 46,2 \\
\hline
\end{tabular}

\section{LEGENDA :}

$\mathrm{T} 1$ = calc.calcítico

T 2 = calc.magnesiano

T 3 = calc.dolomítico $1(70 \%)+$ gesso

T $4=$ calc. dolomítico 2

T 5 = magnesita

Médias seguidas da mesma letra, na vertical, não diferem entre si (Tukey a $10 \%$ ).

T 6 = magnesita $(25 \%)+$ calc.calcítico $(75 \%)$

T $7=$ magnesita $(15 \%)+$ calc.calcítico $(85 \%)$

T 8 = magnesita $(15 \%)+$ gesso $(85 \%)$

T $9=$ gesso

$\mathrm{T} 10=$ testemunha

Em subsuperficie, na camada 25 - $50 \mathrm{~cm}$, notou-se 2 comportamentos , conforme o local amostrado : nas amostras retiradas na linha da cana-de-açúcar, a 
magnesita aplicada isolada mostrou maiores teores de $\mathrm{Mg}^{2+}$, significativamente diferenciados de todos os tratamentos, com exceção do que recebeu a mistura de magnesita (a $25 \%$ ) com calcário calcítico. Já na entrelinha da cultura, a mistura de gesso agrícola com magnesita mostrou maiores teores de $\mathrm{Mg}^{2+}$, significativamente diferentes de todos os demais tratamentos; resultados idênticos foram obtidos na entrelinha da camada $75-100 \mathrm{~cm}$.

A partir da colheita da primeira soca, os maiores teores de $\mathrm{Mg}^{2+}$ detectados nestes tratamentos foram notados em todo o perfil do solo, tendência esta que foi notada também na época da colheita da segunda soqueira.

Tabela 24. Resultados de análise de solo para $\mathrm{Mg}^{2+}\left(\mathrm{meq} / 100 \mathrm{~cm}^{3}\right)$ na colheita da segunda soca, na linha e na entrelinha, ao longo do perfil do solo; dados médios de 5 repetições.

\begin{tabular}{|c|cc|cc|cc|cc|}
\hline TRATA & \multicolumn{2}{|c|}{$\mathbf{0}-\mathbf{2 5} \mathbf{~ c m}$} & \multicolumn{2}{|c|}{$\mathbf{2 5}-\mathbf{5 0} \mathbf{~ c m}$} & \multicolumn{2}{|c|}{$\mathbf{5 0}-\mathbf{7 5} \mathbf{~ c m}$} & \multicolumn{2}{|c|}{$\mathbf{7 5}-\mathbf{1 0 0} \mathbf{~ c m}$} \\
\cline { 2 - 9 } MENTO & $\mathbf{L}$ & $\mathbf{E L}$ & $\mathbf{L}$ & $\mathbf{E L}$ & $\mathbf{L}$ & $\mathbf{E L}$ & $\mathbf{L}$ & $\mathbf{E L}$ \\
\hline T 1 & $0,15 b c$ & $0,13 c d$ & $0,09 b$ & $0,08 d$ & $0,07 b c$ & $0,07 c d$ & $0,05 d$ & $0,06 b$ \\
T 2 & $0,21 b c$ & $0,27 b c d$ & $0,11 b$ & $0,15 c d$ & $0,09 a b c$ & $0,11 c d$ & $0,08 c d$ & $0,08 b$ \\
T 3 & $0,62 a b$ & $0,45 b c$ & $0,27 a b$ & $0,18 c d$ & $0,14 a b c$ & $0,12 c d$ & $0,11 b c d$ & $0,09 a b$ \\
T 4 & $0,48 a b c$ & $0,51 b c$ & $0,28 a b$ & $0,28 b c$ & $0,14 a b c$ & $0,17 b c$ & $0,09 b c d$ & $0,13 a b$ \\
T 5 & $0,95 a$ & $1,05 a$ & $0,50 a$ & $0,56 a$ & $0,30 a$ & $0,36 a$ & $0,18 a b$ & $0,18 a$ \\
T 6 & $0,48 a b c$ & $0,38 b c d$ & $0,52 a$ & $0,29 b c$ & $0,28 a b$ & $0,17 b c$ & $0,17 a b c$ & $0,10 a b$ \\
T 7 & $0,29 b c$ & $0,23 c d$ & $0,31 a b$ & $0,15 c d$ & $0,19 a b c$ & $0,12 c d$ & $0,11 b c d$ & $0,08 b$ \\
T 8 & $0,90 a$ & $0,63 b$ & $0,36 a b$ & $0,36 b$ & $0,24 a b c$ & $0,25 a b$ & $0,20 a$ & $0,18 a$ \\
T 9 & $0,07 c$ & $0,06 d$ & $0,05 b$ & $0,06 d$ & $0,05 c$ & $0,05 d$ & $0,05 d$ & $0,05 b$ \\
T 10 & $0,06 c$ & $0,07 d$ & $0,05 b$ & $0,05 d$ & $0,05 c$ & $0,05 d$ & $0,05 d$ & $0,07 b$ \\
\hline F & $6,65^{* *}$ & $12,6^{* *}$ & $5,48^{* *}$ & $16,5^{* *}$ & $3,33^{* *}$ & $11,0^{* *}$ & $5,32^{* *}$ & $3,69^{* *}$ \\
dms & 0,54 & 0,37 & 0,32 & 0,17 & 0,22 & 0,12 & 0,10 & 0,10 \\
CV (\%) & 65,7 & 50,0 & 64,9 & 39,6 & 71,7 & 42,5 & 48,2 & 51,0 \\
\hline
\end{tabular}

LEGENDA :

$\mathrm{T} 1$ = calc. calcítico

T $6=$ magnesita $(25 \%)+$ calc. calcítico $(75 \%)$

$\mathrm{T} 2$ = calc.magnesiano

T 3 = calc.dolomítico $1(70 \%)+$ gesso

T $4=$ calc. dolomítico 2

T 7 = magnesita $(15 \%)+$ calc.calcítico $(85 \%)$

T 5 = magnesita

T 8 = magnesita $(15 \%)+$ gesso $(85 \%)$

$\mathrm{T} 9=$ gesso

$\mathrm{T} 10=$ testemunha

Médias seguidas da mesma letra, na vertical, não diferem entre si (Tukey a 10\%). 
Deve ser lembrado que os teores de $\mathrm{Mg}^{2+}$ considerados como níveis críticos para a cultura da cana-de-açúcar por diversos autores - ESPIRONELO \& OLIVEIRA (1972), ORLANDO FILHO \& ZAMBELLO JÚNIOR (1980), ZAMBELLO JÚNIOR \& ORLANDO FILHO (1981) - foram ultrapassados por diversos tratamentos, na camada arável, até a última avaliação realizada, após a colheita da segunda soca. Assim, a magnesita, aplicada isoladamente ou em mistura com gesso ou com calcário calcítico (este a $75 \%$ em peso) e o calcário dolomítico, aplicado isoladamente ou em mistura com o gesso, mantiveram, na camada arável, teores de $\mathrm{Mg}^{2+}$ superiores aos considerados como níveis críticos, até a colheita da segunda soca.

Saliente-se o fato de que o calcário magnesiano conseguiu manter os teores de $\mathrm{Mg}^{2+}$ em níveis superiores ao considerado crítico somente até a colheita da cana planta.

Quando se verifica a ação da mistura da magnesita com gesso sobre os teores de $\mathrm{Ca}^{2+}$ e de $\mathrm{Mg}^{2+}$, em profundidade, ao longo do perfil do solo e durante o transcorrer do tempo, conclue-se, lembrando LORENZETTI et al. (1992), que esta mistura muito provavelmente proporcionou melhor distribuição das bases ao longo do perfil do solo.

Mesmo após a colheita da segunda soca, o tratamento que recebeu a mistura de magnesita com gesso ainda continha, na camada arável, o apreciável teor de 3,09 meq de $\mathrm{Ca}^{2+}+\mathrm{Mg}^{2+} / 100 \mathrm{~cm}^{3}$ de solo; na camada situada a $75-100 \mathrm{~cm}$ de profundidade, após 40 meses decorridos da aplicação da mistura, ainda se encontrou teores de $\mathrm{Ca}^{2+}+\mathrm{Mg}^{2+}$ ao redor de $0,5 \mathrm{meq} / 100 \mathrm{~cm}^{3}$ de solo, teores estes que são 
praticamente iguais aos teores encontrados, na camada arável, antes da instalação do experimento. A Figura 1 compara os teores de $\mathrm{Ca}^{2-}+\mathrm{Mg}^{2-}$ da mistura de gesso com magnesita com os da aplicação isolada de gesso e da testemunha, determinados após a colheita da segunda soca.

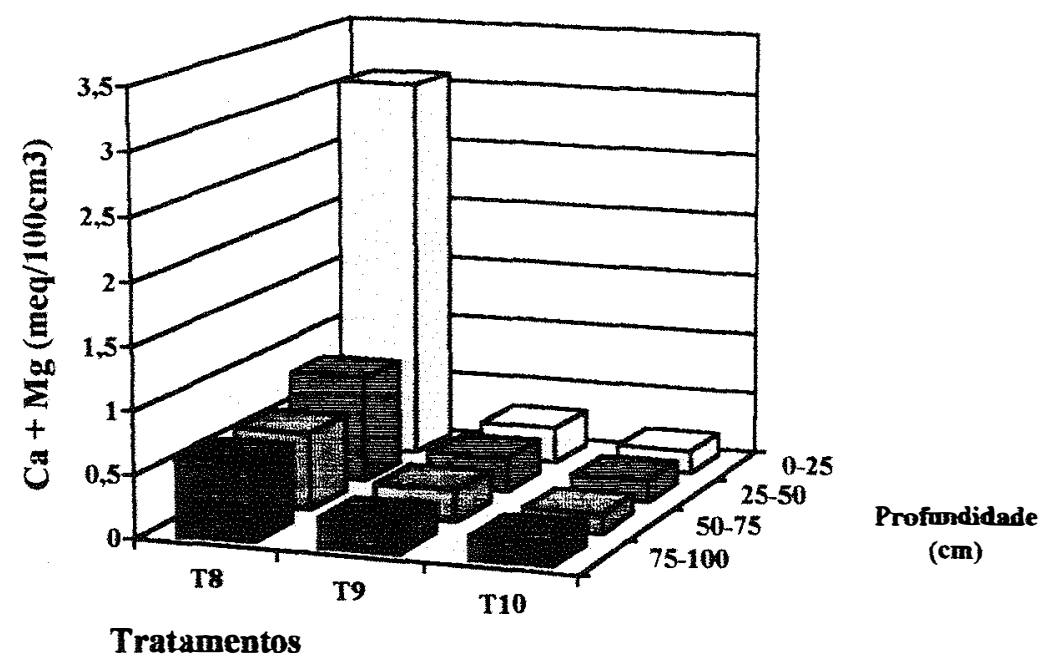

Legenda : T $8=$ magnesita $(15 \%)+$ gesso $(85 \%) ; \mathrm{T} 9=$ gesso; $\mathrm{T} 10=$ testemunha

Figura 1. Teores de $\mathrm{Ca}^{2+}+\mathrm{Mg}^{2+}\left(\mathrm{meq} / 100 \mathrm{~cm}^{3}\right)$ na entrelinha da cana-de-açúcar, ao longo do perfil do solo, após a colheita da segunda soca, na testemunha e nos tratamentos com gesso e gesso em mistura com magnesita.

\subsection{6. $\mathrm{S}-\mathrm{SO}_{4}{ }^{2-}$}

Maiores teores de $\mathrm{S}-\mathrm{SO}_{4}{ }^{2-}$ foram determinados aos 6 meses após a aplicação dos produtos, tanto na linha quanto na entrelinha da cana-de-açúcar, até os 50 
cm de profundidade; as diferenças mais marcantes foram notadas especialmente nos tratamentos que receberam gesso, isoladamente ou em mistura com calcário calcítico e com magnesita, com destaque para este último tratamento. Em todas as profundidades de solo amostradas, tanto na linha quanto na entrelinha da cana-de-açúcar, ao longo do tempo (em todas as avaliações efetuadas), invariavelmente, houve acentuada diferença em favor da mistura de magnesita com gesso, que apresentou altos valores de $\mathrm{S}-\mathrm{SO}_{4}{ }^{2-}$, significativamente diferentes de todos os outros tratamentos, como pode ser observado nas Tabelas 25 a 28.

Tabela 25. Resultados de análise do solo para S - $\mathrm{SO}_{4}{ }^{2-}\left(\mu \mathrm{g} / \mathrm{cm}^{3}\right)$ aos 6 meses após a aplicação dos produtos, na linha e na entrelinha, ao longo do perfil do solo; dados médios de 5 repetições.

\begin{tabular}{|c|cc|cc|cc|cc|}
\hline TRATA & \multicolumn{2}{|c|}{$\mathbf{0}-\mathbf{2 5} \mathbf{~ c m}$} & \multicolumn{2}{c|}{$25-\mathbf{5 0} \mathbf{~ c m}$} & \multicolumn{2}{c|}{$\mathbf{5 0}-\mathbf{7 5} \mathbf{c m}$} & \multicolumn{2}{c|}{$\mathbf{7 5}-\mathbf{1 0 0} \mathbf{~ c m}$} \\
\cline { 2 - 9 } MENTO & $\mathbf{L}$ & $\mathbf{E L}$ & $\mathbf{L}$ & $\mathbf{E L}$ & $\mathbf{L}$ & $\mathbf{E L}$ & $\mathbf{L}$ & $\mathbf{E L}$ \\
\hline T 1 & $12 b$ & $13 d$ & $17 b c$ & $14 c$ & $17 b$ & $7 b$ & $12 b$ & $7 b$ \\
T 2 & $15 b$ & $13 d$ & $20 b c$ & $10 c$ & $18 b$ & $6 b$ & $12 b$ & $7 b$ \\
T 3 & $18 b$ & $59 c$ & $33 b c$ & $24 c$ & $35 b$ & $9 b$ & $22 b$ & $8 b$ \\
T 4 & $14 b$ & $17 c d$ & $14 b c$ & $12 c$ & $20 b$ & $6 b$ & $14 b$ & $6 b$ \\
T 5 & $12 b$ & $14 d$ & $12 c$ & $13 c$ & $19 b$ & $6 b$ & $17 b$ & $7 b$ \\
T 6 & $10 b$ & $13 d$ & $14 b c$ & $16 c$ & $19 b$ & $7 b$ & $12 b$ & $9 b$ \\
T 7 & $14 b$ & $15 d$ & $18 b c$ & $21 c$ & $20 b$ & $6 b$ & $11 b$ & $7 b$ \\
T 8 & $81 a$ & $234 a$ & $74 a$ & $152 a$ & $84 a$ & $38 a$ & $70 a$ & $23 a$ \\
T 9 & $44 b$ & $153 b$ & $34 b$ & $52 b$ & $33 b$ & $14 b$ & $18 b$ & $11 b$ \\
T 10 & $18 b$ & $18 c d$ & $16 b c$ & $13 c$ & $17 b$ & $5 b$ & $14 b$ & $8 b$ \\
\hline F & $7,50 * *$ & $55,3^{* *}$ & $13,7^{* *}$ & $60,5^{* *}$ & $16,9 * *$ & $8,80^{* *}$ & $15,2^{* *}$ & $10,0 * *$ \\
dms & 35 & 44 & 22 & 24 & 21 & 14 & 19 & 6 \\
CV(\%) & 74,8 & 41,7 & 44,2 & 37,8 & 38,4 & 70,8 & 49,8 & 36,6 \\
\hline
\end{tabular}

LEGENDA :

$\mathrm{T} 1$ = calc. calcítico

T 6 = magnesita $(25 \%)+$ calc.calcítico $(75 \%)$

T 2 = calc. magnesiano

T 7 = magnesita $(15 \%)+$ calc.calcítico $(85 \%)$

T 3 = calc.dolomítico $1(70 \%)+$ gesso

T 4 = calc. dolomítico 2

T 8 = magnesita $(15 \%)+$ gesso $(85 \%)$

T 5 = magnesita

$\mathrm{T} 9=$ gesso

T $10=$ testemunha

Médias seguidas da mesma letra, na vertical, não diferem entre si (Tukey a 10\%). 
Em todo o perfil do solo detectou-se teores acentuadamente maiores de $\mathrm{S}^{-\mathrm{SO}_{4}}{ }^{2-}$ no tratamento que recebeu a mistura de gesso com magnesita; este fato aconteceu tanto na linha quanto na entrelinha, alcançando valores ainda maiores nas colheitas das primeira e segunda soqueiras.

Estes dados confirmam os obtidos por VITTI et al. (1993), pois também demonstram a movimentação do sulfato através do perfil do solo e comprovam a capacidade do gesso de aumentar os teores de sulfato em camadas mais profundas do perfil de solo, melhorando o ambiente radicular, ao longo do tempo.

Tabela 26. Resultados da análise de solo para $\mathrm{S}-\mathrm{SO}_{4}{ }^{2-}\left(\mu \mathrm{g} / \mathrm{cm}^{3}\right)$ na colheita da cana planta, na linha e na entrelinha, ao longo do perfil do solo; dados médios de 5 repetições.

\begin{tabular}{|c|cc|cc|cc|cc|}
\hline TRATA & \multicolumn{2}{|c|}{$\mathbf{0}-\mathbf{2 5} \mathbf{~ c m}$} & \multicolumn{2}{c|}{$25-\mathbf{5 0} \mathbf{c m}$} & \multicolumn{2}{c|}{$\mathbf{5 0}-\mathbf{7 5} \mathbf{~ c m}$} & \multicolumn{2}{|c|}{$\mathbf{7 5}-\mathbf{1 0 0} \mathbf{c m}$} \\
\cline { 2 - 9 } MENTO & $\mathbf{L}$ & $\mathbf{E L}$ & $\mathbf{L}$ & $\mathbf{E L}$ & $\mathbf{L}$ & $\mathbf{E L}$ & $\mathbf{L}$ & $\mathbf{E L}$ \\
\hline T 1 & $15 c$ & $12 b$ & $18 c d$ & $11 c$ & $26 b c d$ & $13 b$ & $17 b c d$ & $12 b$ \\
T 2 & $15 c$ & $17 b$ & $19 b c d$ & $14 c$ & $24 c d$ & $14 b$ & $14 d e$ & $12 b$ \\
T 3 & $20 b c$ & $35 b$ & $25 b c$ & $37 b$ & $33 b$ & $24 b$ & $26 b$ & $18 b$ \\
T 4 & $14 c$ & $11 b$ & $18 c d$ & $11 c$ & $26 b c d$ & $14 b$ & $17 b c d$ & $12 b$ \\
T 5 & $17 c$ & $9 b$ & $14 d$ & $12 c$ & $22 d$ & $11 b$ & $17 b c d$ & $15 b$ \\
T 6 & $14 c$ & $9 b$ & $14 d$ & $13 c$ & $24 c d$ & $9 b$ & $16 c d e$ & $13 b$ \\
T 7 & $21 b c$ & $21 b$ & $18 c d$ & $11 c$ & $25 c d$ & $9 b$ & $7 e$ & $10 b$ \\
T 8 & $35 a$ & $145 a$ & $37 a$ & $121 a$ & $49 a$ & $71 a$ & $45 a$ & $85 a$ \\
T 9 & $30 a b$ & $126 a$ & $29 a b$ & $56 b$ & $31 b c$ & $24 b$ & $25 b c$ & $17 b$ \\
T 10 & $22 b c$ & $22 b$ & $21 b c d$ & $16 c$ & $25 c d$ & $15 b$ & $16 c d e$ & $14 b$ \\
\hline F & $5,50 * *$ & $12,9 * *$ & $7,51 * *$ & $56,9 * *$ & $15,6 * *$ & $5,17 * *$ & $18,6 * *$ & $40,3 * *$ \\
dms & 13 & 61 & 11 & 20 & 8 & 35 & 10 & 15 \\
CV(\%) & 32,3 & 76,9 & 26,2 & 34,1 & 15,3 & 87,7 & 25,7 & 37,3 \\
\hline
\end{tabular}

\section{LEGENDA :}

$\mathrm{T} 1$ = calc. calcítico

T 2 = calc.magnesiano

T $6=$ magnesita $(25 \%)+$ calc.calcítico $(75 \%)$

T 3 = calc. dolomítico $1(70 \%)+$ gesso

T $4=$ calc. dolomítico 2

T 7 = magnesita $(15 \%)+$ calc.calcítico $(85 \%)$

T $5=$ magnesita

T $8=$ magnesita $(15 \%)+$ gesso $(85 \%)$

$\mathrm{T} 9=$ gesso

$\mathrm{T} 10=$ testemunha

Médias seguidas da mesma letra, na vertical, não diferem entre si (Tukey a 10\%). 
Tabela 27. Resultados da análise de solo para $\mathrm{S}-\mathrm{SO}_{4}{ }^{2-}\left(\mu \mathrm{g} / \mathrm{cm}^{3}\right)$ na colheita da primeira soca, na linha e na entrelinha, ao longo do perfil do solo; dados médios de 5 repetições.

\begin{tabular}{|c|cc|cc|cc|cc|}
\hline TRATA & \multicolumn{2}{|c|}{$\mathbf{0}-\mathbf{2 5} \mathbf{~ c m}$} & \multicolumn{2}{|c|}{$\mathbf{2 5}-\mathbf{5 0} \mathbf{~ c m}$} & \multicolumn{2}{c|}{$\mathbf{5 0}-\mathbf{7 5} \mathbf{~ c m}$} & \multicolumn{2}{c|}{$\mathbf{7 5}-\mathbf{1 0 0} \mathbf{~ c m}$} \\
\cline { 2 - 9 } MENTO & $\mathbf{L}$ & $\mathbf{E L}$ & $\mathbf{L}$ & $\mathbf{E L}$ & $\mathbf{L}$ & $\mathbf{E L}$ & $\mathbf{L}$ & $\mathbf{E L}$ \\
\hline T 1 & $6 b$ & $3 b$ & $7 a b$ & $4 c$ & $7 b$ & $6 c d$ & $12 b c d$ & $4 c$ \\
T 2 & $3 b$ & $4 b$ & $3 b$ & $4 c$ & $6 b$ & $4 d$ & $7 c d$ & $3 c$ \\
T 3 & $4 b$ & $6 b$ & $5 b$ & $13 c$ & $11 b$ & $17 c$ & $15 b c$ & $16 c$ \\
T 4 & $4 b$ & $4 b$ & $5 b$ & $5 c$ & $7 b$ & $4 d$ & $8 b c d$ & $3 c$ \\
T 5 & $3 b$ & $3 b$ & $6 a b$ & $4 c$ & $8 b$ & $7 c d$ & $12 b c d$ & $5 c$ \\
T 6 & $4 b$ & $3 b$ & $3 b$ & $4 c$ & $6 b$ & $8 c d$ & $8 b c d$ & $4 c$ \\
T 7 & $4 b$ & $3 b$ & $5 b$ & $4 c$ & $8 b$ & $5 d$ & $6 c d$ & $3 c$ \\
T 8 & $22 a$ & $29 a$ & $8 a b$ & $36 a$ & $17 a$ & $50 a$ & $31 a$ & $69 a$ \\
T 9 & $8 b$ & $32 a$ & $11 a$ & $25 b$ & $17 a$ & $36 b$ & $18 b$ & $34 b$ \\
T 10 & $4 b$ & $3 b$ & $5 a b$ & $4 c$ & $8 b$ & $3 d$ & $4 d$ & $3 c$ \\
\hline F & $2,84^{*}$ & $17,4^{* *}$ & $2,56^{*}$ & $17,6^{* *}$ & $6,87^{* *}$ & $33,1^{* *}$ & $8,34^{* *}$ & $38,8 * *$ \\
dms & 14 & 11 & 6 & 11 & 6 & 12 & 11 & 15 \\
CV(\%) & 94,1 & 65,0 & 52,9 & 56,6 & 35,5 & 43,8 & 48,3 & 52,7 \\
\hline
\end{tabular}

LEGENDA :

$\mathrm{T} 1$ = calc.calcítico

T 6 = magnesita $(25 \%)+$ calc.calcítico $(75 \%)$

$\mathrm{T} 2$ = calc.magnesiano

$\mathrm{T} 7$ = magnesita $(15 \%)+$ calc.calcítico $(85 \%)$

T 3 = calc.dolomítico $1(70 \%)+$ gesso $\quad$ T $8=$ magnesita $(15 \%)+$ gesso $(85 \%)$

T 4 = calc. dolomítico 2

$\mathrm{T} 9=$ gesso

T $5=$ magnesita

$\mathrm{T} 10=$ testemunha

Médias seguidas da mesma letra, na vertical, não diferem entre si (Tukey a 10\%).

Devem ser salientados os resultados obtidos com as aplicações do gesso agricola e de sua mistura com a magnesita, que mantiveram altos teores de $\mathrm{S}_{-} \mathrm{SO}_{4}{ }^{2-}$ em subsuperficie e ao longo do tempo. 
Tabela 28. Resultados da análise de solo para S - $\mathrm{SO}_{4}{ }^{2-}\left(\mu \mathrm{g} / \mathrm{cm}^{3}\right)$ na colheita da segunda soca, na linha e na entrelinha, ao longo do perfil do solo; dados médios de 5 repetições.

\begin{tabular}{|c|cc|cc|cc|cc|}
\hline TRATA & \multicolumn{2}{|c|}{$\mathbf{0}-\mathbf{2 5} \mathbf{~ c m}$} & \multicolumn{2}{|c|}{$\mathbf{2 5}-\mathbf{5 0} \mathbf{~ c m}$} & \multicolumn{2}{c|}{$\mathbf{5 0}-\mathbf{7 5} \mathbf{~ c m}$} & \multicolumn{2}{|c|}{$\mathbf{7 5 - 1 0 0 ~} \mathbf{~ c m}$} \\
\cline { 2 - 8 } MENTO & $\mathbf{L}$ & $\mathbf{E L}$ & $\mathbf{L}$ & $\mathbf{E L}$ & $\mathbf{L}$ & $\mathbf{E L}$ & $\mathbf{L}$ & $\mathbf{E L}$ \\
\hline T 1 & $5 b$ & $4 b$ & $3 b$ & $6 b c$ & $8 c$ & $4 c$ & $9 c d$ & $14 b c d$ \\
T 2 & $4 b$ & $3 b$ & $4 b$ & $3 c$ & $6 c$ & $5 c$ & $4 d$ & $5 d$ \\
T 3 & $7 b$ & $4 b$ & $7 b$ & $7 b c$ & $14 b c$ & $20 b c$ & $18 b c$ & $25 b c$ \\
T 4 & $4 b$ & $3 b$ & $5 b$ & $3 c$ & $6 c$ & $9 b c$ & $8 c d$ & $7 c d$ \\
T 5 & $5 b$ & $4 b$ & $4 b$ & $4 c$ & $8 c$ & $6 c$ & $12 b c d$ & $11 b c d$ \\
T 6 & $4 b$ & $4 b$ & $4 b$ & $4 c$ & $6 c$ & $5 c$ & $6 c d$ & $10 b c d$ \\
T 7 & $5 b$ & $4 b$ & $4 b$ & $3 c$ & $6 c$ & $4 c$ & $7 c d$ & $9 c d$ \\
T 8 & $29 a$ & $44 a$ & $18 a$ & $20 a$ & $31 a$ & $41 a$ & $40 a$ & $55 a$ \\
T 9 & $12 a b$ & $8 a b$ & $17 a$ & $14 a b$ & $25 a b$ & $24 b$ & $24 b$ & $28 b$ \\
T 10 & $7 b$ & $6 b$ & $7 b$ & $5 c$ & $7 c$ & $4 c$ & $8 c d$ & $4 d$ \\
\hline F & $2,63 *$ & $1,87^{+}$ & $8,29 * *$ & $7,13^{* *}$ & $8,81^{* *}$ & $9,74^{* *}$ & $11,1^{* *}$ & $12,5 * *$ \\
dms & 21 & 37 & 8 & 9 & 13 & 17 & 14 & 19 \\
CV(\%) & 97,6 & 92,5 & 53,9 & 64,4 & 56,1 & 70,1 & 52,8 & 57,8 \\
\hline
\end{tabular}

LEGENDA :

T 1 = calc. calcítico

T 2 = calc. magnesiano

T 3 = calc.dolomítico $1(70 \%)+$ gesso

T 4 = calc. dolomítico 2

T $5=$ magnesita

T 6 = magnesita $(25 \%)+$ calc. calcítico $(75 \%)$

$\mathrm{T} 7=$ magnesita $(15 \%)+$ calc.calcítico $(85 \%)$

T 8 = magnesita $(15 \%)+$ gesso $(85 \%)$

$\mathrm{T} 9=$ gesso

$\mathrm{T} 10=$ testemunha

Médias seguidas da mesma letra, na vertical, não diferem entre si (Tukey a 10\%).

Os teores de $\mathrm{S}_{-} \mathrm{SO}_{4}{ }^{2-}$ no tratamento que recebeu a mistura de magnesita e gesso mantiveram-se, também nesta última época de avaliação, muito superiores aos demais tratamentos, como pode ser observado na Figura 2, que compara os teores de S$\mathrm{SO}_{4}{ }^{2-}$ encontrados na testemunha e nos tratamentos que receberam gesso, gesso em mistura com magnesita e com calcário dolomítico e magnesita em mistura com calcário calcítico (a 85\%), das amostras retiradas na entrelinha da cana-de-açúcar. 


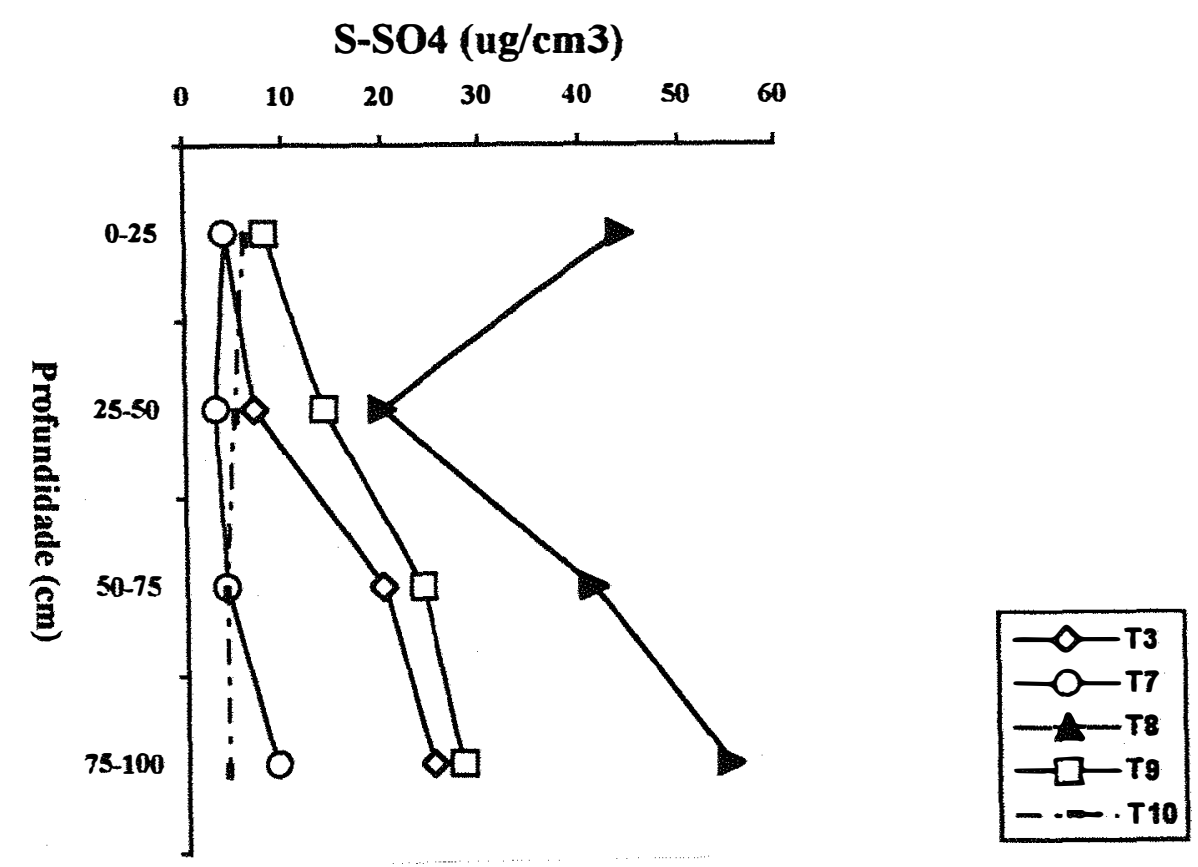

Figura 2. Teores de $\mathrm{S}-\mathrm{SO}_{4}{ }^{2-}\left(\mu \mathrm{g} / \mathrm{cm}^{3}\right)$ na entrelinha da cana-de-açúcar, ao longo do perfil do solo, após a colheita da segunda soca na testemunha e nos tratamentos que receberam gesso, gesso em mistura com magnesita e com calcário dolomítico e magnesita em mistura com calcário calcítico (a 85\%).

Ainda com referência ao enxofre, é importante salientar que os teores deste macronutriente mantiveram-se nos teores aproximados de $50 \mu \mathrm{g}$ de $\mathrm{S}-\mathrm{SO}_{4}{ }^{2-} / \mathrm{cm}^{3}$ de solo, ao longo do perfil do solo, até 1 metro de profundidade, na avaliação realizada após a colheita da segunda soca, no tratamento que recebeu a mistura de gesso com magnesita. Estes teores são considerados adequados por VITTI et al. (1988a) para a cultura da cana-de-açúcar e foram os maiores teores encontrados para o elemento em 
questão, nesta profundidade e época de avaliação, quando se compara todos os tratamentos estudados. $\mathrm{O}$ comportamento do $\mathrm{S}^{-\mathrm{SO}_{4}}{ }^{2-}$ neste tratamento, durante $\mathrm{o}$ decorrer do tempo e ao longo do perfil do solo, das amostras retiradas na entrelinha da cultura, pode ser melhor visualizado na Figura 3.
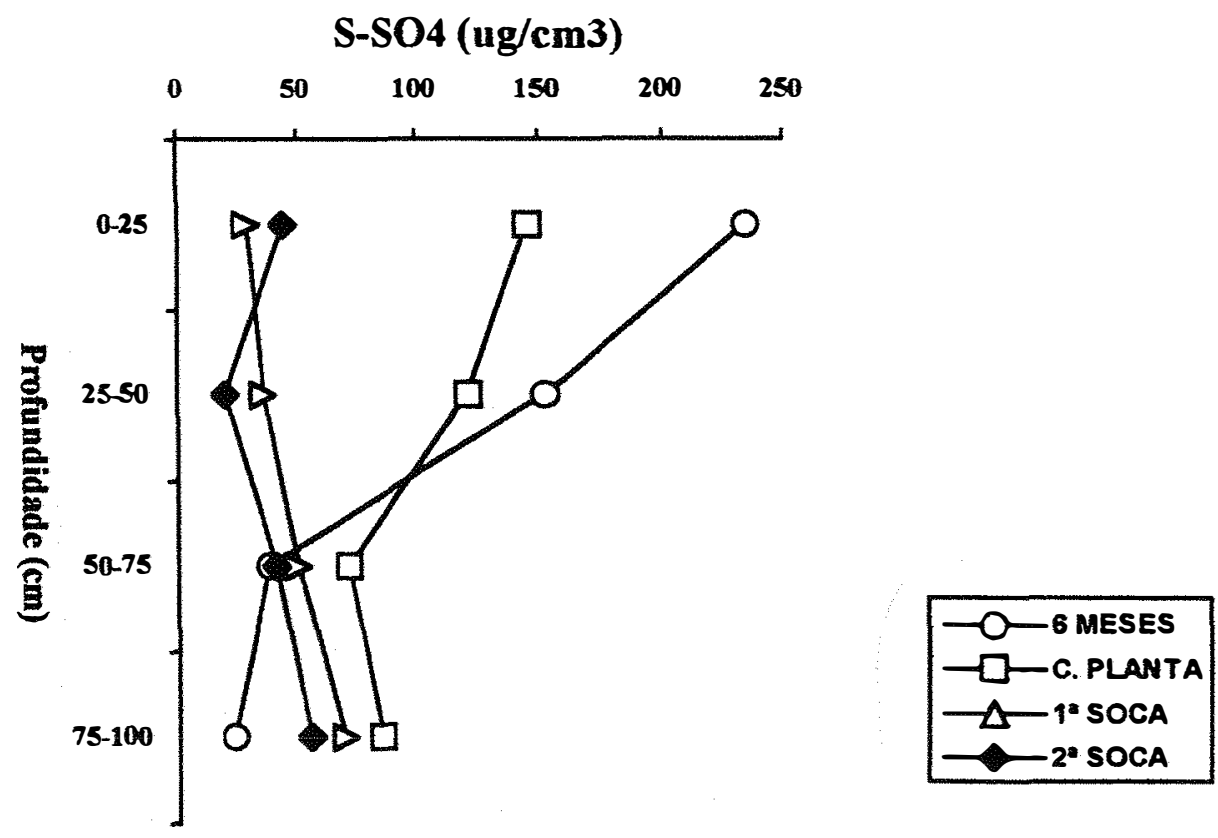

Figura 3. Teores de $\mathrm{S}_{-} \mathrm{SO}_{4}{ }^{2-}\left(\mu \mathrm{g} / \mathrm{cm}^{3}\right)$ na entrelinha da cana-de-açúcar, ao longo do perfil do solo, aos 6 meses após a aplicação da mistura de gesso com magnesita e após as colheitas da cana planta e das duas primeiras socas.

\subsection{7. $\mathrm{Al}^{3+}$}

$\mathrm{O}$ comportamento do $\mathrm{Al}^{3+}$ no perfil do solo pode ser observado pela análise dos dados indicados nas Tabelas 29 a 32. Níveis considerados tóxicos para a 
cana-de-açúcar - maiores que $0,5 \mathrm{meq} / 100 \mathrm{~cm}^{3}$ de solo, segundo ESPIRONELLO \& OLIVEIRA (1972) - foram detectados em subsuperficie, comprovando a ineficiência dos diversos tipos de calcário em atuar em profundidade; na camada arável, todos os produtos, com exceção do gesso, corrigiram este nível tóxico, tanto na linha quanto na entrelinha da cana-de-açúcar.

Tabela 29. Resultados de análises de solo para $\mathrm{Al}^{3+}\left(\mathrm{meq} / 100 \mathrm{~cm}^{3}\right)$ aos 6 meses após a aplicação dos produtos, na linha e na entrelinha, ao longo do perfil do solo; dados médios de 5 repetições.

\begin{tabular}{|c|cc|cc|cc|cc|}
\hline TRATA & \multicolumn{2}{|c|}{$\mathbf{0}-\mathbf{2 5} \mathbf{~ c m}$} & \multicolumn{2}{c|}{$\mathbf{2 5}-\mathbf{5 0} \mathbf{~ c m}$} & \multicolumn{2}{c|}{$\mathbf{5 0}-\mathbf{7 5} \mathbf{~ c m}$} & \multicolumn{2}{c|}{$\mathbf{7 5}-\mathbf{1 0 0} \mathbf{~ c m}$} \\
\cline { 2 - 9 } MENTO & $\mathbf{L}$ & $\mathbf{E L}$ & $\mathbf{L}$ & $\mathbf{E L}$ & $\mathbf{L}$ & $\mathbf{E L}$ & $\mathbf{L}$ & $\mathbf{E L}$ \\
\hline T 1 & $0,20 b c$ & $0,24 b$ & $0,80 a b c$ & $0,88 a b c$ & $0,76 b$ & 0,78 & 0,92 & 0,70 \\
T 2 & $0,32 b c$ & $0,14 b$ & $0,84 a b c$ & $0,82 a b c d$ & $0,92 a b$ & 0,72 & 0,88 & 0,62 \\
T 3 & $0,22 b c$ & $0,40 b$ & $0,90 a b$ & $0,94 a b$ & $0,96 a b$ & 0,60 & 0,84 & 0,72 \\
T 4 & $0,20 b c$ & $0,00 b$ & $0,74 a b c$ & $0,54 d$ & $0,98 a b$ & 0,58 & 0,88 & 0,58 \\
T 5 & $0,20 b c$ & $0,02 b$ & $0,54 c$ & $0,68 b c d$ & $0,78 a b$ & 0,70 & 0,80 & 0,66 \\
T 6 & $0,04 c$ & $0,12 b$ & $0,50 c$ & $0,70 b c d$ & $0,74 b$ & 0,64 & 0,88 & 0,66 \\
T 7 & $0,40 b$ & $0,24 b$ & $1,00 a b$ & $0,80 a b c d$ & $1,02 a b$ & 0,68 & 0,82 & 0,66 \\
T 8 & $0,22 b c$ & $0,00 b$ & $0,72 b c$ & $0,62 c d$ & $1,06 a$ & 0,70 & 0,84 & 0,66 \\
T 9 & $1,12 a$ & $0,98 a$ & $1,04 a b$ & $1,02 a$ & $0,94 a b$ & 0,80 & 0,94 & 0,72 \\
T 10 & $1,26 a$ & $1,16 a$ & $1,08 a$ & $1,04 a$ & $1,06 a$ & 0,70 & 0,82 & 0,76 \\
\hline F & $26,5 * *$ & $19,0 * *$ & $5,62 * *$ & $6,29 * *$ & $2,98 * *$ & 1,18 & 1,35 & 1,50 \\
dms & 0,35 & 0,41 & 0,36 & 0,29 & 0,30 & 0,28 & 0,17 & 0,18 \\
CV (\%) & 43,4 & 64,0 & 22,8 & 18,7 & 17,0 & 20,8 & 10,1 & 14,2 \\
\hline
\end{tabular}

LEGENDA :

T 1 = calc.calcítico

T 2 = calc.magnesiano

T 3 = calc.dolomítico $1(70 \%)+$ gesso

T $4=$ calc. dolomítico 2

T 5 = magnesita

Módias seguidas da mesma letra, na vertical, não diferem entre si (Tukey a 10\%).

$\mathrm{Na}$ camada arável, esta tendência já começou a se manifestar aos 6 meses após a aplicação dos produtos; a partir dos $25 \mathrm{~cm}$ de profundidade, nesta época de avaliação, nenhum dos tratamentos estudados foi capaz de corrigir o $\mathrm{Al}^{3+}$ tóxico do solo, 
o mesmo acontecendo na colheita da cana planta, concordando com os resultados obtidos por NASCIMENTO et al. (1983). Tais resultados podem ser explicados, muito provavelmente, pela ausência de chuvas ocorrida no período analisado.

Uma vez que os produtos foram incorporados até $40 \mathrm{~cm}$ e imediatamente antes do plantio, somente a partir da colheita da primeira soca, com melhor distribuição de chuvas, é que se pôde notar maior influência dos diversos tipos de calcário, da magnesita e das misturas estudadas nos níveis de $\mathrm{Al}^{3+}$, em maiores profundidades no perfil do solo, até a camada $25-50 \mathrm{~cm}$.

Tabela 30. Resultados de análises de solo para $\mathrm{Al}^{3+}\left(\mathrm{meq} / 100 \mathrm{~cm}^{3}\right)$ na colheita da cana planta, na linha e na entrelinha, ao longo do perfil do solo; dados médios de 5 repetições.

\begin{tabular}{|c|cc|cc|cc|cc|}
\hline TRATA & \multicolumn{2}{c}{$\mathbf{0}-\mathbf{2 5} \mathbf{c m}$} & \multicolumn{2}{c|}{$\mathbf{2 5}-\mathbf{5 0} \mathbf{~ c m}$} & \multicolumn{2}{c|}{$\mathbf{5 0}-\mathbf{7 5} \mathbf{~ c m}$} & \multicolumn{2}{c|}{$\mathbf{7 5}-\mathbf{1 0 0} \mathbf{~ c m}$} \\
\cline { 2 - 9 } MENTO & $\mathbf{L}$ & $\mathbf{E L}$ & $\mathbf{L}$ & $\mathbf{E L}$ & $\mathbf{L}$ & $\mathbf{E L}$ & $\mathbf{L}$ & $\mathbf{E L}$ \\
\hline T 1 & $0,28 b$ & $0,32 b$ & 0,54 & 0,74 & $1,02 a b c$ & 0,74 & $1,08 a b$ & 0,70 \\
T 2 & $0,40 b$ & $0,16 b$ & 0,64 & 0,82 & $1,00 a b c$ & 0,78 & $0,96 a b$ & 0,66 \\
T 3 & $0,26 b$ & $0,40 b$ & 0,66 & 0,96 & $1,04 a b c$ & 0,78 & $1,06 a b$ & 0,82 \\
T 4 & $0,26 b$ & $0,18 b$ & 0,68 & 0,74 & $1,06 a b c$ & 0,86 & $1,10 a$ & 0,84 \\
T 5 & $0,34 b$ & $0,12 b$ & 0,54 & 0,58 & $0,84 c$ & 0,78 & $1,04 a b$ & 0,78 \\
T 6 & $0,28 b$ & $0,36 b$ & 0,54 & 0,94 & $0,92 a b c$ & 0,74 & $1,06 a b$ & 0,82 \\
T 7 & $0,30 b$ & $0,20 b$ & 0,70 & 0,80 & $0,98 a b c$ & 0,84 & $0,96 a b$ & 0,66 \\
T 8 & $0,26 b$ & $0,14 b$ & 0,66 & 0,62 & $0,86 b c$ & 0,76 & $1,04 a b$ & 0,66 \\
T 9 & $1,00 a$ & $0,88 a$ & 0,90 & 0,92 & $1,08 a b$ & 0,88 & $1,02 a b$ & 0,78 \\
T 10 & $0,96 a$ & $0,86 a$ & 0,92 & 0,90 & $1,10 a$ & 0,88 & $0,92 b$ & 0,78 \\
\hline F & $27,9 * *$ & $11,5 * *$ & 2,15 & 2,28 & $2,71 *$ & 0,92 & $2,07 *$ & 2,01 \\
dms & 0,23 & 0,36 & 0,40 & 0,38 & 0,23 & 0,25 & 0,17 & 0,22 \\
CV (\%) & 28,3 & 62,4 & 30,6 & 24,2 & 12,3 & 16,0 & $\mathbf{8 , 8}$ & 15,2 \\
\hline
\end{tabular}

\section{LEGENDA :}

$\mathrm{T} 1=$ calc.calcítico

$\mathrm{T} 2$ = calc.magnesiano

T 3 = calc.dolomítico $1(70 \%)+$ gesso

T 4 = calc. dolomítico 2

T 5 = magnesita
T 6 = magnesita $(25 \%)+$ calc.calcítico $(75 \%)$

T $7=$ magnesita $(15 \%)+$ calc.calcítico $(85 \%)$

T $8=$ magnesita $(15 \%)+$ gesso $(85 \%)$

$\mathrm{T} 9=$ gesso

$\mathrm{T} 10=$ testemunha

Médias seguidas da mesma letra, na vertical, não diferem entre si (Tukey a 10\%). 
Em todas as épocas analisadas, na camada arável, na linha e na entrelinha da cana-de-açúcar, todos os tratamentos, com exceção do gesso aplicado isoladamente, que se igualou estatisticamente à testemunha, apresentaram menores teores de $\mathrm{Al}^{3+}$. Por sua vez, os teores encontrados nas camadas mais profundas (pelo menos até os $50 \mathrm{~cm}$ de profundidade), em todos os tratamentos, com exceção novamente do gesso agrícola aplicado isolado e da testemunha, se mantiveram baixos, inferiores ao limite considerado tóxico à cana-de-açúcar, na época das colheitas das primeira e segunda socas.

Tabela 31. Resultados de análises de solo para $\mathrm{Al}^{3+}\left(\mathrm{meq} / 100 \mathrm{~cm}^{3}\right)$ na colheita da primeira soca, na linha e na entrelinha, ao longo do perfil do solo; dados médios de 5 repetições.

\begin{tabular}{|c|c|c|c|c|c|c|c|c|}
\hline \multirow{2}{*}{$\begin{array}{l}\text { TRATA } \\
\text { MENTO }\end{array}$} & \multicolumn{2}{|c|}{$0-25 \mathrm{~cm}$} & \multicolumn{2}{|c|}{$25-50 \mathrm{~cm}$} & \multicolumn{2}{|c|}{$50-75 \mathrm{~cm}$} & \multicolumn{2}{|c|}{$75-100 \mathrm{~cm}$} \\
\hline & $\mathbf{L}$ & EL & $\mathbf{L}$ & $\mathbf{E L}$ & $\mathbf{L}$ & $\mathbf{E L}$ & $\mathbf{L}$ & EL \\
\hline T 1 & $0,14 b$ & $0,18 b$ & $0,26 b c$ & $0,28 a b c$ & $0,27 c$ & 0,28 & $0,31 a b$ & 0,27 \\
\hline T 2 & $0,14 b$ & $0,20 b$ & $0,30 b c$ & $0,24 b c$ & $0,25 c$ & 0,41 & $0,25 a b$ & 0,24 \\
\hline T 3 & $0,15 b$ & $0,12 b$ & $0,20 c$ & $0,32 a b c$ & $0,23 c$ & 0,33 & $0,24 a b$ & 0,29 \\
\hline T 4 & $0,13 b$ & $0,14 b$ & $0,21 b c$ & $0,24 b c$ & $0,30 b c$ & 0,30 & $0,25 a b$ & 0,25 \\
\hline T 5 & $0,18 b$ & $0,11 b$ & $0,20 c$ & $0,15 c$ & $0,26 c$ & 0,24 & $0,27 a b$ & 0,25 \\
\hline T 6 & $0,13 b$ & $0,10 b$ & $0,15 c$ & $0,18 c$ & $0,14 d$ & 0,26 & $0,23 a b$ & 0,29 \\
\hline $\mathbf{T} 7$ & $0,17 b$ & $0,21 b$ & $0,22 b c$ & $0,26 a b c$ & $0,26 c$ & 0,27 & $0,33 a$ & 0,28 \\
\hline T 8 & $0,11 b$ & $0,08 b$ & $0,14 c$ & $0,21 b c$ & $0,14 d$ & 0,24 & $0,20 b$ & 0,28 \\
\hline T 9 & $0,53 a$ & $0,51 a$ & $0,40 a b$ & $0,39 a b$ & $0,36 a b$ & 0,35 & $0,30 a b$ & 0,28 \\
\hline T 10 & $0,54 a$ & $0,57 a$ & $0,50 a$ & $0,44 a$ & $0,40 a$ & 0,34 & $0,30 a b$ & 0,31 \\
\hline $\mathbf{F}$ & $13,3^{* *}$ & $17,3^{* *}$ & $5,71^{* *}$ & $3,64 * *$ & $13,5^{* *}$ & 0,90 & $1,91^{+}$ & 0,81 \\
\hline dms & 0,19 & 0,18 & 0,20 & 0,20 & 0,09 & 0,24 & 0,12 & 0,09 \\
\hline CV (\%) & 44,8 & 41,3 & 40,6 & 39,0 & 18,5 & 41,5 & 23,4 & 17,4 \\
\hline \multicolumn{9}{|c|}{ LEGENDA } \\
\hline \multirow{2}{*}{\multicolumn{4}{|c|}{$\begin{array}{l}\text { T } 1=\text { calc.calcítico } \\
\text { T } 2 \text { = calc.magnesiano }\end{array}$}} & \multicolumn{5}{|c|}{$\mathrm{T} 6=$ magnesita $(25 \%)+$ calc.calcítico $(75 \%)$} \\
\hline & & & & \\
\hline \multicolumn{4}{|c|}{ T 3 = calc dolomítico $1(70 \%)+$ gesso } & \multicolumn{5}{|c|}{$\mathrm{T} 8=$ magnesita $(15 \%)+$ gesso $(85 \%)$} \\
\hline \multicolumn{4}{|c|}{$\mathrm{T} 4=$ calc. dolomítico 2} & \multirow{2}{*}{\multicolumn{5}{|c|}{$\begin{array}{l}\text { T } 9=\text { gesso } \\
\text { T } 10=\text { testemunha }\end{array}$}} \\
\hline \multicolumn{4}{|c|}{ T $5=$ magnesita } & & & & & \\
\hline
\end{tabular}

Médias seguidas da mesma letra, na vertical, não diferem entre si (Tukey a 10\%). 
Porém, por ocasião da colheita da segunda soca, na profundidade de 75 $100 \mathrm{~cm}$, todos os tratamentos apresentaram teores similares deste elemento, tanto na linha quanto na entrelinha da cana-de-açúcar.

Estes resultados são em muito similares aos obtidos por SUZUKI

Tabela 32. Resultados de análises de solo para $\mathrm{Al}^{3+}\left(\mathrm{meq} / 100 \mathrm{~cm}^{3}\right)$ na colheita da segunda soca, na linha e na entrelinha, ao longo do perfil do solo; dados médios de 5 repetições.

\begin{tabular}{|c|cc|cc|cc|cc|}
\hline TRATA & \multicolumn{2}{|c|}{$\mathbf{0}-\mathbf{2 5} \mathbf{~ c m}$} & \multicolumn{2}{|c|}{$\mathbf{2 5}-\mathbf{5 0} \mathbf{~ c m}$} & \multicolumn{2}{|c|}{$\mathbf{5 0}-\mathbf{7 5} \mathbf{~ c m}$} & \multicolumn{2}{|c|}{$\mathbf{7 5}-\mathbf{1 0 0} \mathbf{~ c m}$} \\
\cline { 2 - 9 } MENTO & $\mathbf{L}$ & $\mathbf{E L}$ & $\mathbf{L}$ & $\mathbf{E L}$ & $\mathbf{L}$ & $\mathbf{E L}$ & $\mathbf{L}$ & $\mathbf{E L}$ \\
\hline T 1 & $0,36 b$ & $0,29 b$ & $0,43 a b c$ & $0,44 a b c$ & 0,59 & $0,47 a b$ & 0,56 & 0,47 \\
T 2 & $0,33 b$ & $0,15 b$ & $0,51 a b c$ & $0,27 c d$ & 0,52 & $0,37 b$ & 0,51 & 0,44 \\
T 3 & $0,23 b$ & $0,23 b$ & $0,40 b c$ & $0,36 b c d$ & 0,55 & $0,45 a b$ & 0,54 & 0,47 \\
T 4 & $0,20 b$ & $0,12 b$ & $0,36 c$ & $0,30 c d$ & 0,56 & $0,38 b$ & 0,60 & 0,41 \\
T 5 & $0,29 b$ & $0,22 b$ & $0,40 b c$ & $0,26 c d$ & 0,49 & $0,37 b$ & 0,48 & 0,47 \\
T 6 & $0,23 b$ & $0,25 b$ & $0,32 c$ & $0,38 b c d$ & 0,49 & $0,39 b$ & 0,52 & 0,44 \\
T 7 & $0,24 b$ & $0,30 b$ & $0,38 c$ & $0,40 b c d$ & 0,52 & $0,43 a b$ & 0,56 & 0,44 \\
T 8 & $0,17 b$ & $0,13 b$ & $0,34 c$ & $0,20 d$ & 0,44 & $0,37 b$ & 0,54 & 0,47 \\
T 9 & $0,73 a$ & $0,62 a$ & $0,68 a b$ & $0,53 a b$ & 0,69 & $0,57 a$ & 0,65 & 0,53 \\
T 10 & $0,83 a$ & $0,76 a$ & $0,71 a$ & $0,62 a$ & 0,68 & $0,57 a$ & 065 & 0,53 \\
\hline F & $7,81^{* *}$ & $13,9^{* *}$ & $4,03^{* *}$ & $6,95^{* *}$ & 1,85 & $3,94^{* *}$ & 1,33 & 1,07 \\
dms & 0,35 & 0,24 & 0,29 & 0,21 & 0,26 & 0,16 & 0,21 & 0,15 \\
CV (\%) & 50,5 & 40,9 & 33,6 & 28,7 & 23,9 & 19,6 & 19,1 & 16,7 \\
\hline
\end{tabular}

LEGENDA :

$\mathrm{T} 1$ = calc.calcítico

T 6 = magnesita $(25 \%)+$ calc. calcítico $(75 \%)$

T 2 = calc.magnesiano

T $7=$ magnesita $(15 \%)+$ calc.calcítico $(85 \%)$

T $3=$ calc.dolomítico $1(70 \%)+$ gesso $\quad$ T $8=$ magnesita $(15 \%)+$ gesso $(85 \%)$

T 4 = calc. dolomítico 2

T $9=$ gesso

T $5=$ magnesita

$\mathrm{T} 10=$ testemunha

Médias seguidas da mesma letra, na vertical, não diferem entre si (Tukey a 10\%).

A representação gráfica dos dados de saturação de alumínio - m \% após a colheita da segunda soca, na entrelinha da cana-de-açúcar, na testemunha e nos tratamentos que receberam gesso, gesso em mistura com magnesita e com calcário dolomítico e magnesita em mistura com calcário calcítico (a 85\%) pode ser observada 
na Figura 4. Verificou-se que o calcário dolomítico, em mistura com gesso agrícola e o calcário calcítico, em mistura com magnesita apresentaram saturação de alumínio relativamente baixa, ao redor de $20 \%$, somente na cama arável, elevando-se muito este índice quando se desce no perfil do solo, praticamente igualando-se ao gesso agrícola aplicado isoladamente e à testemunha na camada de 75 a $100 \mathrm{~cm}$. Observou-se também que o único tratamento que apresentou baixos índices de saturação de alumínio, mesmo nas camadas mais profundas, foi o que recebeu a mistura de gesso agrícola com magnesita.

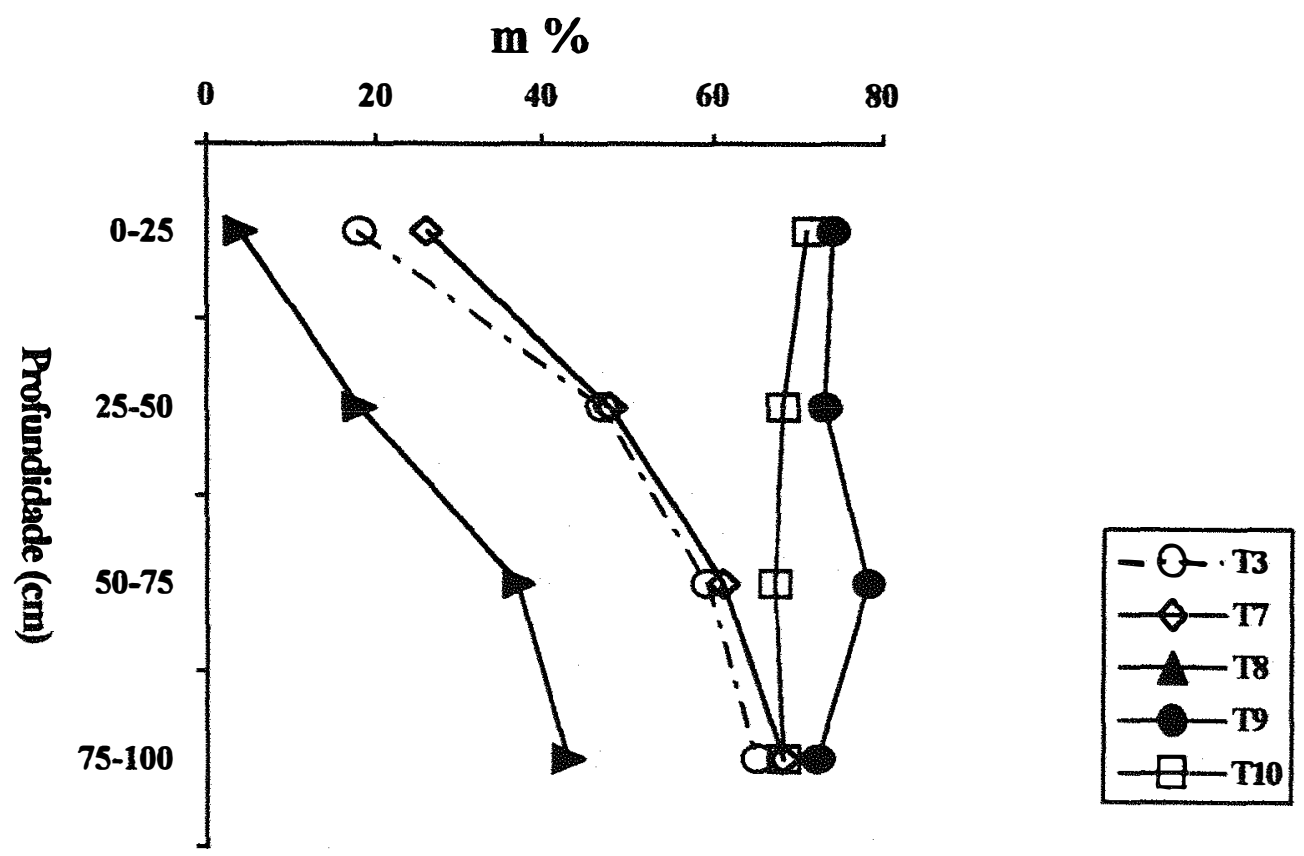

Figura 4. Saturação de alumínio - (m \%) - na entrelinha da cana-de-açúcar, ao longo do perfil do solo, após a colheita da segunda soca, na testemunha e nos tratamentos que receberam gesso, gesso em mistura com magnesita e com calcário dolomítico e magnesita em mistura com calcário calcítico (a 85\%). 


\subsubsection{CTC}

Os valores de CTC obtidos nos diversos tratamentos, épocas e locais amostrados podem ser visualizados nas Tabelas 33 a 36 .

Tabela 33. Resultados de análises de solo para CTC (meq/100 $\mathrm{cm}^{3}$ ) aos 6 meses após a aplicação dos produtos, na linha e na entrelinha, ao longo do perfil do solo; dados médios de 5 repetições.

\begin{tabular}{|c|c|c|c|c|c|c|c|c|}
\hline \multirow{2}{*}{$\begin{array}{l}\text { TRATA } \\
\text { MENTO } \\
\end{array}$} & \multicolumn{2}{|c|}{$0-25 \mathrm{~cm}$} & \multicolumn{2}{|c|}{$25-50 \mathrm{~cm}$} & \multicolumn{2}{|c|}{$50-75 \mathrm{~cm}$} & \multicolumn{2}{|c|}{$75-100 \mathrm{~cm}$} \\
\hline & $\mathbf{L}$ & EL & $\mathbf{L}$ & $\mathbf{E L}$ & $\mathbf{L}$ & EL & $\mathbf{L}$ & $\mathbf{E L}$ \\
\hline T 1 & $3,86 a b$ & $5,74 b$ & $3,24 a b$ & $3,64 a b$ & 2,80 & 2,54 & $2,54 a b$ & 2,14 \\
\hline T 2 & $4,58 a$ & $5,86 b$ & $3,30 a b$ & $3,56 a b$ & 2,54 & 2,58 & $2,46 a b$ & 2,06 \\
\hline T 3 & $4,00 a b$ & $4,24 b$ & $3,08 a b$ & $3,66 a b$ & 2,98 & 2,68 & $2,56 a b$ & 2,22 \\
\hline T 4 & $3,86 a b$ & $5,26 b$ & $3,06 a b$ & $3,38 b$ & 2,98 & 2,66 & $2,60 a b$ & 2,08 \\
\hline T 5 & $3,28 b$ & $4,02 b$ & $2,90 a b$ & $3,40 b$ & 2,50 & 2,48 & $2,46 a b$ & 1,96 \\
\hline T 6 & $4,38 a$ & $5,76 b$ & $2,80 b$ & $3,60 a b$ & 2,52 & 2,44 & $2,40 a b$ & 2,10 \\
\hline T 7 & $3,80 a b$ & $4,82 b$ & $3,20 a b$ & $3,64 a b$ & 2,94 & 2,54 & $2,54 a b$ & 2,10 \\
\hline T 8 & $4,32 a$ & $8,98 a$ & $3,44 a$ & $4,38 a$ & 3,16 & 2,72 & $2,74 a$ & 2,04 \\
\hline T 9 & $4,18 a b$ & $4,80 b$ & $3,44 a$ & $4,10 a b$ & 3,00 & 2,74 & $2,48 a b$ & 2,26 \\
\hline T 10 & $4,28 a b$ & $4,20 b$ & $3,26 a b$ & $3,76 a b$ & 2,72 & 2,60 & $2,26 b$ & 2,12 \\
\hline $\bar{F}$ & $2,50^{*}$ & $4,62 * *$ & $2,47^{*}$ & $2,31^{*}$ & 2,12 & 0,62 & $1,85^{+}$ & 1,01 \\
\hline dms & 1,02 & 2,91 & 0,58 & 0,88 & 0,69 & 0,55 & 0,40 & 0,37 \\
\hline CV $(\%)$ & 13,0 & 27,8 & 9,5 & 12,1 & 12,7 & 10,9 & 8,3 & 9,0 \\
\hline \multicolumn{9}{|c|}{ LEGENDA } \\
\hline \multicolumn{4}{|c|}{$\mathrm{T} 1=$ calc calcítico } & \multicolumn{5}{|c|}{ T $6=$ magnesita $(25 \%)+$ calc.calcítico $(75 \%)$} \\
\hline \multicolumn{4}{|c|}{$\mathrm{T} 2=$ calc.magnesiano } & \multicolumn{5}{|c|}{ T $7=$ magnesita $(15 \%)+$ calc.calcítico $(85 \%)$} \\
\hline \multirow{2}{*}{\multicolumn{4}{|c|}{$\begin{array}{l}\text { T } 3=\text { calc } \text { dolomítico } 1(70 \%)+\text { gesso } \\
\text { T } 4=\text { calc dolomítico } ?\end{array}$}} & \multicolumn{5}{|c|}{ T $8=$ magnesita $(15 \%)+$ gesso $(85 \%)$} \\
\hline & & & & \multicolumn{5}{|c|}{$\mathrm{T} 9=$ gesso } \\
\hline \multicolumn{4}{|c|}{ T $5=$ magnesita } & \multicolumn{5}{|c|}{$\mathrm{T} 10=$ testemunha } \\
\hline
\end{tabular}

Médias seguidas da mesma letra, na vertical, não diferem entre si (Tukey a 10\%).

Observou-se que, aos 6 meses após a aplicação dos produtos, todos os tratamentos mantiveram-se, na linha da cana-de-açúcar, com níveis baixos de CTC, em todas as profundidades estudadas; na entrelinha, alguns tratamentos acusaram CTC média (maior que $5 \mathrm{meq} / 100 \mathrm{~cm}^{3}$ ) na camada arável, salientando-se o tratamento que 
recebeu o gesso agrícola em mistura com a magnesita, que apresentou valores significativamente diferentes dos demais tratamentos. Porém, na colheita das socas, todos os tratamentos, com exceção da mistura de gesso com magnesita, apresentaram-se com níveis de CTC baixa a muito baixa, como pode ser observado nas Tabelas 35 e 36 .

Tabela 34. Resultados de análises de solo para CTC (meq/100 $\left.\mathrm{cm}^{3}\right)$ na colheita da cana planta, na linha e na entrelinha, ao longo do perfil do solo; dados médios de 5 repetições.

\begin{tabular}{|c|c|c|c|c|c|c|c|c|}
\hline \multirow{2}{*}{$\begin{array}{l}\text { TRATA } \\
\text { MENTO }\end{array}$} & \multicolumn{2}{|c|}{$0-25 \mathrm{~cm}$} & \multicolumn{2}{|c|}{$25-50 \mathrm{~cm}$} & \multicolumn{2}{|c|}{$50-75 \mathrm{~cm}$} & \multicolumn{2}{|c|}{$75-100 \mathrm{~cm}$} \\
\hline & $\mathbf{L}$ & EL & $\mathbf{L}$ & EL & $\mathbf{L}$ & $\overline{\mathbf{E L}}$ & $\mathbf{L}$ & EL \\
\hline T 1 & 4,12 & 4,46 & 2,54 & $2,48 b$ & 3,06 & 2,26 & 2,68 & $2,04 a b$ \\
\hline T 2 & 3,48 & 5,92 & 2,40 & $2,82 a b$ & 3,06 & 2,56 & 2,54 & $1,92 b$ \\
\hline T 3 & 3,36 & 4,08 & 2,52 & $2,98 a b$ & 3,10 & 2,34 & 2,52 & $2,12 a b$ \\
\hline T 4 & 3,38 & 4,42 & 2,44 & $2,54 b$ & 3,20 & 2,34 & 2,72 & $2,04 a b$ \\
\hline T 5 & 3,32 & 4,16 & 2,58 & $2,64 b$ & 3,10 & 2,38 & 2,48 & $2,20 a b$ \\
\hline T 6 & 3,54 & 4,08 & 2,56 & $2,80 a b$ & 3,04 & 2,20 & 2,64 & $2,08 a b$ \\
\hline $\mathbf{T} 7$ & 3,46 & 5,12 & 2,44 & $2,54 b$ & 2,94 & 2,26 & 2,58 & $2,04 a b$ \\
\hline T 8 & 3,48 & 5,42 & 2,62 & $3,50 a$ & 2,86 & 2,36 & 2,58 & $2,28 a$ \\
\hline T 9 & 3,56 & 5,00 & 2,62 & $3,14 a b$ & 3,36 & 2,38 & 2,72 & $2,08 a b$ \\
\hline T 10 & 3,44 & 3,62 & 2,58 & $2,68 b$ & 3,08 & 2,38 & 2,52 & $1,98 b$ \\
\hline $\mathbf{F}$ & 0,59 & 1,53 & 0,65 & $3,49 * *$ & 0,50 & 0,80 & 0,63 & $2,34^{*}$ \\
\hline dms & 1,27 & 2,50 & 0,42 & 0,74 & 0,82 & 0,47 & 0,47 & 0,29 \\
\hline CV (\%) & 18,5 & 27,8 & 8,5 & 13,5 & 13,8 & 10,3 & 9,4 & 7,2 \\
\hline \multicolumn{9}{|c|}{ LEGENDA } \\
\hline \multicolumn{4}{|c|}{$\mathrm{T} 1$ = calc calcítico } & \multicolumn{5}{|c|}{ T $6=$ magnesita $(25 \%)+$ calc.calcítico $(75 \%)$} \\
\hline \multicolumn{4}{|c|}{$\mathrm{T} 2$ = calc magnesiano } & \multicolumn{5}{|c|}{$\mathrm{T} 7=$ magnesita $(15 \%)+$ calc.calcítico $(85 \%)$} \\
\hline \multirow{2}{*}{\multicolumn{4}{|c|}{$\begin{array}{l}\text { T } 3=\text { calc dolomítico } 1(70 \%)+\text { gesso } \\
\text { T } 4=\text { calc dolomítico } 2\end{array}$}} & \multicolumn{5}{|c|}{$\mathrm{T} 8=$ magnesita $(15 \%)+\operatorname{gesso}(85 \%)$} \\
\hline & & & & \multicolumn{5}{|c|}{$\mathrm{T} 9=$ gesso } \\
\hline \multicolumn{4}{|c|}{$\mathrm{T} 5=$ magnesita } & \multicolumn{5}{|c|}{$\mathrm{T} 10=$ testemunha } \\
\hline
\end{tabular}

Médias seguidas da mesma letra, na vertical, não diferem entre si (Tukey a 10\%).

Em todas as camadas estudadas, tanto na linha quanto na entrelinha, a CTC manteve-se baixa, indicando que não houve maior influência dos tratamentos efetuados sobre a capacidade adsortiva do solo. 
Estes resultados são coincidentes com os obtidos por VITTI et al. (1993), que não encontraram grandes variações na CTC ao aplicarem corretivos de acidez do solo em áreas já cultivadas anteriormente.

Tabela 35. Resultados de análises de solo para CTC $\left(\mathrm{meq} / 100 \mathrm{~cm}^{3}\right)$ na colheita da primeira soca, na linha e na entrelinha, ao longo do perfil do solo; dados médios de 5 repetições.

\begin{tabular}{|c|cc|cc|cc|cc|}
\hline \multirow{2}{*}{ TRATA } & \multicolumn{2}{|c|}{$\mathbf{0}-\mathbf{2 5} \mathbf{~ c m}$} & \multicolumn{2}{|c|}{$\mathbf{2 5}-\mathbf{5 0} \mathbf{~ c m}$} & \multicolumn{2}{|c|}{$\mathbf{5 0}-\mathbf{7 5} \mathbf{~ c m}$} & \multicolumn{2}{|c|}{$\mathbf{7 5}-\mathbf{1 0 0} \mathbf{~ c m}$} \\
\cline { 2 - 9 } MENTO & $\mathbf{L}$ & $\mathbf{E L}$ & $\mathbf{L}$ & $\mathbf{E L}$ & $\mathbf{L}$ & $\mathbf{E L}$ & $\mathbf{L}$ & $\mathbf{E L}$ \\
\hline T 1 & 4,16 & $3,72 a b$ & 3,45 & $2,98 a b c$ & 2,85 & 2,70 & $2,77 a$ & 2,53 \\
T 2 & 3,95 & $3,60 b$ & 3,35 & $2,95 b c$ & 2,64 & 2,77 & $2,43 a b$ & 2,36 \\
T 3 & 4,07 & $3,56 b$ & 3,43 & $3,45 a b$ & 2,80 & 3,06 & $2,61 a b$ & 2,03 \\
T 4 & 4,17 & $3,65 b$ & 3,24 & $3,03 a b c$ & 2,73 & 2,76 & $2,50 a b$ & 2,57 \\
T 5 & 3,98 & $3,48 b$ & 3,10 & $2,92 c$ & 2,84 & 2,80 & $2,40 b$ & 2,54 \\
T 6 & 3,99 & $3,67 b$ & 3,21 & $2,89 c$ & 2,70 & 2,79 & $2,51 a b$ & 2,47 \\
T 7 & 3,76 & $3,61 b$ & 3,14 & $3,18 a b c$ & 2,81 & 2,85 & $2,59 a b$ & 2,65 \\
T 8 & 4,27 & $4,13 a b$ & 3,21 & $3,09 a b c$ & 2,72 & 2,92 & $2,71 a b$ & 2,84 \\
T 9 & 4,26 & $4,47 a$ & 3,25 & $3,48 a$ & 3,11 & 3,00 & $2,54 a b$ & 2,72 \\
T 10 & 4,64 & $4,06 a b$ & 3,58 & $3,14 a b c$ & 3,07 & 2,83 & $2,68 a b$ & 2,58 \\
\hline F & 1,03 & $2,92 *$ & 2,01 & $2,95 * *$ & 2,01 & 1,62 & $2,19 *$ & 1,33 \\
dms & 1,02 & 0,80 & 0,48 & 0,53 & 0,47 & 0,38 & 0,35 & 0,82 \\
CV (\%) & 12,7 & 10,9 & 7,3 & $\mathbf{8 , 7}$ & 8,5 & 6,9 & 7,1 & 16,7 \\
\hline
\end{tabular}

LEGENDA :

$\mathrm{T} 1$ = calc.calcítico

$\mathrm{T} 2$ = calc.magnesiano

T 3 = calc. dolomítico $1(70 \%)+$ gesso

T 4 = calc. dolomítico 2

T $5=$ magnesita
T 6 = magnesita $(25 \%)+$ calc.calcítico $(75 \%)$

T 7 = magnesita $(15 \%)+$ calc.calcítico $(85 \%)$

T 8 = magnesita $(15 \%)+$ gesso $(85 \%)$

T $9=$ gesso

$\mathrm{T} 10=$ testemunha

Médias seguidas da mesma letra, na vertical, não diferem entre si (Tukey a 10\%).

Estes resultados discordam, em parte, porém, dos obtidos por NASCIMENTO et al. (1983) que obtiveram acréscimos nos valores de CTC, com a adição de calcário, em amostras efetuadas 1 ano após a aplicação dos produtos e na camada $0-20 \mathrm{~cm}$ de profundidade. 
Tabela 36. Resultados de análises de solo para CTC $\left(\mathrm{meq} / 100 \mathrm{~cm}^{3}\right)$ na colheita da segunda soca, na linha e na entrelinha, ao longo do perfil do solo; dados médios de 5 repetições.

\begin{tabular}{|c|cc|cc|cc|cc|}
\hline TRATA & \multicolumn{2}{|c|}{$\mathbf{0}-\mathbf{2 5} \mathbf{~ c m}$} & \multicolumn{2}{c|}{$\mathbf{2 5}-\mathbf{5 0} \mathbf{~ c m}$} & \multicolumn{2}{c|}{$\mathbf{5 0 -} \mathbf{7 5} \mathbf{~ c m}$} & \multicolumn{2}{c|}{$\mathbf{7 5}-\mathbf{1 0 0} \mathbf{~ c m}$} \\
\cline { 2 - 9 } MENTO & $\mathbf{L}$ & $\mathbf{E L}$ & $\mathbf{L}$ & $\mathbf{E L}$ & $\mathbf{L}$ & $\mathbf{E L}$ & $\mathbf{L}$ & $\mathbf{E L}$ \\
\hline T 1 & $4,36 b c$ & $3,77 a b$ & $3,66 a b$ & 3,14 & 3,24 & 3,01 & $2,93 b$ & 2,63 \\
T 2 & $3,72 c$ & $3,29 b$ & $3,22 a b$ & 2,73 & 3,13 & 2,94 & $3,05 a b$ & 2,65 \\
T 3 & $4,84 a b$ & $3,26 b$ & $3,90 a$ & 2,84 & 3,36 & 2,87 & $3,13 a b$ & 2,72 \\
T 4 & $3,92 b c$ & $3,46 a b$ & $3,23 a b$ & 2,91 & 3,33 & 2,68 & $3,06 a b$ & 2,64 \\
T 5 & $3,82 c$ & $4,00 a b$ & $3,33 a b$ & 3,15 & 3,10 & 2,99 & $2,88 b$ & 2,51 \\
T 6 & $4,28 b c$ & $3,75 a b$ & $3,75 a b$ & 3,08 & 3,43 & 2,59 & $3,14 a b$ & 2,54 \\
T 7 & $4,26 b c$ & $3,80 a b$ & $3,54 a b$ & 3,12 & 3,37 & 2,84 & $3,31 a b$ & 2,49 \\
T 8 & $5,56 a$ & $5,38 a$ & $3,92 a$ & 3,11 & 3,54 & 3,39 & $3,59 a$ & 2,86 \\
T 9 & $3,60 c$ & $2,76 b$ & $3,18 b$ & 2,54 & 3,53 & 2,74 & $3,11 a b$ & 2,81 \\
T 10 & $3,64 c$ & $3,20 b$ & $3,49 a b$ & 2,86 & 3,26 & 2,81 & $3,09 a b$ & 2,59 \\
\hline F & $8,10^{* *}$ & $2,31^{*}$ & $2,79^{*}$ & 1,09 & 0,57 & 0,60 & $2,04^{+}$ & 0,41 \\
dms & 0,93 & 2,01 & 0,72 & 0,86 & 0,86 & 1,23 & 0,60 & 0,83 \\
CV (\%) & 11,4 & 28,2 & 10,5 & 14,9 & 13,2 & 22,0 & 9,9 & 16,1 \\
\hline
\end{tabular}

LEGENDA :

$\mathrm{T} 1$ = calc. calcítico

T 6 = magnesita $(25 \%)+$ calc.calcítico $(75 \%)$

$\mathrm{T} 2$ = calc.magnesiano

T 7 = magnesita $(15 \%)+$ calc.calcítico $(85 \%)$

T $3=$ calc.dolomítico $1(70 \%)+$ gesso $\quad$ T $8=$ magnesita $(15 \%)+$ gesso $(85 \%)$

T $4=$ calc. dolomítico 2

T $9=$ gesso

T $5=$ magnesita

T $10=$ testemunha

Médias seguidas da mesma letra, na vertical, não diferem entre si (Tukey a 10\%).

\subsection{9. $\mathrm{V} \%$}

Pelos dados apresentados nas Tabelas 37 a 40 observa-se que, com exceção do gesso, todos os produtos e misturas estudadas elevaram a saturação por bases da camada arável, tanto na linha quanto na entrelinha, aos 6 meses após a aplicação. Na época da colheita da cana planta, da mesma forma, maiores niveis de saturação por bases foram detectados apenas na camada arável, em todos os tratamentos, com exceção do T 9 (gesso agrícola) e T 10 (testemunha). 
Tabela 37. Resultados de análises de solo para V\% aos 6 meses após a aplicação dos produtos, na linha e na entrelinha, ao longo do perfil do solo; dados médios de 5 repetições.

\begin{tabular}{|c|cc|cc|cc|cc|}
\hline TRATA & \multicolumn{2}{|c|}{$\mathbf{0}-\mathbf{2 5} \mathbf{~ c m}$} & \multicolumn{2}{c|}{$\mathbf{2 5}-\mathbf{5 0} \mathbf{~ c m}$} & \multicolumn{2}{c|}{$\mathbf{5 0}-\mathbf{7 5} \mathbf{~ c m}$} & \multicolumn{2}{c|}{$\mathbf{7 5}-\mathbf{1 0 0} \mathbf{~ c m}$} \\
\cline { 2 - 8 } MENTO & $\mathbf{L}$ & $\mathbf{E L}$ & $\mathbf{L}$ & $\mathbf{E L}$ & $\mathbf{L}$ & $\mathbf{E L}$ & $\mathbf{L}$ & $\mathbf{E L}$ \\
\hline T 1 & $50 a$ & $57 a b c$ & $19 a b c$ & $19 b c$ & $12 b$ & $16 a b$ & $14 b c$ & 10 \\
T 2 & $47 a$ & $69 a b$ & $16 b c$ & $18 b c$ & $13 b$ & $12 a b$ & $14 b c$ & 10 \\
T 3 & $46 a$ & $42 b c d$ & $16 b c$ & $11 c$ & $13 b$ & $16 a b$ & $16 a b$ & 9 \\
T 4 & $50 a$ & $77 a$ & $18 a b c$ & $24 b$ & $15 a b$ & $20 a$ & $18 a b$ & 14 \\
T 5 & $46 a$ & $67 a b$ & $31 a$ & $26 b$ & $10 b$ & $12 a b$ & $17 a b$ & 10 \\
T 6 & $61 a$ & $70 a b$ & $30 a b$ & $25 b$ & $15 a b$ & $15 a b$ & $16 a b$ & 13 \\
T 7 & $39 a$ & $59 a b c$ & $21 a b c$ & $23 b$ & $11 b$ & $13 a b$ & $14 b c$ & 10 \\
T 8 & $47 a$ & $83 a$ & $27 a b$ & $40 a$ & $22 a$ & $19 a$ & $21 a$ & 11 \\
T 9 & $15 b$ & $27 c d$ & $13 c$ & $18 b c$ & $14 b$ & $10 b$ & $16 a b$ & 12 \\
T 10 & $11 b$ & $11 d$ & $8 c$ & $10 c$ & $11 b$ & $10 b$ & $9 c$ & 9 \\
\hline F & $8,47 * *$ & $7,98 * *$ & $4,66 * *$ & $8,83 * *$ & $2,99 * *$ & $2,74 *$ & $3,09 * *$ & 1,11 \\
dms & 23 & 35 & 14 & 12 & 8 & 9 & 7 & 7 \\
CV (\%) & 29,3 & 32,0 & 37,0 & 29,4 & 32,0 & 32,9 & 24,9 & 32,2 \\
\hline
\end{tabular}

LEGENDA :

T 1 = calc.calcítico

T 2 = calc.magnesiano

T 3 =calc.dolomítico 1

T 4 = calc. dolomítico 2

T $5=$ magnesita

Médias seguidas da mesma letra, na vertical, não diferem entre si (Tukey a 10\%).

Sensíveis aumentos na saturação por bases apenas na superficie também foram citados por MORELLI et al. (1986), não existindo na $2^{a}$ camada analisada praticamente nenhuma alteração; da mesma forma, resultados muito similares foram obtidos por NASCIMENTO et al. (1983).

Esta mesma tendência foi observada nas colheitas da primeira e segunda socas, destacando-se os valores de $\mathrm{V} \%$ conseguidos pelo tratamento de gesso com magnesita que, apesar de também cair ao longo do tempo, conseguiu se manter em níveis que podem ser considerados como muito bons para a cana-de-açúcar. 
Valores que ainda podem ser considerados como razoáveis para subsuperficie (camada de 25 a $50 \mathrm{~cm}$ ) foram encontrados, até a última avaliação efetuada, com a aplicação de gesso em mistura com a magnesita.

De qualquer forma, conseguiu-se alcançar os valores desejados de 60 a $70 \%$ de saturação por bases apenas na camada superficial com os tratamentos à base de calcário magnesiano, calcário dolomítico e magnesita, aplicada isoladamente ou em mistura com calcário calcítico e, principalmente, com o gesso agrícola.

Tabela 38. Resultados de análise de solo para V\% na colheita da cana planta, na linha e na entrelinha, ao longo do perfil do solo; dados médios de 5 repetições.

\begin{tabular}{|c|cc|cc|cc|cc|}
\hline TRATA & \multicolumn{2}{|c|}{$\mathbf{0}-\mathbf{2 5} \mathbf{~ c m}$} & \multicolumn{2}{c|}{$\mathbf{2 5}-\mathbf{5 0} \mathbf{~ c m}$} & \multicolumn{2}{|c|}{$\mathbf{5 0}-\mathbf{7 5} \mathbf{~ c m}$} & \multicolumn{2}{|c|}{$\mathbf{7 5}-\mathbf{1 0 0} \mathbf{~ c m}$} \\
\cline { 2 - 10 } MENTO & $\mathbf{L}$ & $\mathbf{E L}$ & $\mathbf{L}$ & $\mathbf{E L}$ & $\mathbf{L}$ & $\mathbf{E L}$ & $\mathbf{L}$ & $\mathbf{E L}$ \\
\hline T 1 & $48 a$ & $52 a b$ & $19 a b c$ & $12 b$ & 8 & 9 & $8 b c$ & $9 b$ \\
T 2 & $35 a b$ & $66 a$ & $10 b c$ & $14 b$ & 8 & 8 & $8 b c$ & $12 b$ \\
T 3 & $41 a$ & $40 a b c$ & $16 a b c$ & $9 b$ & 7 & 11 & $7 c$ & $9 b$ \\
T 4 & $41 a$ & $59 a b$ & $17 a b c$ & $12 b$ & 11 & 10 & $7 c$ & $11 b$ \\
T 5 & $39 a b$ & $60 a b$ & $33 a$ & $19 b$ & 16 & 14 & $7 c$ & $12 b$ \\
T 6 & $38 a b$ & $44 a b c$ & $26 a b c$ & $12 b$ & 12 & 9 & $7 c$ & $9 b$ \\
T 7 & $41 a$ & $62 a b$ & $16 a b c$ & $13 b$ & 9 & 9 & $11 a$ & $9 b$ \\
T 8 & $43 a$ & $66 a$ & $27 a b$ & $34 a$ & 13 & 16 & $10 a b$ & $22 a$ \\
T 9 & $11 c$ & $36 b c$ & $9 c$ & $11 b$ & 10 & 10 & $8 b c$ & $9 b$ \\
T 10 & $19 b c$ & $16 c$ & $10 b c$ & $8 b$ & 7 & 8 & $7 c$ & $11 b$ \\
\hline F & $5,25^{* *}$ & $5,67^{* *}$ & $3,76^{* *}$ & $6,82^{* *}$ & 1,25 & 1,62 & $3,25^{* *}$ & $5,19^{* *}$ \\
dms & 21 & 29 & 18 & 12 & 10 & 8 & 3 & 7 \\
CV (\%) & 31,1 & 29,8 & 50,3 & 43,4 & 53,1 & 42,8 & 21,2 & 31,7 \\
\hline
\end{tabular}

\section{LEGENDA :}

$\mathrm{T} 1$ = calc.calcítico

$\mathrm{T} 2$ = calc .magnesiano

T 6 = magnesita $(25 \%)+$ calc.calcítico $(75 \%)$

T 3 = calc.dolomítico $1(70 \%)+$ gesso

T 4 = calc. dolomítico 2

T $7=$ magnesita $(15 \%)+$ calc.calcítico $(85 \%)$

T 5 = magnesita

T 8 = magnesita $(15 \%)+$ gesso $(85 \%)$

$\mathrm{T} 9=$ gesso

$\mathrm{T} 10=$ testemunha

Médias seguidas da mesma letra, na vertical, não diferem entre si (Tukey a 10\%). 
Tabela 39. Resultados de análise de solo para V\% na colheita da primeira soca, na linha e na entrelinha, ao longo do perfil do solo; dados médios de 5 repetições.

\begin{tabular}{|c|c|c|c|c|c|c|c|c|}
\hline \multirow{2}{*}{$\begin{array}{l}\text { TRATA } \\
\text { MENTO }\end{array}$} & \multicolumn{2}{|c|}{$0-25 \mathrm{~cm}$} & \multicolumn{2}{|c|}{$25-50 \mathrm{~cm}$} & \multicolumn{2}{|c|}{$50-75 \mathrm{~cm}$} & \multicolumn{2}{|c|}{$75-100 \mathrm{~cm}$} \\
\hline & $\mathbf{L}$ & EL & $\mathbf{L}$ & EL & $\mathbf{L}$ & EL & $\mathbf{L}$ & EL \\
\hline T 1 & $39 a$ & $33 b$ & $27 a$ & $18 c d$ & $17 b c$ & $16 b c$ & $18 a b$ & $14 b c$ \\
\hline T 2 & $34 a$ & $29 b c$ & $27 a$ & $19 b c d$ & $16 b c$ & $16 b c$ & $14 b c$ & $13 b c$ \\
\hline T 3 & $39 a$ & $31 b c$ & $29 a$ & $17 c d$ & $20 b$ & $15 b c$ & $18 a b$ & $12 b c$ \\
\hline T 4 & $36 a$ & $35 b$ & $26 a$ & $18 c d$ & $16 b c$ & $14 b c$ & $17 a b c$ & $17 a b c$ \\
\hline T 5 & $29 a b$ & $38 a b$ & $24 a b$ & $28 a b$ & $18 b$ & $19 a b$ & $14 b c$ & $18 a b c$ \\
\hline T 6 & $35 a$ & $38 a b$ & $32 a$ & $24 a b c$ & $27 a$ & $18 a b$ & $16 b c$ & $13 b c$ \\
\hline $\mathbf{T} 7$ & $35 a$ & $29 b c$ & $26 a$ & $16 c d$ & $15 b c$ & $16 b c$ & $15 b c$ & $13 b c$ \\
\hline T 8 & $42 a$ & $52 a$ & $33 a$ & $33 a$ & $28 a$ & $23 a$ & $22 a$ & $24 a$ \\
\hline T 9 & $16 b c$ & $17 c d$ & $14 b c$ & $13 d$ & $16 b c$ & $14 b c$ & $14 b c$ & $19 a b$ \\
\hline T 10 & $13 c$ & $9 d$ & $13 c$ & $11 d$ & $10 c$ & $10 c$ & $12 c$ & $11 c$ \\
\hline $\mathbf{F}$ & $8,59 * *$ & $9,10 * *$ & $6,94 * *$ & $7,74^{* *}$ & $9,01 * *$ & $4,53 * *$ & $3,39 * *$ & $4,73^{* *}$ \\
\hline dms & 14 & 16 & 11 & 10 & 7 & 7 & 6 & 8 \\
\hline $\operatorname{CV}(\%)$ & 23,3 & 27,6 & 22,7 & 27,4 & 21,3 & 21,9 & 21,0 & 26,4 \\
\hline
\end{tabular}

LEGENDA :

$\mathrm{T} 1$ = calc.calcítico

T 6 = magnesita $(25 \%)+$ calc.calcítico $(75 \%)$

T 2 = calc. magnesiano

T $7=$ magnesita $(15 \%)+$ calc.calcítico $(85 \%)$

T 3 = calc. dolomítico $1(70 \%)+$ gesso

T 4 = calc. dolomítico 2

T $8=$ magnesita $(15 \%)+$ gesso $(85 \%)$

T 5 = magnesita

$\mathrm{T} 9=$ gesso

$\mathrm{T} 10=$ testemunha

Médias seguidas da mesma letra, na vertical, não diferem entre si (Tukey a 10\%).

A mistura de gesso agrícola com magnesita foi, portanto, o único tratamento que proporcionou, após a colheita da segunda soca, valores de saturaçãe por bases na camada arável, ao redor de $50 \%$. Todos os demais tratamentos, em qualquer camada do perfil de solo analisado, apresentaram valores de $\mathrm{V} \%$ mais baixos. Abaixo dos $50 \mathrm{~cm}$ e até 1,0 metro de profundidade, esta mistura proporcionou valores de saturação por bases ao redor de $20 \%$, índice praticamente igual ao valor encontrado antes do início do ensaio, enquanto que todos os outros tratamentos igualaram-se à testemunha. 
Tabela 40. Resultados de análise de solo para V\% na colheita da segunda soca, na linha e na entrelinha, ao longo do perfil do solo; dados médios de 5 repetições.

\begin{tabular}{|c|c|c|c|c|c|c|c|c|}
\hline \multirow{2}{*}{$\begin{array}{l}\text { TRATA } \\
\text { MENTO }\end{array}$} & \multicolumn{2}{|c|}{$0-25 \mathrm{~cm}$} & \multicolumn{2}{|c|}{$25-50 \mathrm{~cm}$} & \multicolumn{2}{|c|}{$50-75 \mathrm{~cm}$} & \multicolumn{2}{|c|}{$75-100 \mathrm{~cm}$} \\
\hline & $\mathbf{L}$ & EL & $\mathbf{L}$ & EL & $\mathbf{L}$ & EL & $\mathbf{L}$ & EL \\
\hline T 1 & $33 a b c$ & $31 b$ & $26 a b c$ & $18 b c$ & $19 a b$ & $9 b c$ & 15 & $7 b$ \\
\hline T 2 & $32 a b c$ & $31 b$ & $24 a b c$ & $16 b c d$ & $19 a b$ & $10 a b c$ & 20 & $8 b$ \\
\hline T 3 & $43 a$ & $28 b$ & $27 a b$ & 13 cde & $20 a b$ & $11 a b c$ & 19 & $9 b$ \\
\hline T 4 & $41 a$ & $31 b$ & $30 a b$ & $17 b c d$ & $19 a b$ & $11 a b c$ & 17 & $8 b$ \\
\hline T 5 & $36 a b$ & $31 b$ & $27 a b$ & $23 a b$ & $23 a b$ & $17 a b$ & 19 & $10 b$ \\
\hline T 6 & $42 a$ & $32 a b$ & $31 a b$ & $21 a b c$ & $23 a b$ & $11 a b c$ & 20 & $8 b$ \\
\hline $\mathbf{T} 7$ & $41 a$ & $22 b c$ & $31 a b$ & 14 cde & $22 a b$ & $9 b c$ & 19 & $8 b$ \\
\hline T 8 & $50 a$ & $49 a$ & $32 a$ & $27 a$ & $28 a$ & $18 a$ & 23 & $20 a$ \\
\hline T 9 & $18 b c$ & $7 c$ & $18 b c$ & $7 e$ & $14 b$ & $6 c$ & 18 & $7 b$ \\
\hline T 10 & $13 c$ & $9 c$ & $13 c$ & $9 d e$ & $12 b$ & $9 b c$ & 14 & $8 b$ \\
\hline $\mathbf{F}$ & $5,30 * *$ & $8,26 * *$ & $3,08 * *$ & $7,71^{* *}$ & $2,66^{*}$ & $2,81^{*}$ & 1,68 & $3,60^{* *}$ \\
\hline dms & 21 & 18 & 14 & 9 & 12 & 9 & 9 & 8 \\
\hline CV (\%) & 31,7 & 34,3 & 29,3 & 28,9 & 31,5 & 41,9 & 24,6 & 46,1 \\
\hline
\end{tabular}

LEGENDA :

$\mathrm{T} 1$ = calc. calcítico

T $6=$ magnesita $(25 \%)+$ calc.calcítico $(75 \%)$

T 2 = calc.magnesiano

T $7=$ magnesita $(15 \%)+$ calc.calcítico $(85 \%)$

T 3 = calc.dolomítico $1(70 \%)+$ gesso

T $4=$ calc. dolomítico 2

T $8=$ magnesita $(15 \%)+$ gesso $(85 \%)$

T 5 = magnesita

T $9=$ gesso

$\mathrm{T} 10=$ testemunha

Médias seguidas da mesma letra, na vertical, não diferem entre si (Tukey a 10\%).

A Figura 5 ilustra estas considerações, comparando os valores de saturação por bases obtidos após a colheita da segunda soca na testemunha ( $\mathrm{T} 10)$ com os tratamentos que receberam o gesso isoladamente ( $\mathrm{T}$ 9) e em mistura com calcário dolomítico (T 3) e com magnesita (T 8) e magnesita em mistura com calcário calcítico ( $\mathrm{T}$ 7). 

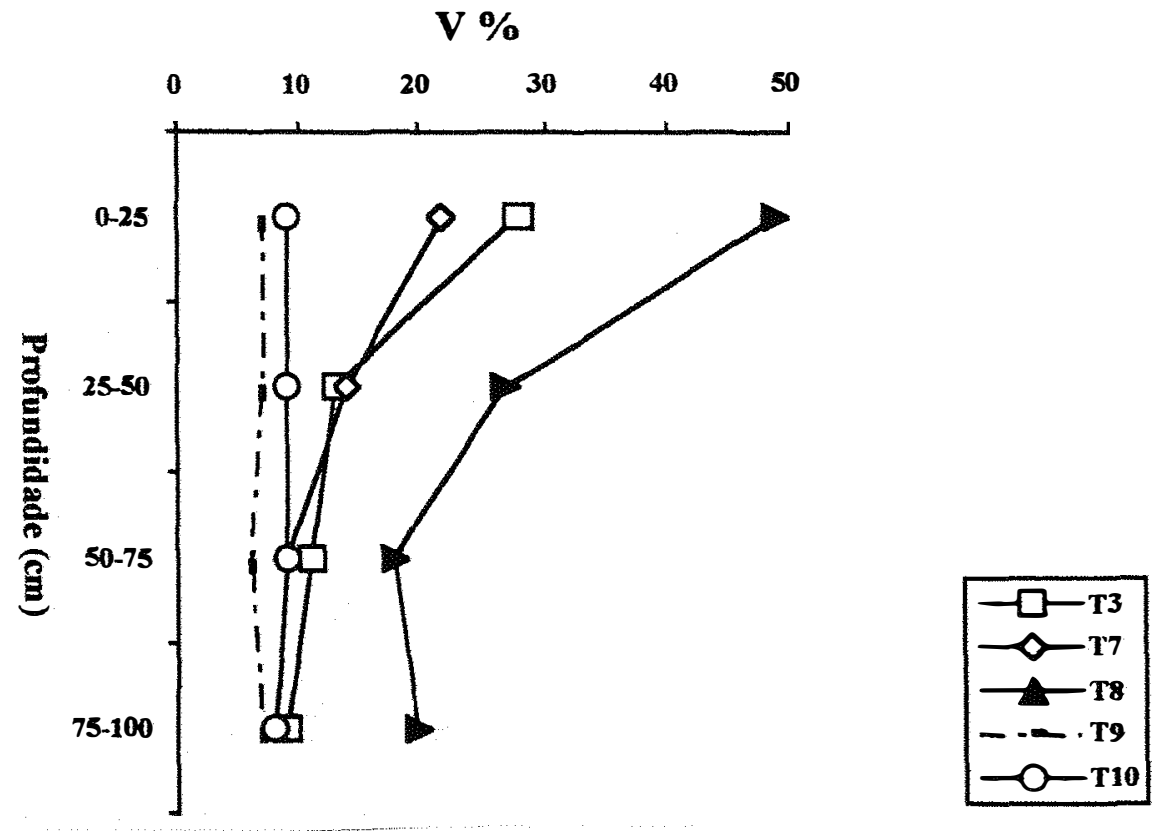

Figura 5. Saturação por bases (V \% ) na entrelinha da cana-de-açúcar, ao longo do perfil do solo, após a colheita da segunda soca, na testemunha e nos tratamentos que receberam o gesso isoladamente e em mistura com calcário dolomítico e com magnesita e magnesita em mistura com calcário calcítico.

\subsection{Efeitos nos teores de nutrientes nas folhas}

Aos 6 meses após a aplicação dos produtos coletou-se a folha +3 (15 folhas por parcela) e procedeu-se à análise dos teores foliares de $\mathrm{N}, \mathrm{P}, \mathrm{K}, \mathrm{Ca}, \mathrm{Mg}, \mathrm{S} \mathrm{e}$ $\mathrm{Mn}$. Os resultados obtidos indicaram que todos os tratamentos se encontravam 
deficientes em $\mathrm{N}, \mathrm{P}$ e Ca; teores adequados de $\mathrm{K}, \mathrm{Mg}$ e $\mathrm{Mn}$ foram encontrados em todos os tratamentos estudados, inclusive, com teores bastante elevados de Mg quando se aplicou magnesita isoladamente ou em mistura com gesso. Este tratamento também foi o único que proporcionou teores foliares adequados em $\mathrm{S}$; todos os demais tratamentos acusaram estar deficientes neste nutriente.

Novas análises foram efetuadas 4 meses após o cultivo da primeira soca, quando, apesar de se notar algumas diferenças significativas entre alguns tratamentos, em todos eles todos os nutrientes analisados anteriormente se encontravam em teores considerados como deficientes na folha, a não ser o $\mathrm{S}$ no tratamento que recebeu a mistura de magnesita com gesso, que se apresentou com teores adequados neste nutriente.

Todas estas considerações podem ser melhor visualizadas nas Tabelas 41 a 47. Pela análise dos dados contidos na Tabela 41, vê-se que todos os tratamentos encontravam-se deficientes em $\mathrm{N}$, aos 6 meses após a aplicação dos produtos, resultados similares aos citados por MALAVOLTA et al. (1974).

$\mathrm{Na}$ primeira soca, porém, encontrou-se teores maiores de $\mathrm{N}$ foliar em quase todos os tratamentos, que se situaram próximos aos teores considerados adequados por MALAVOLTA (1980), TRANI et al. (1983), BATAGLIA \& DECHEN (1986) e RAIJ (1994); salientou-se nesta época o tratamento onde foi aplicado gesso isoladamente, que apresentou diferença significativa com o tratamento onde entrou em mistura com a magnesita. 
A avaliação efetuada aos 4 meses após o cultivo da segunda soca, entretanto, acusou teores de $\mathrm{N}$ nas folhas extremamente baixos, situando todos os tratamentos como muito deficientes neste nutriente.

Tabela 41. Teores médios de $\mathrm{N}(\mathrm{em} \%)$ nas folhas de cana-de-açúcar, aos 6 meses após a aplicação dos produtos (cana planta) e aos 4 meses após o cultivo das soqueiras; dados médios de 5 repetições.

\begin{tabular}{|c|ccc|}
\hline TRATAMENTO & \multicolumn{3}{|c|}{ N (\%) } \\
\cline { 2 - 4 } & CANA PLANTA & $\mathbf{1}^{\mathbf{a}}$ SOCA & $\mathbf{2}^{\mathbf{a}}$ SOCA \\
\hline T 1 & $1,38 a b$ & $1,55 a b c$ & 0,80 \\
T 2 & $1,26 b$ & $1,55 a b c$ & 0,98 \\
T 3 & $1,38 a b$ & $1,55 a b c$ & 0,91 \\
T 4 & $1,53 a$ & $1,52 a b c$ & 0,93 \\
T 5 & $1,42 a b$ & $1,62 a b c$ & 0,99 \\
T 6 & $1,49 a$ & $1,49 b c$ & 0,93 \\
T 7 & $1,47 a b$ & $1,60 a b c$ & 0,93 \\
T 8 & $1,42 a b$ & $1,46 c$ & 0,96 \\
T 9 & $1,47 a b$ & $1,69 a$ & 0,96 \\
T 10 & $1,38 a b$ & $1,65 a b$ & 0,99 \\
\hline F & $2,13 *$ & $2,24^{*}$ & 0,68 \\
dms & 0,22 & 0,20 & 0,28 \\
CV (\%) & 8,1 & 6,6 & 15,8 \\
\hline
\end{tabular}

LEGENDA :

$\mathrm{T} 1$ = calc.calcítico

T 6 = magnesita $(25 \%)+$ calc.calcítico $(75 \%)$

T 2 = calc.magnesiano

T $7=$ magnesita $(15 \%)+$ calc.calcítico $(85 \%)$

T 3 = calc. dolomítico $1(70 \%)+$ gesso

T 4 = calc. dolomítico 2

T $8=$ magnesita $(15 \%)+$ gesso $(85 \%)$

T $5=$ magnesita

T $9=$ gesso

$\mathrm{T} 10=$ testemunha

Médias seguidas da mesma letra, na vertical, não diferem entre si (Tukey a 10\%).

$\mathrm{O}$ teor de $0,12 \%$ de $\mathrm{P}$ foliar, considerado como nível crítico deste nutriente por diversos autores, tais como MALAVOLTA et al. (1974), GALLO et al. (1968), TRANI et al. (1983), BATAGLIA \& DECHEN (1986), não foi obtido por nenhum dos tratamentos estudados, na avaliação realizada aos 6 meses após a aplicação dos produtos, em cana planta, como se vê na Tabela 42 . 
Similarmente aos resultados obtidos para o $\mathrm{N}$, os teores de $\mathrm{P}$ foliares por ocasião da avaliação realizada na $1^{\mathrm{a}}$ soca foram relativamente maiores, revelando valores próximos aos níveis considerados adequados por GALLO et al. (1968) e por RAIJ (1994), porém ainda abaixo dos limites críticos citados por MALAVOLTA (1980) e por MALAVOLTA et al. (1989).

Tabela 42. Teores médios de $\mathrm{P}(\mathrm{em} \%)$ nas folhas de cana-de-açúcar, aos 6 meses após a aplicação dos produtos (cana planta) e aos 4 meses após o cultivo das soqueiras; dados médios de 5 repetições.

\begin{tabular}{|c|ccc|}
\hline TRATAMENTO & \multicolumn{3}{|c|}{ P (\%) } \\
\cline { 2 - 4 } & CANA PLANTA & $\mathbf{1}^{\mathbf{a}}$ SOCA & $\mathbf{2}^{\mathbf{a}}$ SOCA \\
\hline T 1 & $0,09 b c$ & $0,15 b c$ & 0,06 \\
T 2 & $0,10 a b$ & $0,17 a b$ & 0,09 \\
T 3 & $0,08 c$ & $0,14 c$ & 0,08 \\
T 4 & $0,10 a b$ & $0,17 a b$ & 0,09 \\
T 5 & $0,10 a b$ & $0,19 a$ & 0,09 \\
T 6 & $0,11 a$ & $0,16 b c$ & 0,09 \\
T 7 & $0,09 b c$ & $0,17 a b$ & 0,09 \\
T 8 & $0,11 a$ & $0,16 b c$ & 0,09 \\
T 9 & $0,08 c$ & $0,16 b c$ & 0,09 \\
T 10 & $0,09 b c$ & $0,17 a b$ & 0,09 \\
\hline F & $2,78^{*}$ & $2,11 *$ & 1,42 \\
dms & 0,02 & 0,03 & 0,02 \\
CV (\%) & 14,2 & 11,5 & 16,5 \\
\hline
\end{tabular}

LEGENDA :

$\mathrm{T} 1$ = calc. calcítico

T 6 = magnesita $(25 \%)+$ calc.calcítico $(75 \%)$

$\mathrm{T} 2$ = calc.magnesiano

T $7=$ magnesita $(15 \%)+$ calc.calcítico $(85 \%)$

T 3 = calc.dolomítico $1(70 \%)+$ gesso

T 4 = calc. dolomítico 2

T 8 = magnesita $(15 \%)+$ gesso $(85 \%)$

T $5=$ magnesita

$\mathrm{T} 9=$ gesso

T $10=$ testemunha

Médias seguidas da mesma letra, na vertical, não diferem entre si (Tukey 10\%). 
Da mesma forma, na segunda soca, os teores foliares voltaram a se situar em níveis mais baixos, caracterizando bem uma situação de deficiência deste nutriente nas plantas de todos os tratamentos estudados.

Teores foliares adequados de $\mathrm{K}$, levando-se em consideração os níveis propostos por GALLO et al. (1968), TRANI et al. (1983) e BATAGLIA \& DECHEN (1986), foram determinados somente no tratamento efetuado com calcário dolomítico aplicado isoladamente, como pode ser visto na Tabela 43.

Tabela 43. Teores médios de $\mathrm{K}$ (em \%) nas folhas de cana-de-açúcar, aos 6 meses após a aplicação dos produtos (cana planta) e aos 4 meses após o cultivo das soqueiras; dados médios de 5 repetições.

\begin{tabular}{|c|c|c|c|}
\hline \multirow[t]{2}{*}{ TRATAMENTO } & \multicolumn{3}{|c|}{$\mathbf{K}(\%)$} \\
\hline & CANA PLANTA & $1^{2}$ SOCA & $2^{2}$ SOCA \\
\hline$\overline{T 1}$ & 1,10 & $0,98 a b$ & $0,76 b$ \\
\hline T 2 & 1,12 & $0,97 a b c$ & $1,30 a$ \\
\hline T 3 & 1,08 & $0,82 b c d$ & $1,29 a$ \\
\hline T 4 & 1,20 & $0,89 a b c d$ & $1,29 a$ \\
\hline T 5 & 1,12 & $0,78 c d$ & $1,20 a$ \\
\hline T 6 & 1,18 & 0,90 abcd & $1,22 a$ \\
\hline $\mathbf{T} 7$ & 1,15 & $0,86 a b c d$ & $1,22 a$ \\
\hline T 8 & 1,17 & $0,75 d$ & $1,10 a b$ \\
\hline T 9 & 1,11 & $0,88 a b c d$ & $1,19 a$ \\
\hline T 10 & 1,17 & $1,03 a$ & $1,29 a$ \\
\hline $\mathbf{F}$ & 1,32 & $3,83 * *$ & $3,79 * *$ \\
\hline dms & 0,15 & 0,20 & 0,36 \\
\hline CV (\%) & 6,8 & 11,5 & 15,6 \\
\hline \multicolumn{4}{|l|}{ LEGENDA } \\
\hline \multirow{2}{*}{\multicolumn{2}{|c|}{$\begin{array}{l}\text { T } 1=\text { calc.calcítico } \\
\text { T } 2=\text { calc magnesiano }\end{array}$}} & \multicolumn{2}{|c|}{ T $6=$ magnesita $(25 \%)+$ calc.calcítico $(75 \%)$} \\
\hline & & \multirow{2}{*}{\multicolumn{2}{|c|}{$\begin{array}{l}\text { T } 7=\text { magnesita }(15 \%)+\text { calc.calcítico }(85 \%) \\
\text { T } 8=\text { mannesita }(15 \%)+\text { gesso }(85 \%)\end{array}$}} \\
\hline \multicolumn{2}{|c|}{$\begin{array}{l}\text { T } 2=\text { calc } \text { magnesiano } \\
\text { T } 3=\text { calc } \text { dolomítico } 1(70 \%)+\text { gesso }\end{array}$} & & \\
\hline T $4=$ calc dolomítico 2 & $\cos 2$ & \\
\hline \multicolumn{2}{|c|}{$5=$ manosita } & $\mathrm{T} 10=$ testemunha & \\
\hline
\end{tabular}

Médias seguidas da mesma letra, na vertical, não diferem entre si (Tukey 10\%). 
Porém, ao se levar em conta os critérios propostos por MALAVOLTA (1980), todos os tratamentos apresentaram-se com teores adequados de $\mathrm{K}$ nas folhas, em condições de cana planta.

Na primeira soca, entretanto, ainda levando-se em consideração este último autor, apenas a testemunha, sem aplicação de corretivos e/ou gesso, é que se mostrou com teores adequados do nutriente analisado.

Já na segunda soca, todos os tratamentos, com exceção do calcário calcítico, apresentaram níveis foliares de $\mathrm{K}$ adequados, de acôrdo com todos os autores já citados e, também com MALAVOLTA et al. (1989) e com RAIJ (1994).

As plantas situadas nas parcelas onde se efetuou o tratamento exclusivo com magnesita, em avaliações visuais realizadas a partir do $6^{\circ}$ mes de instalação do ensaio, começaram a apresentar, de início, pequenas manchas cloróticas nas folhas mais velhas, as quais foram evoluindo até o aparecimento de manchas necróticas internervais, não tendo crescimento uniforme, tornando-se tortuosas e enroladas na ponta. Nas folhas mais novas notou-se um amarelecimento do limbo foliar, acompanhado de murchamento. Tais sintomas são típicos, segundo MALAVOLTA (1980), da deficiência de $\mathrm{Ca}^{2+}$ na planta.

E, realmente, em todas as avaliações efetuadas, como se pode notar pelos dados apresentados na Tabela 44, este tratamento apresentou-se como deficiente neste elemento, com teores menores do que o considerado como nível crítico - $(0,2 \%)$ por GALLO et al. (1968) e por BATAGLIA \& DECHEN (1986). 
Os maiores teores foliares de $\mathrm{Ca}$ foram encontrados nos tratamentos onde se usou gesso, isoladamente ou em mistura, em todas as épocas de avaliação. Nestes tratamentos, os maiores níveis, considerados como adequados por MALAVOLTA (1980), foram detectados por ocasião da avaliação realizada na primeira soca.

Tabela 44. Teores médios de $\mathrm{Ca}$ (em \%) nas folhas de cana-de-açúcar, aos 6 meses após a aplicação dos produtos (cana planta) e aos 4 meses após o cultivo das soqueiras; dados médios de 5 repetições.

\begin{tabular}{|c|c|c|c|}
\hline \multirow[t]{2}{*}{ TRATAMENTO } & \multicolumn{3}{|c|}{ Ca (\%) } \\
\hline & CANA PLANTA & $1^{\mathrm{a}} \mathrm{SOCA}$ & $2^{2} \mathrm{SOCA}$ \\
\hline $\mathbf{T} 1$ & $0,27 a b$ & $0,59 a b$ & $0,34 a$ \\
\hline T 2 & $0,24 a b$ & $0,52 a b$ & $0,36 a$ \\
\hline T 3 & $0,29 a b$ & $0,47 b c d$ & $0,36 a$ \\
\hline T 4 & $0,20 b c$ & $0,35 d e$ & $0,27 a b$ \\
\hline T 5 & $0,12 c$ & $0,19 f$ & $0,13 c$ \\
\hline T 6 & $0,22 a b c$ & 0,39 cde & $0,29 a b$ \\
\hline $\mathbf{T} 7$ & $0,23 a b$ & $0,36 d e$ & $0,31 a b$ \\
\hline T 8 & $0,25 a b$ & $0,49 b c$ & $0,35 a$ \\
\hline T 9 & $0,32 a$ & $0,63 a$ & $0,37 a$ \\
\hline $\mathbf{T} 10$ & $0,21 b c$ & 0,29 ef & $0,21 b c$ \\
\hline $\mathbf{F}$ & $3,90 * *$ & $20,2 * *$ & $6,55 * *$ \\
\hline dms & 0,11 & 0,13 & 0,13 \\
\hline CV $(\%)$ & 24,9 & 15,7 & 22,1 \\
\hline \multicolumn{4}{|l|}{ LEGENDA : } \\
\hline \multicolumn{2}{|l|}{ T $1=$ calc calcítico } & \multicolumn{2}{|c|}{$\mathrm{T} 6=$ magnesita $(25 \%)+$ calc.calcítico $(75 \%)$} \\
\hline \multicolumn{2}{|c|}{$\mathrm{T} 2=$ calc magnesiano } & \multicolumn{2}{|c|}{$\mathrm{T} 7=$ magnesita $(15 \%)+$ calc.calcítico $(85 \%)$} \\
\hline \multicolumn{2}{|c|}{ T 3 = calc.dolomítico $1(70 \%)+$ gesso } & \multicolumn{2}{|c|}{ T $8=$ magnesita $(15 \%)+$ gesso $(85 \%)$} \\
\hline \multicolumn{2}{|c|}{ T $4=$ calc dolomítico 2} & \multicolumn{2}{|l|}{ T $9=$ gesso } \\
\hline \multicolumn{2}{|c|}{ T $5=$ magnesita } & \multicolumn{2}{|l|}{$\mathrm{T} 10=$ testemunha } \\
\hline
\end{tabular}

Médias seguidas da mesma letra, na vertical, não diferem entre si (Tukey a 10\%).

Teores adequados de Mg foliar, de acôrdo com GALLO et al. (1968) e MALAVOLTA (1980), foram encontrados, na primeira época de avaliação, em todos os tratamentos, com exceção do tratamento efetuado com calcário calcítico e com gesso, 
que não diferiram da testemunha; nestas condições, os maiores teores foram apresentados pelos tratamentos onde se usou a magnesita, isoladamente ou em mistura com gesso.

Tabela 45. Teores médios de $\mathrm{Mg}(\mathrm{em} \%)$ nas folhas de cana-de-açúcar, aos 6 meses após a aplicação dos produtos (cana planta) e aos 4 meses após o cultivo das soqueiras; dados médios de 5 repetições.

\begin{tabular}{|c|ccc|}
\hline TRATAMENTO & \multicolumn{3}{|c|}{ Mg (\%) } \\
\cline { 2 - 4 } & CANA PLANTA & $\mathbf{1}^{\mathbf{a}}$ SOCA & 2 $^{\mathbf{a}}$ SOCA \\
\hline T 1 & $0,13 c d$ & 0,09 ef & $0,06 f$ \\
T 2 & $0,16 b c d$ & $0,12 d e$ & $0,10 e$ \\
T 3 & $0,16 b c d$ & $0,17 c d$ & $0,14 c d$ \\
T 4 & $0,19 a b c$ & $0,23 c$ & $0,15 c$ \\
T 5 & $0,21 a b$ & $0,41 a$ & $0,22 a$ \\
T 6 & $0,18 b c$ & $0,31 b$ & $0,16 c$ \\
T 7 & $0,18 b c$ & $0,23 c$ & $0,12 d e$ \\
T 8 & $0,26 a$ & $0,34 b$ & $0,19 b$ \\
T 9 & $0,09 d$ & $0,05 f$ & $0,04 f$ \\
T 10 & $0,08 e$ & $0,07 e f$ & $0,06 f$ \\
\hline F & $7,67 * *$ & $50,6 * *$ & $45,0 * *$ \\
d ms & 0,08 & 0,07 & 0,03 \\
CV (\%) & 24,6 & 18,7 & 15,2 \\
\hline
\end{tabular}

LEGENDA :-

$\mathrm{T} 1$ = calc. calcítico

$\mathrm{T} 2$ = calc. magnesiano

T 3 = calc.dolomítico $1(70 \%)+$ gesso

T 4 = calc. dolomítico 2

T $5=$ magnesita

Médias seguidas da mesma letra, na vertical, não diferem entre si (Tukey a 10\%).
T 6 = magnesita $(25 \%)+$ calc.calcítico $(75 \%)$

T 7 = magnesita $(15 \%)+$ calc.calcítico $(85 \%)$

T 8 = magnesita $(15 \%)+$ gesso $(85 \%)$

T $9=$ gesso

$\mathrm{T} 10=$ testemunha

Adotando-se os teores entre 0,2 e $0,3 \%$ de $\mathrm{Mg}$ na folha como os teores adequados, conforme proposto por MALAVOLTA et al. (1989), na segunda soca, os tratamentos isolados de calcário dolomítico e de magnesita e as misturas de magnesita com calcário calcítico e com gesso, apresentaram bons níveis de $\mathrm{Mg}$ foliar. Porém, na ápoca da avaliação realizada na $2^{\mathrm{a}}$ soca, somente a magnesita aplicada isoladamente 
apresentou teores considerados adequados por aquele autor e também por RAIJ (1994); os resultados obtidos para as análises foliares de magnésio são encontrados na Tabela 45.

Tabela 46. Teores médios de S (em \%) nas folhas de cana-de-açúcar, aos 6 meses após a aplicação dos produtos (cana planta) e aos 4 meses após o cultivo das soqueiras; dados médios de 5 repetições.

\begin{tabular}{|c|c|c|c|}
\hline \multirow[t]{2}{*}{ TRATAMENTO } & \multicolumn{3}{|c|}{$\mathbf{S}(\%)$} \\
\hline & CANA PLANTA & $1^{\mathrm{a}}$ SOCA & $2^{\mathrm{a}}$ SOCA \\
\hline T 1 & $0,05 c$ & $0,07 c$ & $0,08 d$ \\
\hline T 2 & $0,04 c$ & $0,07 c$ & $0,11 b c$ \\
\hline T 3 & $0,09 b$ & $0,12 b$ & $0,13 a b$ \\
\hline T 4 & $0,06 c$ & $0,07 c$ & $0,10 c d$ \\
\hline T 5 & $0,05 c$ & $0,07 c$ & $0,10 \mathrm{~cd}$ \\
\hline T 6 & $0,05 c$ & $0,07 c$ & $0,09 c d$ \\
\hline T 7 & $0,05 c$ & $0,07 c$ & $0,10 \mathrm{~cd}$ \\
\hline T 8 & $0,20 a$ & $0,17 a$ & $0,15 a$ \\
\hline T 9 & $0,10 b$ & $0,15 a b$ & $0,15 a$ \\
\hline T 10 & $0,04 c$ & $0,07 c$ & $0,11 b c$ \\
\hline $\mathbf{F}$ & $31,3^{* *}$ & $13,8^{* *}$ & $8,95 * *$ \\
\hline dms & 0,03 & 0,04 & 0,03 \\
\hline CV $(\%)$ & 25,2 & 24,1 & 15,4 \\
\hline \multicolumn{4}{|l|}{ LEGENDA:- } \\
\hline \multirow{2}{*}{\multicolumn{2}{|c|}{$\begin{array}{l}\text { T } 1=\text { calc } . \text { calcítico } \\
\text { T } 2=\text { calc } \cdot \text { magnesiano }\end{array}$}} & \multicolumn{2}{|c|}{ T $6=$ magnesita $(25 \%)+$ calc calcítico $(75 \%)$} \\
\hline & & \multirow{2}{*}{\multicolumn{2}{|c|}{$\begin{array}{l}\text { T } 7=\text { magnesita }(15 \%)+\text { calc.calcítico }(85 \%) \\
\text { T } 8=\text { magnesita }(15 \%)+\text { gesso }(85 \%)\end{array}$}} \\
\hline \multicolumn{2}{|c|}{$\begin{array}{l}1 \quad 2=\text { calc. magnesiano } \\
\text { T } 3=\text { calc. dolomítico } 1(70 \%)+\text { gesso }\end{array}$} & & \\
\hline \multicolumn{2}{|c|}{ T $4=$ calc. dolomítico 2} & \multicolumn{2}{|l|}{$\mathrm{T} 9=$ gesso } \\
\hline \multicolumn{2}{|l|}{ T $5=$ magnesita } & $\mathrm{T} 10=$ testemunha & \\
\hline
\end{tabular}

Médias seguidas da mesma letra, na vertical, não diferem entre si (Tukey a 10\%).

Teores extremamente baixos de $\mathrm{S}$ foram encontrados, em cana planta, em todos os tratamentos estudados, com exceção da mistura magnesita e gesso, que, com $0,2 \%$ de $\mathrm{S}$ foliar pode ser considerado como tendo um nível adequado, como cita MALAVOLTA (1980) e RAIJ (1994), ou mesmo, no nível crítico, considerado por BATAGLIA \& DECHEN (1986). Como se pode observar na Tabela 46, nem a 
aplicação isolada de gesso proporcionou, nesta época, teores foliares de $\mathrm{S}$ que se aproximassem dos limites mínimos propostos por estes autores.

Por ocasião das avaliações realizadas nas socas observou-se um relativo acréscimo nos teores foliares deste elemento no tratamento que recebeu a mistura de calcário dolomítico (70\%) e gesso, porém, em ambas as épocas, todos os tratamentos enquadraram-se como deficientes no nutriente, levando-se em consideração os mesmos autores mencionados anteriormente. De qualquer maneira, os maiores teores de $\mathrm{S}$ foliar foram sempre encontrados quando se aplicou a magnesita em mistura com gesso.

Estes resultados são, em parte, concordantes com os obtidos por GAVIOLI et al. (1992). Estes autores também não encontraram teores adequados de S foliar quando aplicaram gesso agrícola, isolado ou em mistura; porém, os teores detectados por eles também não diferiram da testemunha. No presente estudo, por outro lado, sempre foram notadas diferenças significativas nos teores foliares de $\mathrm{S}$ entre os tratamentos que receberam o gesso e a testemunha.

Com referência ao manganês, cujos resultados são encontrados na Tabela 47, as plantas de cana-de-açúcar não acusaram deficiência deste elemento, pois todos os tratamentos, nas avaliações realizadas tanto na cana planta como nas socas, indicaram possuir teores foliares de Mn superiores aos níveis considerados críticos por diversos autores, tais como MALAVOLTA et al. (1974), MALAVOLTA (1980), BATAGLIA \& DECHEN (1986) e RAIJ (1994).

Não se detectou, portanto, uma esperada diminuição nos teores foliares de Mn nos tratamentos que receberam os corretivos de acidez do solo, que seria 
provocada pela interferência destes produtos no $\mathrm{pH}$ do solo (como, de fato, ocorreu) e, que, consequentemente, proporcionaria uma menor absorção de Mn, como observaram GAVIOLI et al. (1992). Por sua vez, a aplicação isolada de gesso, invariavelmente proporcionou os maiores teores foliares do elemento, em todas as épocas analisadas.

Tabela 47. Teores médios de Mn (em ppm) nas folhas de cana-de-açúcar, aos 6 meses após a aplicação dos produtos (cana planta) e aos 4 meses após o cultivo das soqueiras; dados médios de 5 repetições.

\begin{tabular}{|c|c|c|c|}
\hline \multirow{2}{*}{ TRATAMENTO } & \multicolumn{3}{|c|}{ Mn (ppm) } \\
\hline & CANA PLANTA & $1^{\mathrm{a}}$ SOCA & $2^{\mathrm{a}}$ SOCA \\
\hline T1 1 & $158 b c$ & $151 c$ & $78 d$ \\
\hline T 2 & $163 b c$ & $143 c$ & 93 bcd \\
\hline T 3 & $153 c$ & $155 b c$ & $122 b c$ \\
\hline T 4 & $145 c$ & $143 c$ & $99 \mathrm{bcd}$ \\
\hline T 5 & $157 b c$ & $177 b c$ & $90 \mathrm{~cd}$ \\
\hline T 6 & $152 c$ & $141 c$ & $88 c d$ \\
\hline T 7 & $153 c$ & $134 c$ & $100 \mathrm{bcd}$ \\
\hline T 8 & $158 b c$ & $167 b c$ & $133 a b$ \\
\hline T 9 & $239 a$ & $272 a$ & $171 a$ \\
\hline T 10 & $192 b$ & $213 a b$ & $108 \mathrm{bcd}$ \\
\hline $\mathbf{F}$ & $10,3 * *$ & $9,36 * *$ & $7,83 * *$ \\
\hline dms & 38 & 60 & 42 \\
\hline CV $(\%)$ & 11,8 & 18,3 & 20,2 \\
\hline \multicolumn{4}{|l|}{ LEGENDA } \\
\hline \multicolumn{2}{|l|}{ T $1=$ calc.calcítico } & \multicolumn{2}{|c|}{ T $6=$ magnesita $(25 \%)+$ calc. calcítico $(75 \%)$} \\
\hline \multirow{2}{*}{\multicolumn{2}{|c|}{$\begin{array}{l}\text { T } 2=\text { calc } \text { magnesiano } \\
\text { T } 3=\text { lalc }\end{array}$}} & \multicolumn{2}{|c|}{ T $7=$ magnesita $(15 \%)+$ calc calcítico $(85 \%)$} \\
\hline & & \multicolumn{2}{|c|}{ T $8=$ magnesita $(15 \%)+$ gesso $(85 \%)$} \\
\hline \multicolumn{2}{|c|}{$4=$ calc dolomítico 2} & T $9=$ gesso & \\
\hline \multicolumn{2}{|c|}{$\mathrm{T} 5=$ magnesita } & $\mathrm{T} 10=$ testemunha & \\
\hline
\end{tabular}

Médias seguidas da mesma letra, na vertical, não diferem entre si (Tukey a 10\%).

Os teores foliares de alumínio só foram analisados nas soqueiras e os dados são apresentados na Tabela 48. Verificou-se a existência de diferenças significativas nos teores foliares de $\mathrm{Al}$ nas 2 épocas analisadas, sempre com os menores 
teores sendo detectados no tratamento que recebeu a mistura de magnesita com gesso; na $1^{\text {a }}$ soca, os teores encontrados neste tratamento foram significativamente diferentes dos encontrados no tratamento que recebeu a aplicação de gesso isolado e da testemunha. Já na $2^{a}$ soca, houve diferença significativa apenas entre a mistura de gesso agrícola com magnesita e o calcário magnesiano.

Tabela 48. Teores médios de $\mathrm{Al}$ (em ppm) nas folhas de cana-de-açúcar aos 4 meses após o cultivo das soqueiras; dados médios de 5 repetições.

\section{LEGENDA :}

\begin{tabular}{|c|cc|}
\hline TRATAMENTO & \multicolumn{2}{|c|}{ Al (ppm) } \\
\cline { 2 - 3 } & $\mathbf{1}^{\mathrm{a}}$ SOCA & $\mathbf{2}^{\mathrm{a}}$ SOCA \\
\hline T 1 & $6 a b$ & $73 b$ \\
T 2 & $5 b$ & $130 a$ \\
T 3 & $5 b$ & $85 a b$ \\
T 4 & $5 b$ & $94 a b$ \\
T 5 & $6 a b$ & $89 a b$ \\
T 6 & $6 a b$ & $98 a b$ \\
T 7 & $6 a b$ & $81 a b$ \\
T 8 & $5 b$ & $77 b$ \\
T 9 & $7 a$ & $82 a b$ \\
T 10 & $7 a$ & $112 a b$ \\
\hline F & $1,21^{+}$ & $2,18 *$ \\
dms & 2 & 51 \\
CV (\%) & 24,8 & 28,4 \\
\hline
\end{tabular}

T 1 = calc.calcítico

T 2 = calc.magnesiano

T 3 = calc.dolomítico 1 (70\%)+gesso

T 4 = calc. dolomítico 2

T 5 = magnesita
T 6 = magnesita $(25 \%)+$ calc.calcítico $(75 \%)$

T $7=$ magnesita $(15 \%)+$ calc.calcítico $(85 \%)$

T $8=$ magnesita $(15 \%)+$ gesso $(85 \%)$

T $9=$ gesso

$\mathrm{T} 10=$ testemunha

Médias seguidas da mesma letra, na vertical, não diferem entre si (Tukey $10 \%$ ).

É de se ressaltar também que na avaliação realizada na segunda soca observou-se um aumento bastante acentuado nos teores foliares de Alumínio, em todos os tratamentos, os quais atingiram teores maiores do que $70 \mathrm{ppm}$; tais resultados talvez 
sejam devidos à falta de chuvas ocorrida durante a época da cana planta, o que se refletiu em baixa absorção de $\mathrm{Al}^{3+}$ pela planta, que mostrou baixíssimos teores foliares na avaliação realizada na primeira soca. No ano agricola seguinte, que foi normal em termos de precipitações pluviais, houve aumento da água disponível no solo, com consequente aumento do teor do elemento, ocorrendo também maior absorção, que foi acusada pelas plantas de segunda soqueira.

\subsection{Produções finais obtidas}

\subsubsection{Número de colmos industrializáveis}

Por ocasião das colheitas da cana planta e das duas primeiras soqueiras verificou-se diferenças significativas em alguns parâmetros, entre os tratamentos estudados. Pela análise dos dados encontrados na Tabela 49 observa-se que, em cana planta, a magnesita em mistura com gesso e o calcário magnesiano diferenciaram-se significativamente da magnesita aplicada isoladamente, que se apresentou como o pior tratamento.

Da mesma forma houve diferença estatisticamente significativa no número de colmos existentes por metro linear na época da colheita da primeira soca entre o tratamento que recebeu a mistura magnesita + gesso e o tratamento onde se aplicou somente a magnesita e também com a testemunha, sem qualquer produto.

A diferença no "stand" observada entre o tratamento magnesita + gesso

e o tratamento que recebeu a magnesita isoladamente persistiu até a época da $3^{\mathrm{a}}$ avaliação, na colheita da segunda soqueira. 
Tabela 49. Número de colmos industrializáveis ( $\mathrm{n}^{\circ}$ de colmos $/ \mathrm{m}$ linear) na colheita da cana planta e das duas primeiras socas; dados médios de 5 repetições.

\begin{tabular}{|c|c|c|c|}
\hline \multirow[t]{2}{*}{ TRATAMENTO } & \multicolumn{3}{|c|}{$\mathbf{N}^{\circ}$ DE COLMOS INDUSTRIALIZ. (n ${ }^{\circ}$ colmos/m linear) } \\
\hline & CANA PLANTA & 1 $^{2}$ SOCA & $2^{2}$ SOCA \\
\hline T 1 & $7,6 a b$ & $8,3 a b$ & $7,6 a b$ \\
\hline T 2 & $8,1 a$ & $8,3 a b$ & $8,4 a b$ \\
\hline T 3 & $7,0 a b$ & $8,1 a b$ & $8,5 a$ \\
\hline T 4 & $7,8 a b$ & $8,6 a$ & $8,8 a$ \\
\hline T 5 & $6,6 b$ & $6,6 c$ & $6,3 b$ \\
\hline T 6 & $7,5 a b$ & $8,3 a b$ & $8,6 a$ \\
\hline T 7 & $7,5 a b$ & $8,2 a b$ & $9,0 a$ \\
\hline Т 8 & $8,0 a$ & $9,1 a$ & $8,5 a$ \\
\hline Т 9 & $7,4 a b$ & $8,2 a b$ & $8,5 a$ \\
\hline $\mathrm{T} 10$ & $7,7 a b$ & $7,2 b c$ & $6,9 a b$ \\
\hline $\mathbf{F}$ & $1,94+$ & $4,23 * *$ & $2,99 * *$ \\
\hline dms & 1,4 & 1,4 & 2,2 \\
\hline CV (\%) & 9,5 & 9,5 & 14,1 \\
\hline
\end{tabular}

LEGENDA :

$\mathrm{T} 1$ = calc.calcítico

T 6 = magnesita $(25 \%)+$ calc.calcítico $(75 \%)$

T 2 = calc. magnesiano

T 7 = magnesita $(15 \%)+$ calc.calcítico $(85 \%)$

T 3 = calc.dolomítico $1(70 \%)+$ gesso

T $4=$ calc. dolomítico 2

T 8 = magnesita $(15 \%)+$ gesso $(85 \%)$

T $5=$ magnesita

$\mathrm{T} 9=$ gesso

$\mathrm{T} 10=$ testemunha

Médias seguidas da mesma letra, na vertical, não diferem entre si (Tukey a 10\%).

Estes resultados são bons indicativos da provável obtenção de maiores produções nas parcelas tratadas com a mistura de magnesita e gesso, uma vez que a produtividade agrícola final da cana-de-açúcar é função de uma série de parâmetros, sendo que um dos principais é o "stand" existente por ocasião da colheita.

\subsubsection{Produtividades agrícolas}

Este foi o parâmetro que mais acusou diferenças entre os tratamentos estudados. De um modo geral, observou-se que houve uma supremacia do tratamento 
que recebeu a mistura de magnesita (a $15 \%$ em peso) com gesso, na colheita da segunda soca; os dados de produção final obtida, em toneladas de cana/ha, podem ser vistos na Tabela 50. Já por ocasião da colheita da cana planta este tratamento produziu cêrca de $45 \%$ a mais que a testemunha, com a produtividade média de 94,38 toneladas de canade-açúcar/ha, sendo similar às produtividades obtidas com os demais tratamentos, com exceção da aplicação isolada de magnesita, que manteve-se igual à testemunha.

Tabela 50. Produtividades agrícolas ( $\mathrm{t}$ cana/ha) obtidas na colheita da cana planta e das duas primeiras socas e produtividade acumulada nos 3 cortes; dados médios de 5 repetições.

\begin{tabular}{|c|c|c|c|c|}
\hline \multirow[t]{2}{*}{$\begin{array}{l}\text { TRATA } \\
\text { MENTO }\end{array}$} & \multicolumn{4}{|c|}{$\begin{array}{l}\text { PRODUTIVIDADE AGRÍCOLA } \\
\text { ( } t \text { cana } / \mathrm{ha})\end{array}$} \\
\hline & CANA PLANTA & $1^{2} \mathrm{SOCA}$ & $2^{2}$ SOCA & ACUMULADA \\
\hline $\mathbf{T} \mathbf{1}$ & $68,90 a b$ & $80,25 b$ & $69,42 b$ & $218,57 b c d$ \\
\hline $\mathbf{T} 2$ & $80,84 a b$ & $79,96 b$ & $74,17 b$ & $234,97 b$ \\
\hline $\mathbf{T} 3$ & $76,91 a b$ & $85,00 a b$ & $83,58 b$ & $245,49 a b$ \\
\hline $\mathbf{T} 4$ & $81,86 a b$ & $84,83 a b$ & $80,33 b$ & $247,02 a b$ \\
\hline $\mathbf{T} 5$ & $60,63 b$ & $55,33 c$ & $49,08 c$ & $165,04 d$ \\
\hline T 6 & $82,24 a b$ & $83,83 a b$ & $76,83 b$ & $242,90 a b$ \\
\hline $\mathbf{T} 7$ & $78,30 a b$ & $83,33 a b$ & $76,00 b$ & $237,63 b$ \\
\hline T 8 & $94,38 a$ & $102,08 a$ & $99,50 a$ & $295,96 a$ \\
\hline T 9 & $71,95 a b$ & $82,83 a b$ & $74,25 b$ & $229,03 b c$ \\
\hline T 10 & $65,44 b$ & $59,75 c$ & $46,92 c$ & $172,11 c d$ \\
\hline $\mathbf{F}$ & $2,50^{*}$ & $8,57^{* *}$ & $18,8^{* *}$ & $8,32 * *$ \\
\hline dms & 26,75 & 19,72 & 15,51 & 57,01 \\
\hline CV $(\%)$ & 18,0 & 12,7 & 10,9 & 12,8 \\
\hline \multicolumn{5}{|l|}{ LEGENDA } \\
\hline \multicolumn{2}{|c|}{ T 1 = calc calcítico } & \multicolumn{3}{|c|}{$\mathrm{T} 6=$ magnesita $(25 \%)$} \\
\hline \multicolumn{2}{|c|}{$\mathrm{T} 2$ = calc.magnesiano } & \multicolumn{3}{|c|}{$\mathrm{T} 7=$ magnesita $(15 \%)+$ calc calcítico $(85 \%)$} \\
\hline \multicolumn{2}{|c|}{ T $3=$ calc dolomítico $1(70 \%)+$ gesso } & \multicolumn{3}{|c|}{$\mathrm{T} 8=$ magnesita $(15 \%)+\operatorname{gesso}(85 \%)$} \\
\hline \multicolumn{2}{|c|}{$\mathrm{T} 4=$ calc dolomítico 2} & \multicolumn{3}{|c|}{$\mathrm{T} 9=$ gesso } \\
\hline \multicolumn{2}{|c|}{ T $5=$ magnesita } & \multicolumn{3}{|c|}{$\mathrm{T} 10=$ testemunha } \\
\hline
\end{tabular}

Médias seguidas da mesma letra, na vertical, não diferem entre si (Tukey a 10\%). 
A mesma tendência foi observada na época da colheita da primeira soca, quando a mistura de magnesita com gesso foi superior à testemunha, à magnesita aplicda isoladamente e ao calcário magnesiano, estatisticamente diferentes ao nível de $10 \%$ de probabilidade, apresentando uma produtividade média de 102,08 toneladas de cana-deaçúcar/ha.

O relativo aumento de produção obtido em todos os tratamentos, com exceção da testemunha e da aplicação isolada de magnesita, por ocasião do $2^{\circ}$ corte, é um fato que pode ser creditado a fatores genéticos da própria variedade, sendo muito comum, segundo SORDI et al. (1987), a variedade RB72454 se destacar nas produções de soqueiras, mantendo, em boas condições de fertilidade de solo, altas produtividades agrícolas associadas a alta riqueza em sacarose, no seu melhor período de industrialização. Não se pode esquecer também que o ano agrícola na época da $1^{\text {a }}$ soca foi melhor, em termos de distribuição de chuvas, concorrendo também para a obtenção de maiores produtividades o tempo de reação dos corretivos e do gesso agrícola.

Com o decorrer do tempo, pôde-se observar um aumento nestas diferenças entre os tratamentos estudados; assim, por ocasião da colheita da $2^{a}$ soca $\left(3^{\circ}\right.$ corte), o único tratamento que se salientou, mantendo alta produtividade $(99,50$ toneladas de cana-de-açúcar/ha), diferenciando-se de todos os demais, foi a mistura de magnesita com gesso, praticamente apresentando produções dobradas em relação à testemunha ou ao tratamento onde foi aplicada a magnesita isoladamente. Com a produção obtida, este tratamento manteve-se superior também aos tratamentos que receberam calcário dolomítico, isoladamente ou em mistura com gesso. 
Como se observa na Tabela 50, o tratamento que recebeu a mistura do gesso com magnesita foi o que proporcionou maior produção acumulada ao longo dos 3 cortes; tal ocorrência talvez possa ser explicada pela maior disponibilidade, em teores mais balanceados, dos nutrientes $\mathrm{S}_{-} \mathrm{SO}_{4}{ }^{2-}, \mathrm{Ca}^{2+}$ e $\mathrm{Mg}^{2+}$ e também pela maior durabilidade dos efeitos benéficos ao solo proporcionados pela mistura do gesso agrícola com a magnesita em relação ao calcário dolomítico, isolado ou em mistura com gesso, ao longo do tempo e do perfil do solo, como pode ser observado nas Tabelas 17 a 28 .

Pode-se inferir até, quando se observa as produtividades agrícolas obtidas na área testemunha, que se deve esperar um aumento da longevidade do canavial com a aplicação dos corretivos de acidez do solo e do gesso agrícola, com destaque para a mistura de magnesita e gesso agrícola, aplicados na mistura de $15 \%$ em peso de magnesita com $85 \%$ em peso de gesso, o que equivaleu a $1,98 \mathrm{t} / \mathrm{ha}$ de magnesita $+3,54$ tha de gesso, dentro da metodologia utilizada, que foi a de elevar o índice de saturação por bases (V \%) a 70\%, na profundidade 0 a $40 \mathrm{~cm}$ e, no caso do gesso, de elevar o teor de $\mathrm{Ca}^{2+}$ a 2 meq $/ 100 \mathrm{~cm}^{3}$, na mesma profundidade. As colheitas das socas subsequentes, já que o experimento terá continuidade, poderão comprovar esta hipótese. A Figura 5 ilustra visualmente estas considerações. 
PRODUTUVADES AGR COLAS (T/HA) EM 3 CORTES

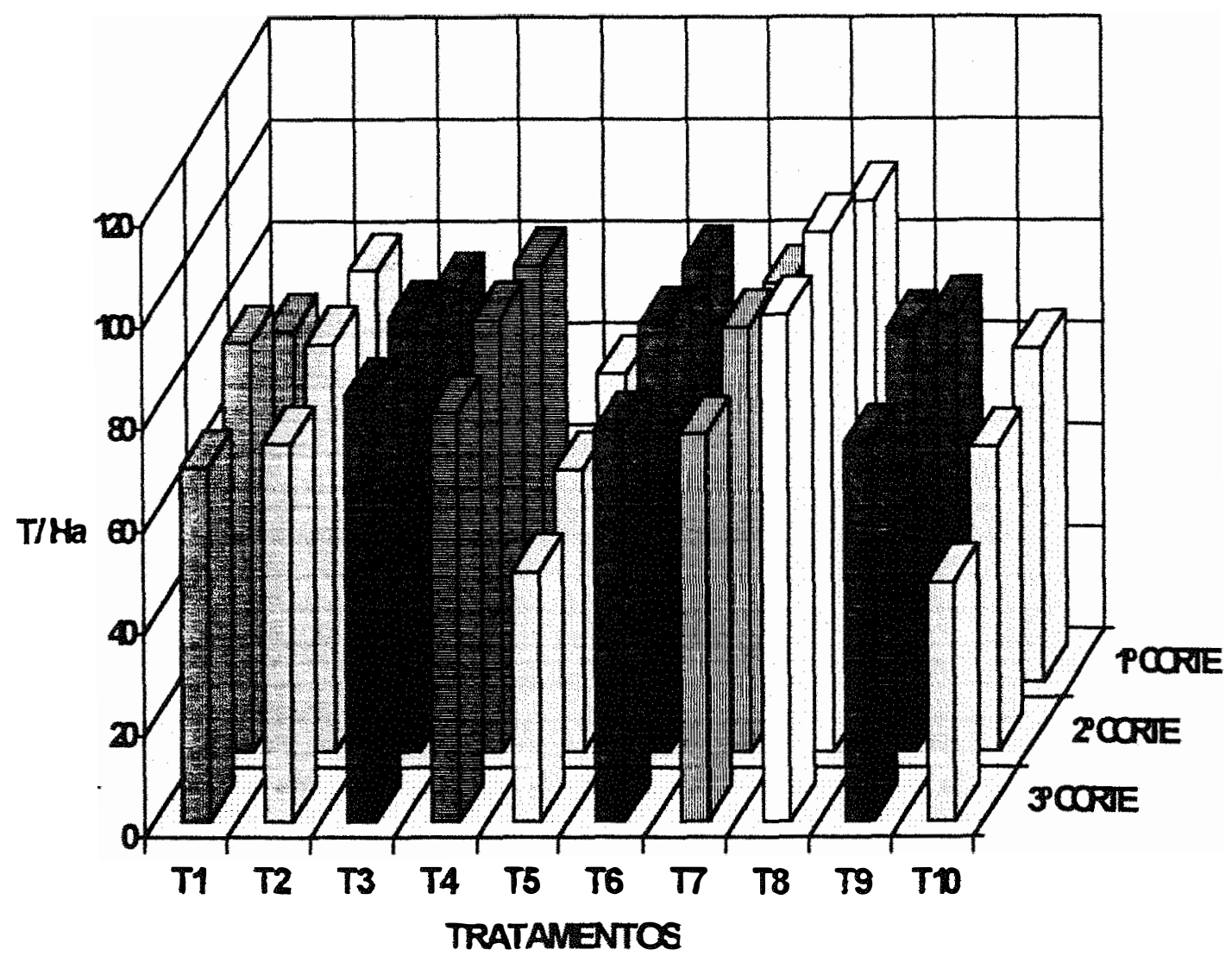

LEGENDA :

T 1 = calcário calcítico

T $6=$ magnesita $(25 \%)+$ calc.calcítico $(75 \%)$

T 2 = calcário magnesiano

T $7=$ magnesita $(15 \%)+$ calc.calcítico $(85 \%)$

T 3 = calc.dolomítico $1(70 \%)+$ gesso

T $8=$ magnesita $(15 \%)+$ gesso

T 4 = calcário dolomítico 2

T $9=$ gesso

T 5 = magnesita

$\mathrm{T} 10=$ testemunha

Figura 6. Produtividades agrícolas ( $\mathrm{t}$ cana/ha) obtidas nos diversos tratamentos, na cana planta e nas duas primeiras socas. 
É interessante notar também que todos os tratamentos estudados, com exceção da magnesita aplicada isoladamente e da testemunha, mantiveram-se com média de produtividade de 3 cortes ao redor de 80 t/ha, o que é superior à média do Estado de São Paulo; o destaque, mais uma vez, ficou para a mistura do gesso agrícola com a magnesita.

\subsubsection{Qualidade da matéria prima}

As Tabelas 51, 52 e 53 apresentam os dados de pol \% cana, fibra \% cana e pureza da matéria prima final obtida por ocasião dos 3 cortes estudados.

Tabela 51. Dados de pol \% cana obtidos na colheita da cana planta e das duas primeiras socas; dados médios de 5 repetições.

\begin{tabular}{|c|ccc|}
\hline TRATAMENTO & \multicolumn{3}{|c|}{ POL \% CANA } \\
\cline { 2 - 4 } & CANA PLANTA & $\mathbf{1}^{\mathbf{a}}$ SOCA & $\mathbf{2}^{\mathbf{a}}$ SOCA \\
\hline T 1 & 14,80 & 15,48 & 16,07 \\
T 2 & 15,46 & 15,69 & 16,01 \\
T 3 & 15,06 & 15,81 & 16,48 \\
T 4 & 15,48 & 15,93 & 16,35 \\
T 5 & 15,85 & 15,82 & 16,30 \\
T 6 & 15,60 & 15,80 & 17,04 \\
T 7 & 15,46 & 15,82 & 16,01 \\
T 8 & 14,61 & 15,63 & 16,05 \\
T 9 & 15,22 & 15,19 & 16,39 \\
T 10 & 15,63 & 15,16 & 16,51 \\
\hline F & 1,63 & 2,20 & 1,46 \\
dms & 1,32 & 0,80 & 1,14 \\
CV (\%) & 4,4 & 2,6 & 3,6 \\
\hline
\end{tabular}

LEGENDA :

$\mathrm{T} 1$ = calc.calcítico

$\mathrm{T} 2$ = calc.magnesiano

T 3 = calc.dolomítico $1(70 \%)+$ gesso

T $4=$ calc. dolomítico 2

T $5=$ magnesita
T 6 = magnesita $(25 \%)+$ calc.calcítico $(75 \%)$

$\mathrm{T} 7=$ magnesita $(15 \%)+$ calc.calcítico $(85 \%)$

T $8=$ magnesita $(15 \%)+$ gesso $(85 \%)$

$\mathrm{T} 9=$ gesso

$\mathrm{T} 10=$ testemunha

Médias seguidas da mesma letra, na vertical, não diferem entre si (Tukey a 10\%). 
Verifica-se que não existiram diferenças significativas entre os tratamentos, quando se analisa os parâmetros de pol \% cana e de pureza, em todas as épocas de avaliação; todos os tratamentos apresentaram-se com bons teores de pol \% cana e com alta pureza, compatíveis com a variedade e com a época de corte realizada.

Tabela 52. Dados de fibra \% cana obtidos na colheita da cana planta e das duas primeiras socas; dados médios de 5 repetições.

\begin{tabular}{|c|ccc|}
\hline TRATAMENTO & \multicolumn{3}{|c|}{ FHBRA \% CANA } \\
\cline { 2 - 4 } & CANA PLANTA & $\mathbf{1}^{\mathbf{2}}$ SOCA & $\mathbf{2}^{\mathbf{a}}$ SOCA \\
\hline T 1 & 14,12 & $14,25 a b c$ & 16,42 \\
T 2 & 14,00 & $13,85 b c$ & 16,14 \\
T 3 & 14,26 & $14,10 a b c$ & 16,31 \\
T 4 & 14,27 & $13,92 b c$ & 15,87 \\
T 5 & 14,04 & $15,98 a b$ & 17,39 \\
T 6 & 13,46 & $14,34 a b c$ & 14,36 \\
T 7 & 13,46 & $14,18 a b c$ & 16,34 \\
T 8 & 14,12 & $13,43 c$ & 15,57 \\
T 9 & 14,70 & $15,42 a b c$ & 15,63 \\
T 10 & 14,26 & $16,30 a$ & 15,86 \\
\hline F & 0,48 & $3,64 * *$ & 0,82 \\
dms & 2,33 & 2,21 & 3,79 \\
CV (\%) & $\mathbf{8 , 5}$ & 7,8 & 12,2 \\
\hline
\end{tabular}

\section{LEGENDA :}

T $1=$ calc.calcítico

T 6 = magnesita $(25 \%)+$ calc.calcítico $(75 \%)$

T 2 = calc.magnesiano

T 7 = magnesita $(15 \%)+$ calc.calcítico $(85 \%)$

T 3 = calc.dolomítico $1(70 \%)+$ gesso

T $4=$ calc. dolomítico 2

T 8 = magnesita $(15 \%)+$ gesso $(85 \%)$

T $9=$ gesso

T $5=$ magnesita

T $10=$ testemunha

Médias seguidas da mesma letra, na vertical, não diferem entre si (Tukey a 10\%).

Apenas no parâmetro de fibra $\%$ cana, por ocasião do $2^{\circ}$ corte (na primeira soca), a testemunha apresentou maiores teores de fibra do que os tratamentos em que se aplicou a mistura de magnesita com gesso,e, também do que os tratamentos que receberam calcário magnesiano ou calcário dolomítico. Porém, os teores de fibra \% 
cana encontrados nestes tratamentos não são em nada comprometedores da boa qualidade da matéria prima obtida.

Tabela 53. Dados de pureza da matéria prima obtidos na colheita da cana planta e das duas primeiras socas; dados médios de 5 repetições.

\begin{tabular}{|c|ccc|}
\hline TRATAMENTO & \multicolumn{3}{|c|}{ PUREZA (\%) } \\
\cline { 2 - 4 } & CANA PLANTA & $\mathbf{1}^{\mathbf{a}}$ SOCA & $\mathbf{2}^{\mathbf{a}}$ SOCA \\
\hline T 1 & $\mathbf{8 8 , 9 2}$ & 90,12 & $\mathbf{8 8 , 9 1}$ \\
T 2 & 90,92 & 90,28 & 89,02 \\
T 3 & 89,82 & 90,84 & 88,71 \\
T 4 & 90,07 & 91,29 & 89,61 \\
T 5 & 90,31 & 90,79 & 90,38 \\
T 6 & 90,72 & 91,30 & 90,68 \\
T 7 & $\mathbf{8 9 , 9 8}$ & 91,96 & 89,11 \\
T 8 & $\mathbf{8 8 , 1 5}$ & 90,41 & 89,78 \\
T 9 & 90,03 & 90,51 & $\mathbf{8 8 , 2 8}$ \\
T 10 & 91,15 & 91,26 & $\mathbf{8 9 , 1 2}$ \\
\hline F & 1,52 & 0,87 & 1,08 \\
dms & $\mathbf{3 , 2 0}$ & 2,66 & 3,14 \\
CV (\%) & $\mathbf{1 , 8}$ & 1,5 & 1,8 \\
\hline
\end{tabular}

LEGENDA :

$\mathrm{T} 1$ = calc.calcítico

T 6 = magnesita $(25 \%)+$ calc.calcítico $(75 \%)$

T 2 = calc.magnesiano

T $7=$ magnesita $(15 \%)+$ calc.calcítico $(85 \%)$

T 3 = calc.dolomítico $1(70 \%)+$ gesso

T 4 = calc. dolomítico 2

T $8=$ magnesita $(15 \%)+$ gesso $(85 \%)$

T 5 = magnesita

$\mathrm{T} 9=$ gesso

$\mathrm{T} 10=$ testemunha

Médias seguidas da mesma letra, na vertical, não diferem entre si (Tukey a 10\%).

Pode-se, portanto, concluir que não houve influência dos produtos corretivos da acidez do solo estudados e do gesso, aplicados isoladamente ou em mistura, nas qualidades tecnológicas da cana-de-açúcar, nos 3 cortes analisados; estes resultados foram muito similares aos obtidos por GAVIOLI et al. (1992). 


\subsection{Correlações entre variáveis aleatórias.}

Mesmo levando-se em consideração que a busca de correlações entre fatores isolados de produção só se torna consistente a partir de um número elevado de dados, obtidos em diferentes condições, procurou-se determinar as correlações havidas entre os diversos parâmetros obtidos nas análises de solo e de planta com as produções obtidas nos 3 cortes, que se consideram importantes apenas como indicação geral e para servir de comparação com outros estudos congêneres.

Dentro desta filosofia, as diversas correlações encontradas entre os parâmetros obtidos nas análises do solo e da planta e as produtividades agrícolas (toneladas de cana/ha) obtidas na cana planta e na $1^{\mathrm{a}}$ e $2^{\mathrm{a}}$ socas acham-se indicadas na Tabela 54 .

Observou-se que a correlação mais forte, altamente significativa, foi para o elemento $\mathrm{Ca}^{2+}$; os teores de $\mathrm{Ca}^{2+}$ encontrados em todo o perfil do solo estudado mostraram-se altamente correlacionados com as produtividades obtidas, especialmente na época da colheita da $1^{\mathrm{a}}$ soca. Com o decorrer do tempo, pode-se notar que as maiores correlações são encontradas para o $\mathrm{Ca}^{2+}$ existente na camada arável. Estes dados são concordantes com os obtidos por VARGAS (1981), que encontrou também correlações altamente significativas entre estes dois parâmetros.

Saliente-se também os resultados de significância estatística obtidos entre as relações de $\mathrm{Ca}^{2+} / \mathrm{K}^{+}$e de $\mathrm{Ca}^{2+}+\mathrm{Mg}^{2+} / \mathrm{K}^{+}$com as produtividades agrícolas da cana planta e das socas, reafirmando o fato que, em solos de baixa CTC, tal como o trabalhado, estas relações passam a ter grande importância. 
Tabela 54. Correlações lineares entre os parâmetros obtidos nas análises de solo e de planta e as produtividades agrícolas (TCH) da cana planta e das duas primeiras socas.

\begin{tabular}{|c|c|c|c|}
\hline \multirow[t]{2}{*}{ PARÂMETROS } & \multicolumn{3}{|c|}{ COEFICIENTE DE CORRELAÇÁO ( $r$ ) } \\
\hline & Cana planta & $1^{2}$ soca & $2^{a}$ soca \\
\hline $\mathrm{Ca}^{2+}$ (perfil) $\times \mathrm{TCH}$ & 0,70 * & $0,93 * \star$ & $0,67^{\star}$ \\
\hline $\mathrm{Ca}^{2+}$ (cam arável) $\times \mathrm{TCH}$ & 0,68 * & $0,90 * *$ & $0,70^{*}$ \\
\hline $\mathrm{Ca}^{2+}$ (profundidade) $\times \mathrm{TCH}$ & 0,65 * & $0,87 * *$ & $0,58 n s$ \\
\hline $\mathrm{Mg}^{2+} \times \mathrm{TCH}$ & $0,19 n s$ & $0,003 n s$ & $0,02 n s$ \\
\hline $\mathrm{K}^{+} \times \mathrm{TCH}$ & $0,01 n s$ & $-0,74 *$ & $-0,64 *$ \\
\hline$\left(\mathrm{Ca}^{2+}+\mathrm{Mg}^{2+}\right) \times \mathrm{TCH}$ & $0,63 n s$ & $0,58 n s$ & $0,54 n s$ \\
\hline$\left(\mathrm{Ca}^{2+} \mathrm{Mg}^{2+}\right) \times \mathrm{TCH}$ & $-0,08 n s$ & $0,02 n s$ & $-0,03 n s$ \\
\hline$\left(\mathrm{Mg}^{2+} / \mathrm{K}^{+}\right) \times \mathrm{TCH}$ & $0,17 n s$ & $0,50 n s$ & $0,45 n s$ \\
\hline$\left(\mathrm{Ca}^{2+} / \mathrm{K}^{+}\right) \times \mathrm{TCH}$ & 0,74 * & 0,75 * & $0,68 *$ \\
\hline$\left(\mathrm{Ca}^{2+}+\mathrm{Mg}^{2+}\right) / \mathrm{K}^{+} \times \mathrm{TCH}$ & $0,60 n s$ & 0,67 * & 0,69 * \\
\hline$\left(\mathrm{S}_{-} \mathrm{SO}_{4}{ }^{2-}\right) \times \mathrm{TCH}$ & $0,55 n s$ & $0,60 n s$ & 0,65 * \\
\hline $\mathrm{Al}^{3+} \times \mathrm{TCH}$ & $-0,33 n s$ & $-0,28 n s$ & $0,51 n s$ \\
\hline V\% (cam.arável) x TCH & $0,46 n s$ & $0,52 n s$ & $0,57 n s$ \\
\hline CTC (cam.arável) x TCH & $0,54 n s$ & $0,23 n s$ & $0,43 n s$ \\
\hline $\mathrm{N}_{\mathrm{F}} \times \mathrm{TCH}$ & $0,13 n s$ & $-0,64 *$ & $0,05 n s$ \\
\hline $\mathrm{P}_{\mathrm{F}} \times \mathrm{TCH}$ & $0,49 n s$ & $-0,59 n s$ & $0,001 n s$ \\
\hline $\mathrm{K}_{\mathrm{F}} \times \mathrm{TCH}$ & $0,41 n s$ & $-0,34 n s$ & $-0,06 n s$ \\
\hline $\mathrm{Ca}_{\mathrm{F}} \times \mathrm{TCH}$ & $0,30 n s$ & $0,61 n s$ & $0,75 *$ \\
\hline $\mathrm{Mg}_{\mathrm{F}} \times \mathrm{TCH}$ & $0,58 n s$ & $-0,15 n s$ & $0,20 n s$ \\
\hline $\mathrm{S}_{\mathrm{F}} \times \mathrm{TCH}$ & $0,62 n s$ & $0,59 n s$ & $0,44 n s$ \\
\hline $\mathrm{Mn}_{\mathrm{F}} \times \mathrm{TCH}$ & $-0,31 n s$ & $-0,24 n s$ & $0,32 n s$ \\
\hline
\end{tabular}

LEGENDA: $n \boldsymbol{s}=$ não significativo; * = significativo ao nivel de $5 \%$ de probabilidade; ** = significativo ao nível de $1 \%$ de probabilidade; símbolo do elemento acompanhado do índice $_{\mathrm{F}}=$ concentração do elemento na folha da planta. 
Por outro lado, não se detectou correlações significativas entre os teores de $\mathrm{S}_{-} \mathrm{SO}_{4}{ }^{2-} \mathrm{e}^{3+}$ no perfil do solo, bem como entre os valores de saturação por bases (V \%) e CTC, ambos da camada arável, e as produções finais obtidas.

Da mesma forma, os teores foliares dos macronutrientes e do manganês, com exceção do $\mathrm{Ca}^{2+}$ na $2^{\mathrm{a}}$ soca, não apresentaram correlação com as quantidades de matéria prima obtidas nas colheitas. 


\section{CONCLUSÕES}

Mediante os objetivos propostos e os resultados obtidos, pode-se tirar as seguintes conclusões :

a) a aplicação de corretivos de acidez do solo e do gesso agrícola, com exceção da magnesita aplicada isoladamente, permitiram a obtenção de altas produtividades de cana-de-açúcar até o $3^{\circ}$ corte; neste contexto, a mistura de gesso agrícola ( $85 \%$ ) com magnesita ( $15 \%)$ se destacou dentre os tratamentos, chegando a produzir o dobro da testemunha na segunda soca;

b) no solo, ao longo do tempo, os teores de $\mathrm{S}_{-} \mathrm{SO}_{4}{ }^{2-}, \mathrm{Ca}^{2+} \mathrm{e} \mathrm{Mg}^{2+}$ foram os mais afetados pelos tratamentos realizados e, em especial, pela mistura de gesso agrícola com magnesita, na camada arável;

c) as entrelinhas da cana-de-açúcar apresentaram maiores teores de S$\mathrm{SO}_{4}{ }^{2-}$ (em todo o perfil do solo, ao longo do tempo) e maiores tores de $\mathrm{Ca}^{2+}$, somente na camada arável e até a colheita da cana planta;

d) na planta, de um modo geral, houve maior influência dos tratamentos nos teores foliares (\%) de S e $\mathrm{Mg}$, sendo mais acentuado na mistura de gesso agrícola com magnesita; 
e) não houve influência dos corretivos e do gesso agrícola na qualidade da matéria prima, expressa em têrmos de pol \% cana, fibra \% cana e pureza, nos 3 cortes estudados.

Por fim, pelos resultados obtidos e pelo fato da magnesita ser um material que só recentemente vem sendo destinado à utilização agrícola, sugere-se maior número de pesquisas com o produto, assim como está se procedendo com o gesso agrícola. 


\section{REFERÊNCIAS BIBLIOGRÁFICAS}

ALCARDE, J.C. A avaliaç̃o da qualidade dos corretivos da acidez dos solos. Campinas, Fundação Cargill, 1986. 40p.

ALVES, H.M.R. \& LOPES, A.S. Redução da saturação de Alumínio em profundidade pela aplicação superficial de calcário e gesso em latossolos sob vegetação de cerrado. In: CONGRESSO BRASILEIRO DE CIÊNCIA DO SOLO, 1, Curitiba, 1983. p.82.

AZEVEDO, D.F. de; GLÓRIA, N.A. da; MANHÃES, M.S. Efeitos da calagem na canaplanta e nas características químicas de dois solos do Estado do Rio de Janeiro. In : CONGRESSO NACIONAL DA STAB, 2, Rio de Janeiro. Anais. v. 3/4 : 71-88, 1981.

BARROS, U.V.; FIGUEIREDO, J.P.; SANTIAGO R.; SILVA, O.A. Estudo comparativo do calcário dolomítico e do calcário calcítico no plantio do cafeeiro em solo LVa cerrado. In : CONGRESSO BRASILEIRO DE PESQUISAS CAFEEIRAS, 12, 1985. Resumos. p. 10-56.

BATAGLIA, O.C. \& DECHEN, A.R. Critérios alternativos para dignose foliar. In : SIMPÓSIO AVANÇADO DE QUÍMICA E FERTILIDADE DO SOLO. Piracicaba. 1986. Campinas, Fundação Cargill, 1986. Anais. p. 115-36. 
BATAGLIA, O.C.; CAMARGO, C.E. de O.; OLIVEIRA, O.F. de; NAGAI, V.; RAMOS, V.J. Revista Brasileira de Ciência do Solo, Campinas, 9(3): 139-47, 1985.

BENEDINI, M.S. Novo conceito no uso de calcário em cana-de-açúcar. Cadernos COPERSUCAR. Série Agronômica, Piracicaba, (16):1-19, set. 1988.

BENEDINI, M.S. \& KORNDORFER, G.H. Avaliação de critérios para recomendação de calcário em cana-de-açúcar. STAB, Piracicaba, 101 (3):205, jan./fev. 1992.

BRAUNER, J.L. \& GARCEZ, J.R.B. Perdas por lixiviação de $\mathrm{K}$, Ca e $\mathrm{Mg}$ em três solos do Rio Grande do Sul submetidos a cinco níveis de CaCO3. In : CONGRESSO BRASILEIRO DE CIÊNCIA DO SOLO, 18, Salvador. 1981. Resumos. p. 114.

BULL, T.L. Influência da relação $\mathrm{K} /(\mathrm{Ca}+\mathrm{Mg})$ do solo na produção de matéria seca e na absorção de potássio por gramínea e leguminosa forrageiras. Piracicaba, 1986. 99p. (Doutorado - ESALQ/USP).

CAMPOS, H. Estatística aplicada à experimentação com cana-de-açúcar. Piracicaba, FEALQ, 1984. $292 \mathrm{p}$.

CARVALHO, L.C.C. Adubação e a cana-de-açúcar no Brasil. In: ORLANDO FILHO, J. Nutrição e adubação da cana-de-açúcar no Brasil. Piracicaba, IAA/PLANALSUCAR, 1983. p. 13-20. (Coleção PLANALSUCAR).

CORDEIRO, D.A. Efeitos da calagem e da adubação potássica sobre a produção de colmo e o equilíbrio nutricional da cana-de-açúcar (Saccharum spp.). Piracicaba, 1978. 102 p. (Mestrado.- ESALQ/USP). 
COPERSUCAR. Amostragem e análise de cana-de-açúcar. Piracicaba, Centro de Tecnologia Copersucar, Divisão Agronômica. 1980. 37 p.

. Seminário de Tecnologia Agronômica, 2, Piracicaba, 1984. Anais. 516p.

. Seminánio de Tecnologia Agronômica, 3, Piracicaba, 1986. Anais. 612p.

DAL BÓ, M.A.; RIBEIRO, A.C.; COSTA, L.M. da; THIEBAUT, J.T.L.; NOVAIS, R.F. Efeito da adição de diferentes fontes de cálcio em colunas de solo cultivadas com cana-de-açúcar. I. Movimentação de bases no solo. Revista Brasileira da Ciência do Solo, Campinas, 10(3):1958, 1986.

EMBRAPA. Centro de Pequisa Agropecuária dos Cerrados.. Relatório Técnico Anual dos Cerrados. Planaltina, 1981. 190p.

. Centro de Pequisa Agropecuária dos Cerrados. Relatório Técnico Anual dos Cerrados. Planaltina, 1982. v.6. 163p.

ESPIRONELO, A. \& OLIVEIRA, H. Orientação geral para a adubação da cana-deacúcar no Estado de São Paulo. Campinas, Instituto Agronômico, 1972. 16p. (Boletim 201).

FAGERIA, N.K. Adubação e nutrição mineral da cultura do arroz. Rio de Janeiro. Campus. 1984. 341p.

FERREIRA, E.S.; KORNDORFER, H.H.; MARTINS, J.; MATTHIENSEN, L.A. Efeitos da aplicação de gesso + calcário sobre algumas características químicas em latossolo vermelho amarelo. Boletim Técnico COPERSUCAR, São Paulo, (38):135, jul. 1987. 
FREITAS, J.A.D.; COELHO, M.A.; FERREYRA H., F.F. Efeito de corretivos químicos e materiais orgânicos no movimento da água e estrutura do solo salino sódico.

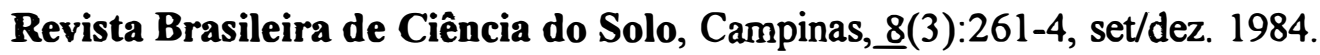

FREITAS, L.M.M. \& RAIJ, B. van. Efeitos residuales del encalado de un latossol en São Paulo, Brasil. In: BORNEMISSA, E. \& ALVARADO, A., ed. Manejo de suelos en la America Tropical. Raleigh, North Carolina State University, 1974. p.304-12.

GALLO, J.R.; HIROCE, R.; ALVAREZ, R. Levantamento do estado nutricional de canaviais de São Paulo pela análise foliar. Bragantia, Campinas. 27 (30) : 365-82. set. 1968.

GARGANTINI, H.; ALVAREZ, R.; CATANI, R.A.; GALLO, J.R. Restauração de solo para a cultura da cana-de-açúcar. Período 1954/56. In : CONGRESSO BRASILEIRO DE CIÊNCIA DO SOLO, 6, Salvador. Anais. 12 p. jul.1957.

GAVIOLI, E. A.; CASAGRANDE, A.A.; MUTTON, M.A.; VITTI, G.C.; PARANHOS, S.B.; CAMPANHÃO, J. Aplicação de calcário, gesso e mistura calcário/gesso em soca de cana-de-açúcar. I. Efeitos na planta. STAB,_10(6):17-24, 1992.

GONZALEZ, E.E.; WOLF, J.M.; NADERMAN, G.; SOARES, W.V.; GALRÃO, E.Z. Relações entre toxidez de alumínio, desenvolvimento de raízes, absorção de água e produção de milho num oxisol (latosol vermelho escuro) do Distrito Federal. Ciência e Cultura, $\underline{28}$ (2) : 181-2. 1976.

IAA/PLANALSUCAR. SUPER. Relatório Anual. Piracicaba, 1982. 160p. COSUL. Relatório anual da Seção de Solos e Adubação : 1983. Araras, São Paulo. 1983. 164p. 
JØRGENSEN, S. S. Metodologia utilizada para análises de rotina : guia analítico. Piracicaba, CENA, 1977. $24 \mathrm{p}$.

KIEHL, J.C. \& FRANCO, O. Efeito do gesso industrial sobre alguns componentes da fertilidade do solo. O Solo, Piracicaba, 76(1):116, jan/jun. 1984.

KOFLER, N.F. A profundidade do sistema radicular e o suprimento de água às plantas no cerrado. Piracicaba, Potafos, 1986. p. 12. (Informações Agronômicas, 33).

KOFFLER, N.F. \& DONZELLI, P.L. Avaliação dos solos brasileiros para a cultura da cana-de-açúcar. In : PARANHOS, S.B. coord. Cana-de-açúcar : cultivo e utilização. Campinas, Fundação Cargill, 1987. v.1. p. 19-41.

LEON, M.; FERNANDEZ, A.; VILLEGAS, $R$ Efecto del encalado sobre las caracteristicas de los suelos ferraliticos rojos e influencia de esta prática en la produccion de la cana de azucar. Boletim INICA, La Habana, (1):316, ene/feb. 1986.

LOPES, A.S.; ALVES, H.M.R. Efeitos da aplicação de corretivos e fertilizantes na diminuição da toxidez de alumínio em profundidade, em amostras sob vegetação de cerrados em Minas Gerais. In : CONGRESSO BRASILEIRO DE CIÊNCIA DO SOLO, 18, 1981. Salvador. Programas e resumos. SPCS, 1981, p. 96.

LORENZETTI, J.M.; RODRIGUES, J.C; MORALES, S.H.; DEMATTÊ, J.L.I. Uso de calcário e gesso em soqueira de cana-de-açúcar. STAB, Piracicaba, 101(3):148, $\mathrm{jan} / \mathrm{fev} 1992$.

MALAVOLTA, E. Elementos de nutricão mineral de plantas. São Paulo, Ceres, 1980. $254 \mathrm{p}$. 
MALAVOLTA, E. Manual de calagem e adubação das principais culturas. São Paulo, Ceres. 1986. 496p.

MALAVOLTA, E.; HAAG, H.P.; MELLO, F.A.F.; BRASIL SOB ${ }^{\circ}$, M.O.C. Nutricão mineral e adubação das plantas cultivadas. São Paulo, Pioneira, 1974. 727 p.

MALAVOLTA, E; VITTI, G.C.; OLIVEIRA, S.A. Avaliacão do estado nutricional das plantas : princípios e aplicações. Piracicaba. POTAFOS, 1989. 201 p.

MARINHO, M.L. \& ALBUQUERQUE, G.A.C. Calibração do Ca $+\mathrm{Mg}$ no solo para cana-de-açúcar em Alagoas. In: CONGRESSO NACIONAL DOS TÉCNICOS AÇUCAREIROS DO BRASIL, 2. Rio de Janeiro, 1981. Anais, p.110-28.

Calagem. In : ORLANDO FILHO, J. coord. Nutrição e adubação da canade-açúcar no Brasil. Piracicaba, 1983. p. 181-208. (Coleção PLANALSUCAR).

MARINHO, M.L. \& ARAUJO FILHO, J.T. Calibração do Al no solo para cana-deaçúcar em Alagoas. Piracicaba, IAA/PLANALSUCAR. COONE, 1981. 17p.

MARINHO, M.L; ALBUQUERQUE, G.A. \& ARAUJO FILHO, J.T. Efeitos da calagem em solo argiloso fortemente ácido em Alagoas. In : Reunião Brasileira de Fertilidade do Solo, 14. Cuiabá, 1981.

MAZZA, J.A. Efeitos do calcário e do gesso aplicados no plantio e em soqueiras de cana-de-açúcar (Saccharum spp.) nos atributos químicos de solos e na produtividade da cultura. Piracicaba, 1993. 141p. (Doutorado - ESALQ/USP).

MIELNICZUK, J. Economicidade da calagem. In : REUNIÃO BRASILEIRA DE FERTILIDADE DO SOLO, 15, Campinas, 1983. p.63-77. 
MIKKELSEN, D.S.; FREITAS, L.M.M. de \& McCLUNG, A.C. Efeitos da calagem e adubação de algodão, milho e soja em três solos de campo cerrado. Matão. Instituto de Pesquisas IRI,. 1962. 48p. (Boletim n² 29).

MORELLI, J.L.; NELLI, E.J.; DEMATTE, J.L.I.; DALBEN, A.E. Efeito do gesso e do calcário nas propriedades químicas de solos arenosos álicos e na produção de canade-açúcar. STAB, Piracicaba, 6(2):24-31, nov/dez. 1986.

NASCDMENTO, V.M.; NEPTUNE, A.M.L.; FERNANDES, F.M. Efeitos da calagem sobre algumas características de fertilidade de um latossolo sob vegetação de cerrado. Científica, São Paulo, 11(2):177-81, 1983.

ORLANDO FILHO, J. \& ZAMBELLO JÚNIOR, E. Viagem de estudos realizada à África do Sul, Filipinas, Havaí e Louisiana. Piracicaba, IAAPLANALSUCAR. SUPER, 1980. 49p.

PAVAN, M.A.; BINGHAN, F.T.; PRATT, P.F. Redistribution of exchangeable calcium, magnesium and aluminium following lime or gypsum applications to a Brazilian oxisoil. Soil Science Society American Journal, $\underline{48}$ (1):33-8, 1984.

PEIXOTO. A.A. Efeitos de cálcio, magnésio e potássio e suas relacões na producão da cana-de-acúcar (Saccharum spp.), em um solo gley pouco húmico do norte fluminense. Viçosa, UFV. 1980. 35p.

PINA, N.A.; HERRERA, O.F.; ARMAS, J.M.; ROJAS, F.A.; SANTANDER, J.B.; PRIETO, J.L.H.; TRUFFIN, J.. Evaluacion del efecto del encalado sobre algumas características de los suelos caneros. Boletim INICA, La Habana, (2):92-101, abr/jun. 1986. 
QUAGGIO, J.A. Reação do solo e seu contrôle. In: SIMPÓSIO AVANÇADO EM QUÍMICA E FERTILIDADE DO SOLO. Piracicaba, 1986. Anais. p.53-89.

QUAGGIO, J.A.; MASCARENHAS, H.A.A.; BATAGLIA, O.C. Resposta da soja à aplicação de doses crescentes de calcário em latossolo roxo distrófico de cerrado. II Efeito residual., Revista Brasileira de Ciência do Solo, 6: 11-38. 1982.

RAIJ, B. van. Uso eficiente de corretivos da acidez. In: SEMINÁRIO FÓSFORO, CÁlCIO, MAGNÉSIO, ENXOFRE E MICRONUTRIENTES. SITUAÇÃO ATUAL E PERSPECTIVAS NA AGRICULTURA, São Paulo, 1986. Anais. p.60-74.

- Gesso agrícola na melhoria do ambiente radicular do subsolo. São Paulo, ANDA, 1988. p. 88.

Diagnose nutricional e economia da adubação em cana-de-açúcar. Araçatuba, UFSCar - Escritório Regional, 1994 (Palestra - mimeo).

RAIJ, B. van \& QUAGGIO, J.A. Método de análise de solo para fins de fertilidade. Boletim Técnico IAC, Campinas, (81):1-31, 1983.

Uso eficiente de calcário e gesso na agricultura. In : SIMPÓSIO SOBRE FERTILIZANTES NA AGRICULTURA BRASILEIRA. Brasilia, EMBRAPA. 1984. p. 323-46.

REEVE, N.G.; SUMNER, M.E. Amelioration of subsoil acidity in Natal oxisoils by beaching of surface-applied amendements. Agrochemophysica, 4:1-6, 1972.

RITCHEY, K.D.; SOUZA, D.M.G.; LOBATO, E. \& CORREIA, O. Calcium leaching to increase rooting depth in a Brazilian Savannah Oxisol. Agron. J. 72:40-4, 1980. 
ROSS, G.J.; LAWTON, K.; ELLIS, B.G. Lime requirement related to physical and chemical properties of nine Michigan soils. Soil Science Society of America Proceedings, Madison, 28(2): 209-13. 1964.

SANCHEZ, O. \& CLEMENTS, H.F. Magnesium in sugarcane culture. In: CONGRESS OF THE ISSCT, 15, Durban. Proceedings. 1974. v.2, p. 552-67.

SCHMEHL, W.R. \& HUMBERT, R.P. Nutrient deficiences in sugarcane crops. In : SPRAGUE, H.B., ed. Hunger signs in 2 rd. crops : a symposium. $3^{\mathrm{a}}$ ed. New York, David Mackay. 1964. cap. 12, p. 415-50.

SORDI, R.A.; BASSINELLO, A.I.; VIEIRA, M.A.S.; HOFFMANN, H.P.; MARTINS, S.; GHELlER, A.C.A.; MASUDA, Y.; ARIZONO, H.; MATSUOKA, S. Resultados experimentais da variedade RB72454 até 1986 no Estado de São Paulo. In : CONGRESSO NACIONAL DA STAB, 4, Olinda, 1987. Anais. p. 212-20.

STOLF, R.; CERQUEIRA LUZ, P.H.; CASAGRANDE, J.C. Metodologia de incorporação profunda de corretivos de solo. Álcool e Açúcar, São Paulo, $\underline{8}(44): 249$, set/out. 1988.

SUZUKI, A. Doses e modos de aplicação de calcário em pomar de macieira em latossolo húmico distrófico do Estado de Santa Catarina. Viçosa, 1989. 75p (Mestrado - UFV).

TRANI, P.E.; HIROCE, R.; BATAGLIA, O.C. Análise Foliar. Fundação Cargill. 1983. $4 p$.

VARGAS, J.T.D. Efeito na cultura de cana-de-açúcar da aplicação de calcário como corretivo e adubo em solo de cerrado. Piracicaba, 1981. 77p. (Mestrado ESALQ/USP). 
VARGAS, J.T.D. Aplicação de calcário em duas profundidades e seus efeitos no solo e na cultura da cana-de-açúcar. Piracicaba, 1989. 122p. (Doutorado - ESALQ/USP).

VITTI, G.C. Acidez do solo, calagem e gessagem. Ilha Solteira, UNESP, 1987. (Palestra - mimeo).

- Avaliação e interpretação do enxofre no solo e na planta. Jaboticabal, FUNEP, 1988 a. 37 p.

Gessagem na agricultura. In : CURSO DE ATUALIZAÇÃO EM FERTILIDADE DO SOLO, Machado, 1988 b. ESACMA - POTAFOS/ANDA, 1988. $15 \mathrm{p}$.

VITTI, G.C.; MUTTON, M.A.; CASAGRANDE, A.A.; GAVIOLI, E.A.; CAMPANHÃO, J.; PARANHOS, S.B. Aplicação de calcário, gesso e mistura de calcário/gesso em soca de cana-de-açúcar. II. Efeitos no solo. STAB, março/abril, 11(4): 8-15, 1993.

YAMADA, T. Capacidade de adsorção máxima de sulfato do solo como parâmetro adicional na recomendação de gesso. Piracicaba, 1988. 73p. (Doutoramento ESALQ/USP).

ZAMBELLO JUNIOR , E. \& ORLANDO FILHO, J. Adubação da cana-de-açúcar na região centro-sul do Brasil. Boletim Técnico PLANALSUCAR, Piracicaba. $\underline{3}$ :526. 1981.

ZAMBELLO JUNIOR, E.; RODELLA, A.A.; ORLANDO FILHO, J.; ARAGÃO, J.A. Interação calcário versus fosfato na cana-de-açúcar. STAB, Piracicaba, 11(6):23-6, jul/ago. 1983. 
ZAMBELLO JUNIOR, E.; ORLANDO FILHO, J.; RODELLA, A.A. Aluminum toxicity classification of soils in Brazil. Sugar Cane, High Wycombe, (5):10-2, sept./oct., 1984. 